\title{
DESENVOLVIMENTO DE UM SISTEMA COMPUTACIONAL PARA ANÁLISE DE EXPERIMENTOS EM BLOCOS INCOMPLETOS
}

GABRIEL ADRIÁN SARRIÉS
Médico Veterinario

Orientador: Prof. Dr. CÁSSIO ROBERTO DE MELO GODOI

Dissertação apresentada à Escola Superior de Agricultura "Luiz de Queiroz", da Universidade de São Paulo, para obtenção do Título de Mestre em Agronomia, Área de Concentração: Estatística e Experimentação Agronômica.

P I R A C I C A B A

Estado de São Paulo - Brasil

Fevereiro - 1989 
Sarriés, Gabriel Adrián

S247d Desenvolvimento de um sistema computacional para análise de experimentos em blocos incompletos. Piracicaba, 1989.

8Ip. ilus.

Diss.(Mestre) - ESALQ

Bibliografia

1. Análise estatística 2. Computador - Sis tema 3. Delineamento de experimento - Análise. 4. Estatística agrícola 5. Informática na es tatística agrícola 6. SABI (Sistema de computação) I. Escola Superior de Agricultura Luiz de Queiroz, Piracicaba

CDD 630.2194. 


\section{DESENVOLVIMENTO DE UM SISTEMA COMPUTACIONAL PARA ANÁLISE DE EXPERIMENTOS EM BLOCOS INCOMPLETOS}

GABRIEL ADRIÁN SARRIÉS

Aprovado em : 11-05-1989

Comissão Julgadora :

Prof. Dr. Cássio Roberto de Melo Godoi ESALQ/USP

Prof. Dr. Décio Barbin ESALQ/USP

Prof. Dr. Fernão de S. R. Germano São Carlos/USP

Prof. Dr. Cassio Roberto de Melo Godoi Orientador 
Aos meus pais e irmãos, ofereço.

Aos meus amigos, dedico. 


\section{AGRADECIMENTOS}

Ao Dr. Cássio Roberto de Melo Godoi, homem brilhante e universal, pela imprescindível orientação que ultrapassa o campo científico.

Aos professores do Departamento de Matenática e Estatística da ESALQ/USP, pelos ensinamentos e cordialidade.

Aos Drs. Humberto de Campos e Décio Barbin, pelo apoio recebido.

Ao Prof. Adriano J. B. V. de Azevedo Filho e ao Analista Carlos Henrique Mattiolli, pelos ensinamentos, apoio e confiança em mim depositados.

Ao Conselho Nacional de Desenvolvimento Científico e Tecnológico $(\mathrm{CNPq})$, pela bolsa de estudo concedida para a realização do curso.

A Marcelo Zacarias, pela indispensável colaboração na elaboração deste trabalho.

À Maria Izalina Ferreira Alves, pela amizade, afeto e colaboração recebida durante o curso de mestrado e na elaboração do presente trabalho.

A meus colegas e amigos, João Carlos Vianna de Oliveira, Clério H. B. da Silva e demais integrantes do Setor de Apoio ao Ensino e à Pesquisa do CIAGRI/USP, pela colaboração na elaboração do presente trabalho.

Aos funcionários do Departamento de Matemática e Estatística da ESALQ/USP e do CIAGRI/USP, pelas gentilezas e agradável convívio.

Aos colegas do Curso de Pós-Graduação em Estatística e Experimentação Agronômica da ESALQ/USP, pela amizade e companheirismo, em especial a João Riboldi pela transmissão de experiência.

À familia Alves, pelo constante estímulo, apoio e amizade.

A todos que, direta ou indiretamente colaboraram para a realização deste trabalho. 


\section{SUMÁRIO}

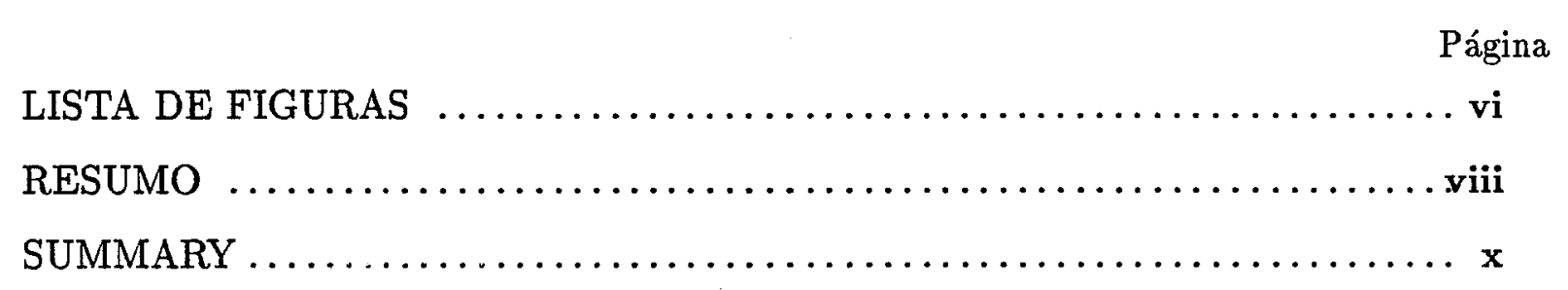

1. INTRODUÇÃ $\ldots \ldots \ldots \ldots \ldots \ldots \ldots \ldots \ldots \ldots \ldots \ldots \ldots \ldots \ldots \ldots \ldots \ldots \ldots$

2. REVISÃO DE LITERATURA $\ldots \ldots \ldots \ldots \ldots \ldots \ldots \ldots \ldots \ldots \ldots \ldots \ldots \ldots \ldots$

2.1. Tópicos de Estatística $\ldots \ldots \ldots \ldots \ldots \ldots \ldots \ldots \ldots \ldots \ldots \ldots \ldots \ldots \ldots \ldots$

2.1.1. O Operador SWEEP $\ldots \ldots \ldots \ldots \ldots \ldots \ldots \ldots \ldots \ldots \ldots \ldots \ldots \ldots \ldots$

2.1.2. Estimabilidade em modelos de dois fatores ...............6

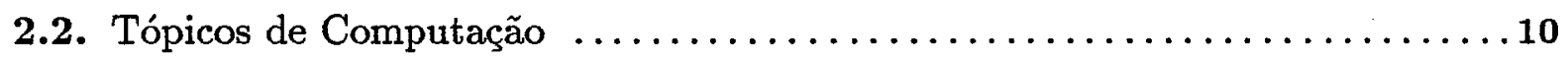

2.2.1. Desenvolvimento e documentação de sistemas . . . . . . . . . . . 10

2.2.2. Ferramentas úteis para o desenvolvimento e documentação de sistemas .. 15

2.2.3. Sistemas para análise estatística $\ldots \ldots \ldots \ldots \ldots \ldots \ldots \ldots \ldots \ldots \ldots \ldots$

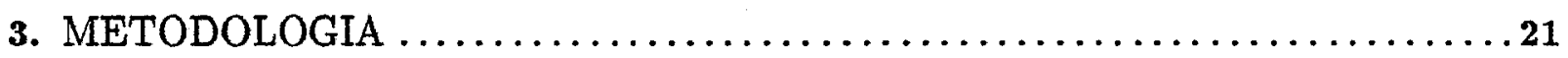

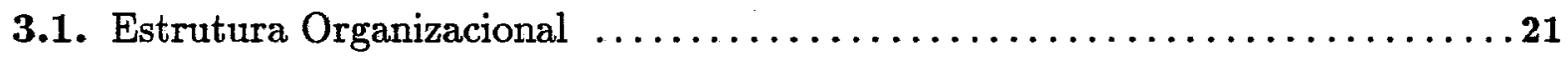

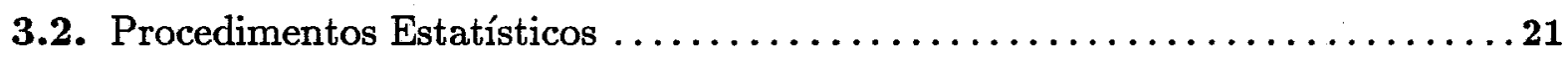

3.2.1. O Operador SWEEP $\ldots \ldots \ldots \ldots \ldots \ldots \ldots \ldots \ldots \ldots \ldots \ldots \ldots \ldots \ldots \ldots \ldots$

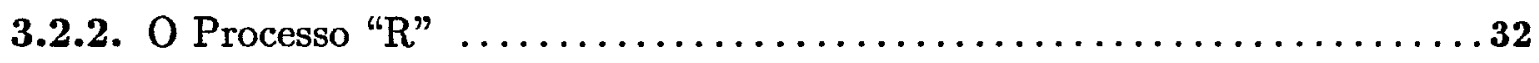

3.2.3. Metodologia de Cálculos Utilizada no SABI $\ldots \ldots \ldots \ldots \ldots \ldots \ldots \ldots \ldots \ldots$

3.3. Procedimentos na Área de Informática $\ldots \ldots \ldots \ldots \ldots \ldots \ldots \ldots \ldots \ldots \ldots \ldots$

3.3.1. Documentação do Sistema $\ldots \ldots \ldots \ldots \ldots \ldots \ldots \ldots \ldots \ldots \ldots \ldots \ldots \ldots \ldots \ldots \ldots \ldots$

3.3.1.1. Diagramas Hierárquicos de Blocos $\ldots \ldots \ldots \ldots \ldots \ldots \ldots \ldots \ldots$

3.3.1.2. Diagramas de Nassi-Schneiderman $\ldots \ldots \ldots \ldots \ldots \ldots \ldots \ldots \ldots \ldots \ldots 49$

3.3.1.3. Recursos Computacionais Utilizados na Documentação Gráfica . . . 49

3.3.2. Implementação do Sistema $\ldots \ldots \ldots \ldots \ldots \ldots \ldots \ldots \ldots \ldots \ldots \ldots \ldots$

3.4. Descrição do SABI - Sistema para Análise de Blocos Incompletos ........ 52

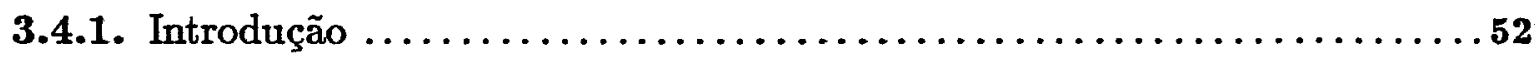

3.4.2. Recursos Oferecidos pelo Sistema $\ldots \ldots \ldots \ldots \ldots \ldots \ldots \ldots \ldots \ldots \ldots \ldots$

3.4.3. Estrutura do Sistema $\ldots \ldots \ldots \ldots \ldots \ldots \ldots \ldots \ldots \ldots \ldots \ldots \ldots \ldots$ 


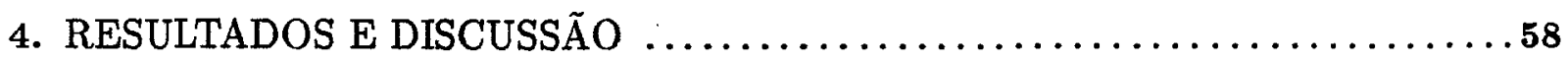

4.1. Análise de Experimentos no Sistema SABI $\ldots \ldots \ldots \ldots \ldots \ldots \ldots \ldots \ldots \ldots 8$

4.1.1. Criação de arquivo e análise de um experimento com delineamento em Blocos Incompletos Balanceados ....................... 59

4.1.2. Criação de arquivo e análise de um experimento com delineamento em Blocos Incompletos Desbalanceados Desconexos ...............66

4.2. Considerações sobre a documentação do SABI $\ldots \ldots \ldots \ldots \ldots \ldots \ldots \ldots \ldots$. 71

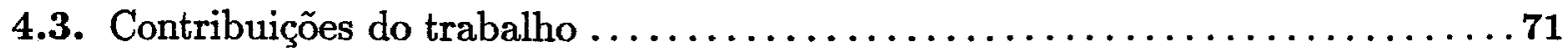

4.4. Sugestões para aperfeiçoamento do trabalho e para o desenvolvimento de sis-

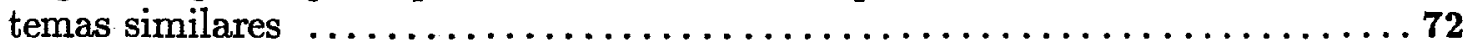

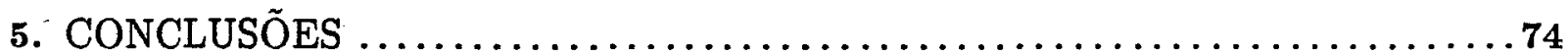

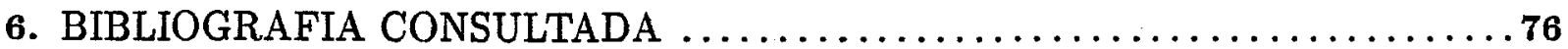




\section{LISTA DE FIGURAS}

Página

1. Grupos conexos num delineamento em blocos incompletos desbalanceados desco-

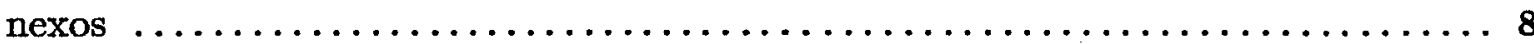

2. Custo relativo para corrigir um erro durante o desenvolvimento do sistema .....11

3. Tendência dos custos de "software"/"hardware" $\ldots \ldots \ldots \ldots \ldots \ldots \ldots \ldots \ldots \ldots$

4. Diagrama Hierárquico de Blocos do Módulo "Faça Testes de Hipóteses" . . . . . 47

5. Diagrama de Nassi-Schneidermann correspondente ao diagrama da Figura 4 ..51

6. Menu principal do SABI ............................

7. Diagrama hierárquico de blocos, representando a estrutura do módulo para análise

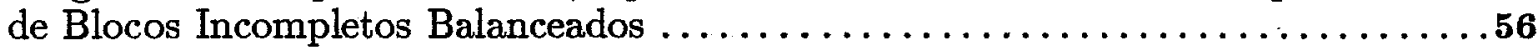

8. Diagrama hierárquico de blocos, representando a estrutura do módulo para análise de Blocos Incompletos Desbalanceados ......................

9. Primeira tela do módulo "Criação de Arquivo Documentado no Editor" . . . . .66

10. Menu com os dispositivos de saída de resultados $\ldots \ldots \ldots \ldots \ldots \ldots \ldots \ldots \ldots \ldots$

11. Menu para selecionar o tipo de análise em Blocos Incompletos Balanceados . . .61

12. Menu de escolha da transformação e dados $\ldots \ldots \ldots \ldots \ldots \ldots \ldots \ldots \ldots \ldots \ldots \ldots$

13. Quadro de ANOVA para a variável Endurecimento, apresentada pelo SABI . ..62

14. Opções após a obtenção do Quadro de ANOVA $\ldots \ldots \ldots \ldots \ldots \ldots \ldots \ldots \ldots \ldots \ldots$

15. Resultado da aplicação do Teste de Tukey $\ldots \ldots \ldots \ldots \ldots \ldots \ldots \ldots \ldots \ldots \ldots$

16. Relatório de saída de resultados dos testes de hipótese para os contrastes solicitados 64

17. Menu de opções para a realização de Intervalos de Confiança . . . . . . . . . .64

18. Relatćicio de saída de Intervaios de Confiança pelo Teste " $t$ " de Student ......65

19. Relatório de saída de Intervalos de Confiança pelo Procedimento de Bonferroni .66

20. Relatório de saída de Intervalos de Confiança pelo Procedimento de Scheffé ....66

21. Estrutura de conexão do delineamento adotado $\ldots \ldots \ldots \ldots \ldots \ldots \ldots \ldots \ldots$

22. Quadro de ANOVA para o exemplo de blocos incompletos desbalanceados desconexos 
23. Alternativas para introdução da hipótese desejada $\ldots \ldots \ldots \ldots \ldots \ldots \ldots \ldots$

24. Resultado do teste da hipótese "Os tratamentos 4,5 e 6 não diferem" ........69.

29. Resultado do teste da hipótese "Os tratamentos 1 e 6 não diferem" .........70 


\title{
DESENVOLVIMENTO DE UM SISTEMA \\ COMPUTACIONAL PARA ANÁLISE DE \\ EXPERIMENTOS EM BLOCOS INCOMPLETOS
}

\author{
Autor: GABRIEL ADRIÁN SARRIÉS \\ Orientador: PROF. DR. CASSIO ROBERTO DE MELO GODOI
}

\section{RESUMO:}

Neste trabalho é apresentado o desenvolvimento de um sistema computacional para análise estatística de experimentos com delineamentos em Blocos Incompletos Balanceados ou Desbalanceados.

O SABI - "Sistema para Análise em Blocos Incompletos" fornece diversas informações estatísticas, Quadro de Análise de Variância completo, Testes de Hipóteses, Intervalos: de Confiança e Teste de Comparações Múltiplas de Tukey.

No módulo "Blocos Incompletos Desbalanceados", incluem-se procedimentos para estudo da estrutura de conexão do delineamento utilizando-se o Processo " $R$ ", econômico em memória e tempo de computador. Para resolução do sistema de equações normais, cálculo de somas de quadrados ajustados e ponto de matrizes utiliza-se o algorítmo SWEEP.

O SABI é um sistema para microcomputadores compatível com o IBM-PC, desenvolvido utilizando-se técnicas de projeto, documentação e implementação de sistemas estruturados, na linguagem Pascal (ambiente Turbo Pascal 3.0). A documentação que acompanha o sistema inclui, "manual do usuário", "manual de referência" e "projeto do sistema".

Pelo fato do sistema estar documentado e ser desenvolvido utilizando-se técnicas de programação estruturada, com diversos procedimentos de uso geral, o presente trabalho pode servir como estrutura de base para outros sistemas com maiores recursos, para análise de experimentos com delineamento em Blocos (por exemplo Blocos Multivariados, Análise de Covariância e Regressão Polinomial) ou, inclusive, para outros delineamentos experimentais. 
Fica comprovada a necessidade de documentação adequada no desenvolvimento de sistemas, aspecto que não tem recebido muita atenção em "softwares" brasileiros. Essa documentação contribui efetivamente no desenvolvimento, manutenção e testes do sistema desenvolvido, bem como facilita a comunicação entre os integrantes da equipe, aspecto importante em projetos de natureza interdisciplinar.

Os diagramas ưilizados para representação da ez̧rutura lógica, Diagramas Hierárquicos de Blocos e de Nassi-Schneiderman, são adequados na etapa de elaboração do projeto do sistema, porém na etapa de análise do sistema seria recomendável a utilização de outro tipo de diagramas, talvez os Diagramas de Fluxos de Dados. 


\section{DEVELOPMENT OF A COMPUTATION \\ SYSTEM FOR EXPERIMENTS IN \\ INCOMPLETE BLOCKS DESIGNS ANALYSIS.}

\section{SUMMARY}

In this work is showed the development of a computation system to statistical analysis of experiments in Incomplete Balanced or Unbalanced Blocks designs.

The SABI - "System for Analysis in Incomplete Blocks" gives different statistical informations, complete Analysis of Variance Table, hipothesis tests, confidence intervals and the Tukey method for multiple comparisions.

In the "Unbalanced Incomplete Blocks" module was included procedures for study of the connection structure desing, by using the " $R$ " Process, economic in memory and time of computer. For the resolution of the normal equation system, sums of squares and the matrices rank, was used the SWEEP algorithm.

The SABI is a System for IBM - PC compatible microcomputers, developed by using project techniques, documentation and implementation for structured system, in Pascal language (ambient Turbo Pascal 3.0). The documentation that come along the system includes "user guide", "reference guide" and "system project".

Because the system is documented and developed making use of thecniques of structured programation, with various procedures of general use, the present work can serve as a base to others systems with bigger recourses, to analysis of experiments in incomplete block designs (for example, multivariate blocks, covariance and Polynomial regression analysis or even for others experimental designs.

It was confirmed the necessity of good documentation in system development, aspect that don't have been recieved atention in Brazilian softwares. This documentation contributes effectively in the development, maintenance and tests of the developed system, as well facilitate the comunication between the integrants of a staff, important aspect in projects of interdisciplinar nature. 
The diagrams used for representation of logical structure, Hierarchical Diagrams of Blocks and Nassi-Schneidermann Diagrams, are adequate in the elaboration stage of system of project, however in the stage of the system analysis should be recomended the utilization of another kind of diagram, maybe the data flux diagrams. 


\section{INTRODUÇÃO}

A técnica de análise de experimentos nos delineamentos em Blocos Incompletos é uma ferramenta importante para o estatístico na área experimental, quando se quer testar uma grande quantidade de tratamentos e quando o material experimental é relativamente heterogêneo.

Como exemplo de aplicação intensiva dessa técnica, poder-se-iam incluir análises de experimentos nas áreas de Genética (envolvendo competição de variedades e experimentos laboratoriais), de Silvicultura, de Fitotecnia e em muitas outras.

Apesar de serem amplamente reconhecidas suas interessantes propriedades, seu uso não é muito frequente na pesquisa agropecuária, devido principalmente, à dificuldade no processo de análise dos dados que, se não for realizada em computador, implica em perda de tempo, frequentes erros de cálculo, e muitas vezes, até na inviabilidade da análise:

Entre as dificuldades que existem para resolver esse tipo de problemas, especialmente nos Blocos Incompletos Desbalanceados, ressalta-se a necessidade de uma abordagem matricial do problema para obtenção das somas de quadrados ajustadas das diferentes fontes de variação, e também para obtenção de uma solução para o sistema de equações normais.

GOODNIGTH (1978) apresenta o operador SWEEP, definindo-o como uma técnica eficiente de inversão de matrizes, uma ferramenta conceitual para entender o processo de mínimos quadrados, e talvez o mais versátil de todos os operadores estatísticos. O SWEEP pode ser programado para calcular inversas generalizadas, fornecendo sub-produtos como a Matriz de Decomposição de Cholesky, a Matriz de Decomposição de Hermite, o determinante da matriz original, as somas de quadrados ou a matriz de somas de quadrados e de produtos cruzados (do modelo matemático completo ou de sub-modelos), e uma solução para o sistema de equações normais.

Uma outra limitação na resolução de problemas envolvendo Blo- 
cos Incompletos Desbalanceados é a obtenção das funções estimáveis no modelo matemático do delineamento, pois nos delineamentos desbalanceados podem haver casos de desconexão. Nesse caso, nem todos os contrastes entre tratamentos são estimáveis. Os testes para detectar estimabilidade em problemas práticos não podem ser executados sem o apoio de um computador.

Para a obtenção das funções lineares estimáveis no modelo, existem diversas técnicas de uso geral em Modeics Lineares, porém, em termos computacionais, essas técnicas gerais são muito onerosas em termos de memória e tempo de processamento. DODGE (1985) apresenta o Processo R, que fornece os grupos conexos de blocos e de tratamentos num delineamento em Blocos Incompletos Desbalanceados Desconexo, assim como uma base e a dimensão do sub-espaço vetorial dos contrastes estimáveis de tratamentos. Esse processo utiliza a matriz de Incidência $(\mathrm{N})$, de natureza combinatorial, requerendo-se, dessa forma, somente operações com números inteiros para obter a estrutura de conexão do delineamento, e então conhecer as funções estimáveis.

O desenvolvimento de sistemas computacionais de boa qualidade não pode ser viabilizadó se eles não forem devidamente planejados e documentados. A correta documentação de um sistema permite a utilização racional de diversos profissionais que participem do seu desenvolvimento. $\mathrm{Na}$ área de Estatística Experimental, especificamente, é prudente que participem desse tipo de projetos especialistas da área que conheçam com profundidade a problemática abordada, e analistas de sistemas com uma base suficiente de conhecimento estatístico, para permitir que interajam com os estatísticos. Além disso, os analistas deverão elaborar um projeto do sistema em função das necessidades colocadas pelos estatísticos, o que servirá como guia para que programadores de sistemas, também integrantes da equipe de trabalho, gerem o código fonte do sistema, supervisionados pelos analistas.

Uma documentação adequada facilita a geração, manutenção e os testes do sistema, além de facilitar a comunicação entre os integrantes da equipe. Essa documentação permitirá que a ausência de qualquer integrante da equipe não acarrete dificuldades intransponíveis no processo de desenvolvimento ou manutenção do sistema. Argumentos a esse respeito podem ser encontrados em vários artigos e livros da área de Ciências da Computação, como ZACMAN (1987), GANE \& SARSON (1983) ou YOURDON (1976), dentre muitos outros.

Levando em consideração o exposto, surgiu a idéia de se criar um sistema computacional, visando contribuir na análise de experimentos em Blocos Incompletos, balanceados ou não. 
O presente trabalho aproveita experiências e algorítmos de sistemas desenvolvidos pelo autor deste trabalho e por outros autores.

Contribuiram significativamente: o sistema MOLIMU (GODOI et alli, 1987), que possibilita a análise de experimentos uni ou multivariados, o Sistema para Análise de Dados Categorizados em Tabelas De Contingência Tridimensionais (SARRIÉS et alli, 1987), apresentado na tese de doutoramento de HERRERA (1987), e o Sistema Correção por "Stand" (ABREU \& SARRít S, 1986), todos eles implementados em linguagem Pascal.

Também contribuiram alguns sistemas desenvolvidos em linguagem BASIC como o RESICOND (SARRIÉS, 1987), utilizado em diversos trabalhos de pesquisa da ESALQ/USP, para cálculo de somas de quadrados ajustadas, inversas generalizadas e soluções de sistemas de equações normais. Por último, alguns programas preparados para o Departamento de Matemática e Estatística da ESALQ/USP, como o SWEEPG2 (SARRIÉS 1985), e diversos programas menores no campo da Análise Multivariada, desenvolvidos para a disciplina Análise Multivariada, oferecida nesse departamento.

Da experiência obtida nesses trabalhos, e em outros realizados pelo autor, junto ao Setor de Apoio à Pesquisa do Centro de Informática na Agricultura (CTAGRI/USP), desenvolvendo, mantendo e utilizando sistemas estatísticos, surgiu a importância de se contar com algorítmos de cálculo eficientes, de documentação correta dos sistemas computacionais, e também a necessidade da geração de "software" estatístico ser uma atividade interdisciplinar.

O autor desempenhou as funções que corresponderiam ao estatístico, ao analista de sistemas e ao programador de sistemas, guiado em todas as etapas por um estatístico com sólidos conhecimentos de computação, por um profissional da área de Ciências da Computação e por um programador de sistemas, que também colaborou na elaboração do código fonte do aplicativo aqui apresentado.

O Sistema foi denominado SABI (Sistema para Análise em Blocos Incompletos), e é composto de quatro sub-sistemos: Operações com Arquivos, Manuseio de Dados, Análise de Blocos Incompletos Balanceados e Análise de Blocos Incompletos Desbalanceados.

Para sua implementação foi usada a linguagem Pascal, utilizandose os conceitos de Programação Estruturada, o que simplificou as diversas etapas do projeto. $\mathrm{O}$ ambiente de desenvolvimento foi o Turbo Pascal, escolhido por sua eficiência, facilidade de uso e ampla difusão no meio científico.

Utilizaram-se, para o desenvolvimento e operação do sistema, 
equipamentos compatíveis com o IBM PC/XT/AT, amplamente usados no meio agropecuário.

Para a utilização do sistema não é indispensável que o usuário tenha conhecimentos profundos de computação, sendo necessária, porém, alguma familiarização com o delineamento experimental Blocos Incompletos.

Pelo fato do sistema estar documentado e ser desenvolvido utilizando-se técnicas de programaçâo estruturada, com diversos procedimentos de uso geral, o presente trabalho poderia servir como estrutura de base para outros sistemas com maiores recursos, para análise de experimentos com delineamento em Blocos (por exemplo, Blocos Multivariados, Análise de Covariância, e Regressão Polinomial), ou, inclusive, para outros delineamentos experimentais. 


\section{REVISÃo DE LITERATURA}

\subsection{Tópicos de Estatística}

\subsubsection{O Operador SWEEP}

GOODNIGHT (1978) ressalta a versatilidade do operador SWEEP, mostrando que pode ser programado para calcular inversas generalizadas e criar sub-produtos, tais como a matriz de Forward Doolittle, a matriz de decomposição de Cholesky e a matriz de formas canônicas de Hermite, o determinante da matriz original, a soma de quadrados e de produtos cruzados de modelos e submodelos matemáticos, assim como a resolução de sistemas de equações normais.

O trabalho, de natureza tutorial, começa descrevendo o uso da eliminação de Gauss-Jordan no processo de obtenção de soluções de mínimos quadrados e descreve um algoritmo que calcula e armazena as matrizes $\left(X^{\prime} X\right)^{-}$, $\left(X^{\prime} X\right)^{-} X^{\prime} X,\left(X^{\prime} X\right)^{-} X^{\prime} Y$ e $Y^{\prime} Y-Y^{\prime} X\left(X^{\prime} X\right)^{-} X^{\prime} Y$, tudo isso unicamente no espaço de uma matriz triangular superior.

Esse artigo é de um valor inestimável para o estatístico na área computacional devido à apresentação didática de um algoritmo relativamente complexo e de múltiplas utilidades para resolver problemas estatísticos, economizando memória e tempo de processamento ${ }^{1}$.

SARRIÉS (1985), baseado fundamentalmente no artigo de GOODNIGTH (1978), tenta, sistematicamente, avaliar e ilustrar as informações

1 Talvez seja de alguma utilidade, para o leitor interessado, saber que na página 35 do artigo mencionado no momento em que é feita a descrição do algoritmo final, cometeu-se um erro de datilografia que faz o algoritmo fornecer informações erradas, assim, considerou-se interessante transcrever corretamente o passo 5 da página 35 , onde é apresentado o algoritmo UTG2 SWEEP (K):

"step 5: For each value of $i: i=1, \ldots, k$

Set $a_{i k}=-a_{i k} / d \quad$ (no lugar de $a_{i j}=-a_{i j} / d$ )

For each value of $j: j=k, \ldots, N$ cols

Set $a_{k j}=a_{k j} / d$

Then set $a_{k k}=1 / d$ and $v_{k}=-v_{k}$ " 
disponíveis relativas ao operador SWEEP.

No trabalho apresenta-se a idéia de como o algoritmo funciona, através de um exemplo no modelo de regressão múltipla, e em seguida oferece-se um programa em linguagem BASIC, para o equipamento TK85 (Sinclair), com vários exemplos de aplicação na análise de experimentos desbalanceados uni e multivariados.

Esse programa cal̄cula inversa generalizada de tipo II, $\left(X^{\prime} X\right)^{-}$, e sub produtos de interesse, como soma de quadrados (caso univariado) ou a matriz de soma de quadrados e de produtos cruzados (caso multivariado) das diferentes fontes de variação, e uma solução para o sistema de equações normais, o vetor ou matriz de estimativas de parâmetros $\left(X^{\prime} X\right)^{-} X^{\prime} Y$, tudo isto dimensionando somente uma matriz, isto é, economizando memória e tempo de computador.

A matriz utilizada no referido programa não é triangular superior, e a técnica de programação é evidentemente rudimentar, indícios de que o programa é perfectível, servindo na oportunidade, meramente como ferramenta didática.

\subsubsection{Estimabilidade em modelos de dois fatores}

JOHN (1971) e SEARLE (1971) concordam ao definir o conceito de estimabilidade. Dizem que uma combinação linear dos parâmetros é estimável se e só se existe uma combinação $c^{\prime} Y$ das observações tal que $E\left(\underline{c}^{\prime} \underline{Y}\right)=\underline{\lambda}^{\prime} \underline{B}$, isto é, se $\underline{c}^{\prime} X \underline{B}=\underline{\lambda^{\prime}} \underline{B}$ para todo $B$, implica em que $\underline{c}^{\prime} X=\underline{\lambda}^{\prime}$, ou seja, que a função é estimável se e somente se $\underline{\lambda}$ é uma combinação linear das linhas de $X$, ou se $r\left(X^{\prime}\right)=r\left(X^{\prime}, \underline{\lambda}\right)$.

JOHN (1971) e IEMMA (1987) partindo da igualdade $c^{\prime} X=\underline{\lambda}^{\prime}$, e pós-multiplicando-a por $H=\left(X^{\prime} X\right)-X^{\prime} X$ chegam a:

$$
\underline{\underline{\lambda}}^{\prime} H=\underline{c}^{\prime} X\left(X^{\prime} X\right)^{-} X^{\prime} X=\underline{c}^{\prime} X X^{+} X=\underline{c}^{\prime} X=\underline{\lambda}^{\prime}
$$

Assim, uma condição necessária e suficiente para $\underline{\lambda^{\prime}} \underline{B}$ estimável é $\underline{\lambda}^{\prime} H=\underline{\lambda}^{\prime}$.

Os sistemas MOLIMU (1987) e SAS (1988) utilizam o teste $\underline{\lambda}^{\prime} H=\underline{\lambda}^{\prime}$ para detectar estimabilidade de funções paramétricas. Trata-se de um método geral para detectar estimabilidade em Modelos Lineares, porém, o cálculo da matriz $H$ envolve operações matriciais que demandam, dependendo do problema, grande quantidade de memória e tempo de computação. Essas limitações tornam, em algumas situações, o teste de estimabilidade pouco funcional ou impraticável.

SEARLE (1971) aborda o problema da falta de conexão em modelos de dois fatores, com e sem interação. Ele mostra que nesse caso a estimabilidade 
de determinadas funções paramétricas se vê grandemente afetada, o que pode fazer com que alguns constrastes entre níveis de um determinado fator não sejam estimáveis. Em seguida o autor deixa, também, claro que o cálculo dos graus de liberdade e dos quadrados médios das diversas fontes de variação também pode ser afetado.

Para poder analisar dados provenientes de delineamentos desconexos, o autor salienta que é necessário conhecer-se a esîrutura de conexão. Com esse fim, apresenta o seguinte método gráfico:

1) Numa matriz de $a \times b$ pontos (onde $a$ é o número de níveis do fator $A$ e $b$ é o número de níveis do fator $B$ devem-se marcar com um " $x$ " os pontos que contém dados no delineamento em estudo.

2) Toma-se qualquer componente da matriz marcado com " $x$ ", que será o $(\mathrm{p}, \mathrm{q})$-ésimo componente localizado na p-ésima linha e q-ésima coluna.

3) Em seguida tenta-se unir esse (p,q)-ésimo componente com outros componentes " $x$ " que estejam na p-ésima linha ou na q-ésima coluna.

4) Em seguida procede-se da mesma forma com outro " $x$ " ligado ao que deu origem ao processo, até esgotar os " $x$ " que ficarão unidos ao " $x$ " original.

5) Nesse momento ficará definido um grupo conexo dentro desse delineamento desconexo.

6) Escolhe-se um " $x$ " que não foi incluido no grupo anterior e procede-se da mesma forma que nos passos $2,3,4$ e 5 .

7) Se restaram ainda " $x$ " não ligados, aplicar o passo 6 novamente.

Tomando por exemplo, um delineamento com $a=7$ e $b=8$, onde existem " $x$ " nos elementos $\left(a_{1} b_{1}\right),\left(a_{1} b_{5}\right),\left(a_{2} b_{3}\right),\left(a_{2} b_{8}\right),\left(a_{3} b_{2}\right),\left(a_{3} b_{6}\right),\left(a_{3} b_{7}\right),\left(a_{4} b_{2}\right)$, $\left(a_{4} b_{7}\right),\left(a_{5} b_{5}\right),\left(a_{6} b_{3}\right),\left(a_{6} b_{8}\right),\left(a_{7} b_{4}\right)$ e $\left(a_{7} b_{5}\right)$ ficará configurado um gráfico com as características da Figura 1. Nesse esquema pode-se ver que existem 3 grupos conexos. Os níveis $a_{1}, a_{5}$, e $a_{7}$ do fator $A$ pertencem ao primeiro grupo conexo desse fator. Qualquer contraste entre esses três níveis será estimável, porém contrates entre elementos desse primeiro grupo conexo e outros elementos não o serão. Por exemplo o contraste $a_{1}-a_{2}$ não é estimável.

Assim, o autor recomenda que os delineamentos desconexos sejam analisados tomando como base para cálculos de graus de liberdade dos quadrados médios e dos testes de interesse, os grupos conexos. Mostra que num delineamento desconexo as equações normais podem ser separadas em tantos conjuntos de equações quantos grupos conexos existirem, podendo os parâmetros de cada 


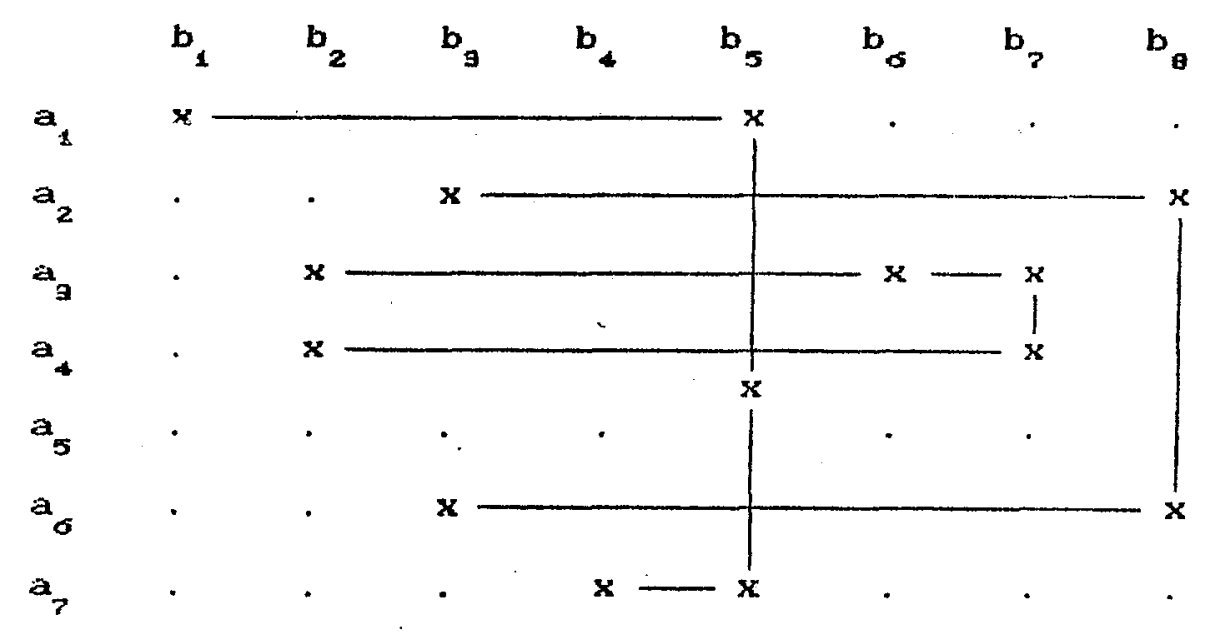

Figura 1 - Grupos conexos num delineamento em blocos incompletos desbalanceados desconexos.

grupo serem estimados separadamente.

O método gráfico de Searle para obtenção de estruturas de conexão de um experimento é didático, porém, do ponto de vista computacional, DODGE (1985) apresenta um algoritmo mais facilmente implementável num programa de computador, o Processo "R".

O Processo "R" trabalha com a matriz de Incidência $(N)$ transformando-a na matriz final $(M)$, formada exclusivamente por zeros e uns. Todas as informações sobre a estrutura de conexão são obtidas a partir da matriz $M$, através de operações simples com variáveis binárias (que assumem valor 0 "falso" - ou 1 - "verdadeiro").

Assim, o Processo "R" não precisa trabalhar com operações de inversão ou multiplicação de matrizes, assim como não precisa armazená-las, as quais, às vezes são de grandes dimensões, como a matriz $X^{\prime} X$. Isso o torna mais interessante para detectar estimabilidade num sistema computacional que o método utilizado nos sistemas MOLIMU e SAS, porém o Processo " $R$ " serve exclusivamente para delineamentos com dois fatores.

Também fornece a dimensão dos sub-espaços dos contrastes es- 
timáveis para os fatores $A$ e $B$, necessária para o cálculo dos graus de liberdade correspondentes. $\mathrm{O}$ modo de calcular os graus de liberdade em delineamentos desconexos não é igual ao dos conexos, trazendo às vezes problemas para o pesquisador da área agropecuária, observados pelo autor deste trabalho quando se utilizam Delineamentos Dialélicos Parciais, ou quando houve perda de material experimental nos delineamentos em Látice parcialmente balanceado.

Livros clássicos de Estatística Experimental, como FISCHER (1935), KEMPTHORNE (1952) e COCHRAN \& COX (1957) utilizam os blocos para controlar uma fonte de variação, o que permite se obter um teste mais poderoso para tratamentos, mas não calculam o quadrado médio nem o teste de F para blocos, deixando implícito que os blocos não devem ser testados.

Existe um consenso entre os estatísticos teóricos a este respeito, porém, na prática, muitos pesquisadores da área agronômica efetuam o teste $F$ para blocos.

Isto poderia dever-se ao fato dos pesquisadores confundirem o modelo de dois fatores sem interação, delineado inteiramente ao acaso, com o delineamento em blocos ao acaso, um modelo de um fator com uma restrição na casualização. Para fins de cálculos de somas de quadrados e de graus de liberdade os dois modelos são idênticos e os livros clássicos não enfatizam a diferença entre ambos.

ANDERSON \& MCLEAN (1974) apresentam o seguinte modelo matemático para o delineamento em blocos ao acaso sem interação:

$$
y_{i j}=\mu+\beta_{i}+\delta_{(i)}+\tau_{j}+\varepsilon_{i j}
$$

onde,

$y_{i j}=$ variável de resposta correspondente ao j-ésimo tratamento no i-ésimo bloco;

$\mu=$ média geral;

$\beta_{i}=$ efeito do i-ésimo bloco;

$\delta_{(i)}=$ i-ésimo erro de restrição;

$\tau_{j}=$ efeito do j-ésimo tratamento;

$\varepsilon_{i j}=$ erro correspondente ao j-ésimo tratamento no i-ésimo bloco, $\operatorname{NID}\left(O, \sigma^{2}\right)$. Com a introdução do erro de restrição no modelo, eles conseguem tornar evidente a diferença entre os modelos matemáticos mencionados, e mostram claramente que não existe um testador para blocos nos delineamentos em blocos casualizados. 
MACHADO (1982) apresenta uma teoria para as análises de variância e covariância em classificações duplas não balanceadas com interação, utilizando o método de ajustamento de constante introduzido por Yates (1934), como gerador de estimativas de parâmetros e somas de quadrados. $\mathrm{O}$ autor estuda a distribuição dos estimadores, as médias ajustadas para os níveis dos fatores, as somas de quadrados e suas esperanças matemáticas, a distribuição das formas quadráticas e testes de significância para a interação. No trabalho são enfatizadas as dificuldades que ocasiona a presença da interação no modelo analisado. No apêndice do trabalho é apresentado um programa na linguagem FORTRAN para viabilizar a análise de dados.

Existem vários trabalhos estatísticos que, como este, apresentam programas de computador. A idéia é a difusão das técnicas estudadas pelos autores, fornecendo ao estatístico, através desses programas, um ferramental que permita a utilização prática dessas técnicas. Normalmente, o programa pode ser redigitado e utilizado ou até copiado eletronicamente, porém, se o usuário desejar fazer alguma modificação ou solicitar informações suplementares, ou sub-produtos das técnicas aplicadas, etc., encontra dificuldade em acompanhar sua lógica, que em geral não segue padrões da programação estruturada. Usualmente esse programa fonte não é acompanhado do projeto do programa, que muitas vezes, inclusive, não existe..

O: usuário encontra-se, então, numa situação muito parecida à de um arquiteto que deve fazer uma modificação num edifício sem ter acesso a sua planta, uma situação extremamente difícil, que geralmente desencoraja qualquer pessoa que queira utilizar um "software" já desenvolvido para geração de novo "software" sem duplicação estéril de esforço.

\subsection{Tópicos de Computação}

\subsubsection{Desenvolvimento e documentação de sistemas}

GANE e SARSON (1983) afirmam que a Análise de Sistemas é, sob vários aspectos, a parte mais difícil do desenvolvimento de um sistema de processamento de dados. Isto dever-se-ia à existência de uma série de dificuldades geradas pelo fato do analista servir de intermediário entre a comunidade de usuários (aqueles que percebem com mais sensibilidade seus problemas, mas acham difícil explicá-los e são vagos sobre o que os computadores podem fazer para ajudar) e a comunidade dos programadores (em geral ansiosos para que a organização tenha uma função de processamento de dados bem definida, mas que 
não possuem informações adequadas para entender aos problemas dos usuários).

Os autores aceitam o fato da Análise de Sistemas ser uma arte inexata, ainda com a incorporação das ferramentas de Análise Estruturada de Sistemas, que são aparentemente as mais apropriadas no auxilio dos analistas na atualidade.

Para justificar a necessidade de mudança das técnicas tradicionais de desenvolvimento para as técnicas de Análise Estruturada de Sistemas, os autores citados apresentam um gráfico que mostra como o custo para corrigir um erro aumenta desproporcionalmente se existir uma demora na deteç̧ão desse erro no ciclo de vida do sistema. O gráfico apresentado na Figura 2 representa o custo relativo da correção de um erro, nas diferentes etapas do ciclo de vida de um sistema (observe-se a escala logarítmica), evidenciando a necessidade de incorporação de um ferramental técnico que permita detectar erros, principalmente nas etapas de definição dos requisitos do sistema e de montagem do projeto.

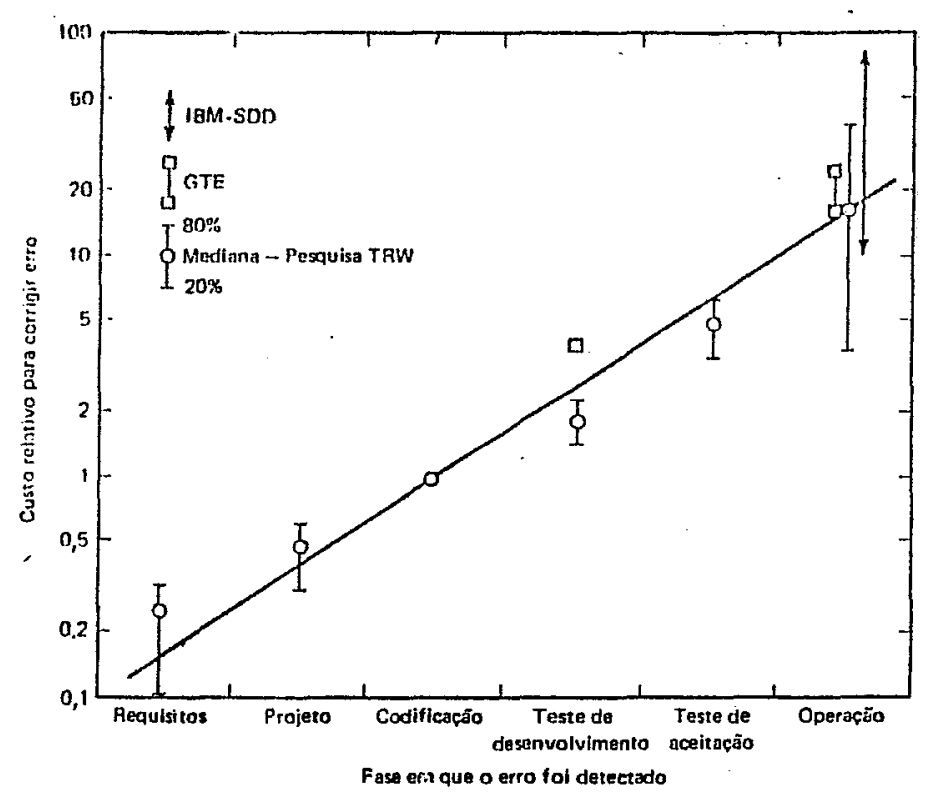

Figura 2 - Custo relativo para corrigir um erro durante o desenvolvimento do sistema. Fonte: GANE \& SARSON (1983)

No mesmo trabalho é abordada a problemática de como elaborar um projeto estruturado a partir do modelo lógico, mostrando a diferença entre as etapas de "análise do sistema" (o que o sistema precisa fazer) e o "projeto do 
sistema" (como será feito). Os autores, numa distinção clara, argumentam os prós e os contras dos projetos: Estruturado, "Top Down", "Bottom Up" e Aleatório.

Com respeito aos objetivos do projeto, afirmam que existem três principais, além do mais importante que é o sistema prover as funções requisitadas pelo usuário. Esses três objetivos são:

- desempenho ou rapidez com que o projeto efetua o trabalho do usuário, dado um determinado recurso de máquina;

- controle: até que ponto o projeto estará seguro contra falhas humanas ou defeitos da máquina;

- "alterabilidade"2: a facilidade com que o projeto permitirá que o sistema seja alterado.

Os autores dão grande ênfase na "alterabilidade" dos sistemas, e salientam que os sistemas projetados para serem mais alteráveis facilitam a etapa de depuração, permitem a adaptação do sistema a novas condições de operação, modificações das linguagens e das máquinas e a incorporação de mudanças e aperfeiçoamentos.

Como exemplo de necessidade de mudanças nas linguagens, poderse-ia mencionar a experiência dos autores do sistema SAS, que precisaram que reescrever o sistema, originalmente escrito em FORTRAN, para a linguagem $\mathrm{C}$, pois com a evolução dos equipamentos (muito influenciada pelo surgimento dos microcomputadores) a linguagem $\mathrm{C}$ é muito mais apropriada que a FORTRAN (PIZANI, 1987) ${ }^{3}$.

GANE \& SARSON (1983) também ilustram as mudanças nas máquinas, com a evolução do custo de um Kbyte de memória RAM desde 1964, quando custava $\operatorname{Cr} \$ 400.000,00$, até 1977, quando custava $\operatorname{Cr} \$ 22.000,00$ (a valores deflacionados). Na atualidade, esse custo continua diminuindo, à média em que aumenta a velocidade de processamento dos equipamentos. A maior "alterabilidade" de um sistema diminui as horas de analista e programador, cujo custo aumenta ano a ano; por exemplo, no periodo de 1964 a 1977, aumentou $7 \%$ ao ano. Assim, os autores defendem o caminho da elaboração de projetos estruturados para "alterabilidade".

2 Termo definido pelos autores como a medida de tempo necessária para efetuar qualquer mudança no sistema, seja removendo falhas ou fazendo aperfeiçoamentos.

3 Anotação pessoal no minicurso sobre o Sistema SAS, ministrado pelo Dr. Luiz Pizani, diretor da SOFT Consultoria em Processamento de Dados Ltda., representante do sistema SAS no Brasil. 
Conclui-se, então, que a elaboração de um projeto estruturado de grande porte, dada a complexidade do assunto, demanda a participação de pessoas treinadas intensivamente na utilização da tecnologia necessária, o que poderá demandar investimentos grandes em recursos humanos. Porém, os prejuizos derivados do não desenvolvimento de um projeto estruturado, seguramente superariam os investimentos em recursos humanos.

ZACHMAN (1987) menciona que a sirquîuetura de sistemas de informação ${ }^{4}$ está recebendo, nos últimos anos considerável atenção na área computacional. Afirma que a complexidade e o alcance dos novos sistemas de informação demanda o uso de algumas construções lógicas (ou arquitetura) para definir o controle, as interfaces e a integração de todos os componentes do sistema. Ele argumenta que há 13 anos esse assunto não era significativo, porque a tecnologia disponível não permitia a geração de sistemas de grande alcance e complexidade, pois os computadores disponíveis naquela época tinham, em média, apenas $4 \mathrm{~Kb}$ de memória RAM.

No mencionado artigo define-se a arquitetura para sistemas de informação por meio de estruturas descritivas, exemplificando com problemas de Engenharia Civil e Aeronáutica. Essas estruturas descritivas são relatórios, diagramas e estruturas de rede, que permitem fundamentalmente mostrar a base lógica do sistema e a comunicação entre os diversos integrantes da equipe multidisciplinar que participa do projeto.

A conclusão do autor é que não existe uma arquitetura para sistemas de informação, mas, sim, um conjunto delas. Essas arquiteturas são aditivas e complementares, servindo para diferentes propósitos. Menciona, por exemplo, que a estrutura descritiva que permite a comunicação engenheiro-proprietário e engenheiro-construtor, num projeto de Engenharia Civil, nao é a mesma.

$O$ enfoque desse artigo pode contribuir no desenvolvimento de sistemas para a área de estatística computacional. Por exemplo, poderia ajudar na comunicação estatístico-analista de sistemas e analista de sistemas- programador. As estruturas descritivas utilizadas com este fim poderiam enfocar diferentes aspectos do problema, podendo, inclusive, não serem as mesmas. Uma outra possível contribuição do artigo é a ênfase da documentação no desenvolvimento de "software", um aspecto importante e geralmente subestimado.

YOURDON (1979) descreve os diferentes métodos de documentação de sistemas estruturados, como o Diagrama Hierárquico de Blocos ("Structure Chart") e o Pseudocódigo ("PseudoCode", "Structured English",

4 Um sistema estatístico é um sistema de informação. 
"Program Design Language" ou "Computer Esperanto"), comparando-os com o fluxograma tradicional, pondo em evidência as vantagens de se trabalhar com os métodos estruturados.

Ressalte-se, porém, que o autor aborda o assunto com exemplos da área administrativa, e para serem implementados na linguagem Cobol. A problemática da Estatística é diferente da Administração, e talvez deveriam ser enfatizados pontos diferentes quando essas técnicas fossem utilizadas para o treinamento de estatísticos. Tendo em vista que na microinformática e no desenvolvimento de sistemas científicos, a linguagem Cobol tem sido substituída por outras linguagens, como a Pascal ou a $\mathrm{C}$, o trabalho não satisfaz a necessidade de comentários especifícos sobre essas linguagens mais modernas.

GUIMARÃES \& LAGES (1985) apresentam a programação estruturada como uma metodologia para o desenvolvimento de algoritmos. Para representar algoritmos valem-se da pseudolinguagem em português, Portugol (equivalente ao pseudocódigo Inglês Estruturado), dos diagramas de Chapin (são os diagramas de Nassi-Shneiderman ou "Structured Flowchart") e dos fluxogramas tradicionais.

Os autores recomendam a utilização do Portugol, que leva a raciocinar e desenvolver a capacidade de abstração de uma forma mais intuitiva, porém, não descartam as formas gráficas de representação (diagramas de Chapin e fluxogramas tradicionais) que podem contribuir para uma melhor visualização em problemas complexos. Fazem um esforço considerável para ensinar o modo de passar os fluxogramas tradicionais para as outras duas técnicas mencionadas, que são aptas para a realização de programas estruturados.

Como motivação para a incorporação de técnicas estruturadas, os autores mostram um gráfico, Figura 3, que ilustra a evolução dos custos de "software" e "hardware" através do tempo.

No gráfico pode-se observar que existiu um aumento relativo muito significativo do preço do "software" em relação ao "hardware". Essa defasagem é justificada pelo argumento de que o custo dos equipamentos eletrônicos (o "hardware") diminuiu pelo rápido desenvolvimento tecnológico, porém, o avanço na tecnologia de "software" não teve, de modo algum, um desenvolvimento compatível.

Essa situação é ilustrada com a afirmação de que, na atualidade, a maior parte dos programadores ainda usam técnicas de programação da época dos computadores de válvulas. Além disso, atribuem os altos custos do desenvolvimento de programas à baixa produtividade dos programadores, a qual, por sua vez, é devida, em grande parte, à falta de uma metodologia de desenvolvimento 


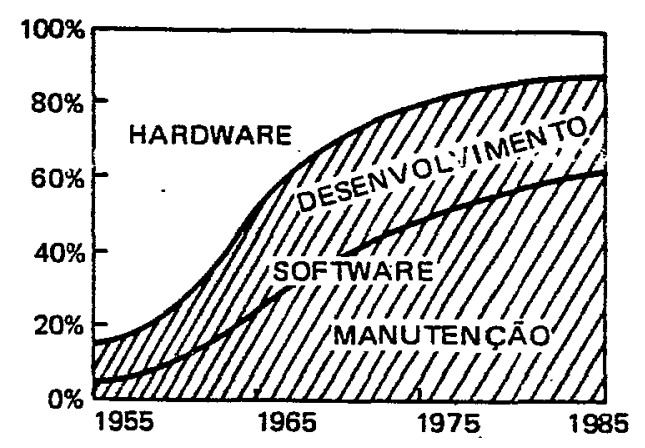

Figura 3 - Tendência dos custos de "software" / "hardware".

Fonte : GUIMARAES \& LAGES (1985)

de programas.

Um aspecto importante do trabalho de GUIMARÃES \& LAGES (1985), especialmente para os leitores da área científica, é que o mapeamento das representações lógicas (Portugol e gráficos), para a codificação em linguagem de computador, é feita para a linguagem Pascal. Além disso, os exemplos são numerosos e de diversas naturezas. Pela riqueza em exemplos e pela boa didática utilizada, esse material poderia servir como ferramenta didática para os analistas e programadores da área agropecuária que não estejam familiarizados com as técnicas de programação estruturada.

AZEVEDO FILHO (1988a, 1988b, 1988c) introduz idéias inovadoras de apresentação de "software" para usuários finais e de documentação de sistemas. A documentação é separada em Leitura Obrigatória, Manual do Usuário, Manual de Referência e Projeto e Listagem do Sistema. As listagens do sistema são padronizadas automaticamente mediante um programa desenvolvido pelo autor.

\subsubsection{Ferramentas úteis para o desenvolvimento e docu- mentação de sistemas}

BARROS, A. $(1988)^{5}$ afirma que existe atualmente uma crise no

5 BARROS, 1988. Anotação pessoal na palestra: "Sistemas para CASE" ministrada na disciplina "Sistemas de Informação" do curso de pós-graduação em Administração da 
desenvolvimento e manutenção de "software", devida possivelmente:

- a um crescente número de aplicações da informática;

- ao processo de elaboração ser lento e altamente manual;

- aos projetos serem inflexíveis, o que torna as mudanças muito difíceis e custosas;

- ao grande esforço que demanda a manutenução dos sistemas.

Assim, esse autor propõe, como contribuição para a solução desses problemas, o desenvolvimento automatizado de sistemas, utilizando princípios de programação estruturada.

A incorporação dessas ferramentas de automação produziriam as seguintes alterações no desenvolvimento de sistemas:

Desenvolvimento Tradicional

- Ênfase em codificação e testes;

- Especificações em papel;

- Codificação manual;

- Documentação manual;

- Testes de programas;

- Manutenção no código.

\section{Desenvolvimento Automatizado}

- Ênfase em ánalise e projeto;

- Prototipação rápida e interativa no computador;

- Geração automática de código;

- Geração automática de documentação;

- Checagem automática de projetos;

- Manutenção nas especificações.

Com esse fim, surgem as ferramentas tipo CASE ("Computer Aided Software Engineering"), definidas pelo United Communications Group (1988) como uma tecnologia de "software" que oferece recursos de engenharia de "software" para o desenvolvimento e manutenção de sistemas, assim como

Universidade de São Paulo, 1988. 
para o gerenciamento de projetos utilizando-se ferramentas automatizadas. Essas ferramentas ajudam na aplicação das técnicas estruturadas desenvolvidas na década de 1970, ou seja, trata-se da engenharia de "software" assistida por computador. Esse tipo de ferramenta (COMPUCENTER, 1987) permite desenvolver aplicações utilizando-se, durante todo o ciclo de vida do sistema a ser gerado, recursos CAD/CAP ("Computer Aided Design / Programming"), ou seja, recursos gráficos e de programação automatizada. Essas ferramentas são executáveis em equipamentos compatíveis com o PC/XT/AT da IBM e colaboram desde a conceituação do problema até a geração de código.

Dentre as vantagens do uso do CASE poder-se-iam enumerar as seguintes (BARROS, 1988):

- torna prático o uso de técnicas estruturadas;

- reforça a engenharia de "software" e de informação;

- melhora a qualidade do "software" devido à checagem automática;

- torna prática a utilização de protótipo;

- simplifica a manutenção;

- acelera o processo de desenvolvimento;

- permite ao profissional ter mais tempo disponivel para concentrar-se na parte criativa do desenvolvimento de "software".

Como conclusão de uma avaliação rápida das ferramentas CASE, pode-se dizer, seguramente, que este recurso será, nos anos 90 , um auxiliar indispensável dos analistas e projetistas de sistemas, assim como poderá vir a ser a forma padrão de comunicação, clara e efetiva, entre os diferentes tipos de profissionais que participam da elaboração de um sistema, atividade que, na atualidade, é notadamente interdisciplinar.

\subsubsection{Sistemas para análise estatística}

EMBRAPA/NTIA (1988); "software" SOC. Esse sistema caracteriza-se por uma boa técnica de programação e fundamentação teórica dos seus algorítmos, assim como por sua funcionalidade. Permite a análise de experimentos em blocos incompletos, aplicando a teoria geral de Modelos Lineares, o que viabiliza a análise de qualquer bloco incompleto balanceado ou não. Porém, a abordagem inespecífica da análise de um experimento no delineamento tratado, limita a capacidade de análise em problemas onde muitos tratamentos e blocos são envolvidos nos delineamentos balanceados ou parcialmente balanceados, por 
gasto excessivo de memória e tempo de computador. Uma outra limitação é que alguns desses delineamentos requerem algumas informações específicas, como por exemplo, os Blocos Incompletos Balanceados (BIB), onde cada tipo demanda informações diferentes.

Uma limitação relativamente séria ençontrada foi a falta de um teste para detectar funções paramétricas estimáveis nos delineamentos abordados, especialmente importante nos delineamentos desbalanceados desconexos, onde $n \in m$ todos os contrastes entre tratamentos são estimáveis.

Percebe-se também alguma dificuldade para a obtenção de intervalos de confiança e testes de comparações múltiplas, devido ao sistema não fornecer médias de tratamentos ajustadas ou as estimativas de parâmetros em arquivo, para se poder entrar no módulo de comparações múltiplas. Uma outra dificuldade é a falta do procedimento de Bonferroni para a obtenção de um número reduzido de inferências com uma confiança conjunta determinada.

Merece destaque o módulo de Álgebra Matricial desse sistema que, por sua versatilidade e potência, pode ser utilizado para colaborar no desenvolvimento de qualquer sistema estatístico que demande uma abordagem matricial e, inclusive, para programar técnicas estatísticas em liguagem SOC.

SARRIÉS, G.A. (1987); "software" RESICOND. Trata-se de um programa para a obtençãa de inversas generalizadas, somas de quadrados ajustadas e estimativas de paramêtros de modelos matemáticos completos ou de sub-modelos. Utiliza o algoritmo SWEEP e o princípio do resíduo condicional para obter essas informações.

O programa é utilizado principalmente para obter somas de quadrados ajustadas em delineamentos Dialélicos Parciais, um delineamento de classificação dupla, como os Blocos Incompletos, ou os modelos de dois fatores, podendo ser utilizado também em outros delineamentos, pois trabalha com o princípio do resíduo condicional em Modelos Lineares.

As limitações do programa encontram-se na funcionalidade e na impossibilidade de realização de testes estatísticos. Porém, apesar dessas limitações, diversos algoritmos e idéias desse programa estão sendo aproveitadas no presente trabalho.

SAS Institute Inc. (1988); "software" SAS. É amplamente conhecida a performance desse sistema para a resoluçã̃o de problemas estatísticos, sendo talvez a ferramenta mais poderosa para o estatístico em termos computacionais, atualmente. 
O SAS analisa experimentos delineados em blocos incompletos, fornecendo diversos recursos para testes de hipóteses, intervalos de confiança e comparações múltiplas. Como limitações para análise completa de um delineamento em blocos incompletos poder-se-iam mencionar as limitações próprias da abordagem do problema utilizando a teoria geral de Modelos Lineares (citadas anteriormente para o sistema SOC), o custo relativamente alto do sistema e alguma dificuldade no aprendizado de utilização, por ser muito abrangente.

No teste de estimabilidade de funções paramétricas, é interessante mencionar que o SAS trabalha com o teste geral de funções estimáveis, dado por:

$$
L H=L
$$

onde $L$ é uma matriz que expressa um conjunto de combinações lineares dos parâmetros do modelo, e $H=\left(X^{\prime} X\right)^{-} X^{\prime} X$, onde $X$ é a matriz do delineamento.

Esse teste é geralmente muito oneroso em tempo e memória de computador, implicando, em determinados problemas, na inviabilidade da aplicação do mesmo. Além disso, o SAS não fornece os grupos de conexão do delineamento, no caso de delineamentos desconexos.

GODOI, C.R.; DIAS, C.T. \& MATTIOLLI, C.H. (1987); "software" MOLIMU. O objetivo principal do sistema é fornecer uma ferramenta capaz de auxiliar professores, estudantes e pesquisadores que se utilizam de Modelos Lineares e Álgebra de Matrizes com fins didáticos e em pesquisas. $\mathrm{O}$ sistema é apropriado para modelos com várias variáveis de resposta, isto é, modelos multidimensionais.

O MOLIMU resolve problemas de Blocos Incompletos, inclusive blocos incompletos multivariados, incluindo covariáveis, e estima equações de regressão polinomial.

As limitações encontradas para analisar esse tipo de problema baseam-se na relativa dificuldade de realização das análises, pelo fato do sistema não ser específico para análise de experimentos em Blocos Incompletos, sendo necessário entrar com a matriz de coeficientes do modelo e realizar operações em suas colunas para se obter os testes de hipóteses desejados. Cabe aqui mencionar o que foi salientado para o sistema SOC e SAS, no que diz respeito à abordagem dos Blocos Incompletos como um caso particular dos Modelos Lineares.

Outra dificuldade encontrada é que o sistema MOLIMU, assim como o SAS, testa a estimabilidade de funções lineares paramétricas através da matriz $H=\left(X^{\prime} X\right)^{-} X^{\prime} X$. Além disso, para os casos balanceados, o sistema não oferece os testes de comparações múltiplas de Tukey, nem o procedimento de Bon- 
ferroni para se realizar inferências sobre os níveis de confiança conjunta.

Os dois grandes módulos do sistema, o de Modelos Lineares e o de Álgebra de Matrizes, foram intensivamente utilizados para desenvolver o sistema $\mathrm{SABI}$, especialmente na etapa de testes do sistema. Inclusive foram aproveitados alguns procedimentos do sistema, gentilmente cedidos pelo autor, como os procedimentos de cálculo de probabilidade na distribuição $F$ e os de cálculo de valores de $F$ para determinadas probabilidades, assim como técniraş de programação e desenvolvimento de sistemas aplicados no MOLIMU.

A manutenção e operação deste sistema foi uma importante experiência para a criação do SABI.

MATTIOLLI, C.H. et alii (1987); "software" LATICE. Esse sistema permite a análise de um caso particular dos blocos incompletos balanceados e parcialmente balanceados, classificados por BOSE \& NAIR (1939). Trata-se experimentos que utilizam o delineamento em "Látice".

O sistema LATICE não utiliza álgebra matricial, assim, em caso de Látices quadrados ou retangulares balanceados, é extremamente rápido e funcional, porém, não permite a análise de casos desbalanceados ou de outros tipos de blocos incompletos. Merecem atenção a apresentação do sistema e os manuais do mesmo, que se destacam entre os manuais de "software" nacional.

ZONTA, E.P.; MACHADO, A.A. \& SILVEIRA Jr, P. (1988); "software" SANEST. Especialmente indicado para utilização de técnicas de análise de variância univariada em delineamentos balanceados, o sistema SANEST também aborda a problemática dos blocos incompletos, no seu aspecto mais geral, os blocos incompletos desbalanceados.

O SANEST emite um bom relatório de saída de resultados, permitindo a realização de análise de covariância, e de polinômios ortogonais, com boa velocidade de processamento.

Dentre as suas limitações, poder-se-ia citar-se que o SANEST carece de um teste para detectar funções paramétricas estimáveis, e que não fornece a estrutura de conexão do delineamento em casos desconexos. O sistema também não permite a realização de intervalos de confiança por nenhum método, assim como testes de hipóteses compostas.

Um outro inconveniente é uma certa dificuldade na funcionalidade do sistema, pela falta de testes de consistência nas entradas e dificuldades para mudar o fluxo de execução do programa em casos de erros. 


\section{METODOLOGIA}

\subsection{Estrutura Organizacional}

O sistema SABI foi desenvolvido totalmente no CIAGRI - Centro de Informática na Agricultura, da ESALQ/USP, com utilização dos equipamentos, programas disponíveis, e com apoio dos técnicos do Centro.

O trabalho foi assessorado por uma equipe, composta fundamentalmente por um elemento da área de Estatística, um Analista de Sistemas e um Programador.

$\mathrm{Na}$ área de Estatística contou-se com a colaboração do Prof. Dr. Cássio Roberto de Melo Godoi, que, além de orientar os passos a serem dados nessa área, contribuiu também, devido a sua longa experiência, na parte computacional.

Na parte de Análise de Sistemas e Projetos colaborou a Analista de Sistemas Gladys Pierri, transmitindo experiências na elaboração de projetos estruturados.

A implementação do sistema na linguagem Pascal contou com a colaboração do Programador de Sistemas Marcelo Zacarias da Silva, quanto à consistência, estética e funcionalidade, assim como na incorporação do editor de textos do Turbo ToolBox utilizado.

Com essa assessoria, o autor do sistema desempenhou as funções do profissional da área de Estatística, do Analista de Sistemas e do Programador.

\subsection{Procedimentos Estatísticos}

Dentre os algorítmos de cálculo utilizados no presente trabalho, merecem uma menção especial, por serem úteis e inovadores, o operador SWEEP e o Processo " $R$ ". Por essa razão, em primeira instância se fará uma apresentação de cada um desses algoritmos, tentando mostrar algumas de suas interessantes propriedades, e dando uma descrição de seu funcionamento através de exemplos de aplicação. Posteriormente serão apresentados os demais algoritmos estatísticos 
utilizados no sistema.

\subsubsection{O Operador SWEEP}

O operador SWEEP é talvez o mais versátil de todos os operadores estatísticos. Ele pode ser adaptado para uso em caso de Mínimos Quadrados Ordinários (inclusive Regressão Linear Múltipla e Modelos Lineares em geral), Mínimos Quadrados em Dois e Três șatágios, Mínimos Quadrados Não-Lineares; Análise de Variância Multivariada, todas as possíveis regressões, "Regression by Leaps and Bounds", Regressão Passo a Passo, Correlações Parciais, e outras técnicas (GOODNIGHT, 1978).

Este operador, mais do que uma técnica de inversão de matrizes, é uma ferramenta conceitual para se entender o processo de Mínimos Quadrados. Pode ser programado para produzir inversas generalizadas de matrizes, e fornecer sub-produtos, como a matriz de Forward-Doolittle, a Matriz de Decomposição de Cholesky, a Matriz de Formas Canônicas de Hermite, o determinante da matriz original, somas de quadrados ou matriz de somas de quadrados e de produtos cruzados do modelo (completo ou não), e uma solução do sistema de equações normais.

A seguir será dada uma idéia de como o algoritmo funciona, através de exemplos de aplicação, para obtenção de: inversa generalizada do tipo II, $\left(X^{\prime} X\right)^{g 2}$, e sub-produtos de interesse, como soma de quadrados (caso univariado), ou matriz de somas de quadrados e de produtos cruzados (multivariado) das diferentes fontes de variação, uma solução para o sistema de equações normais, e o vetor ou matriz de estimativa de parâmetros $\left(X^{\prime} X\right)^{g^{2}} X^{\prime} Y$. Tudo isto dimensionando somente uma matriz triangular superior, economizando, desta forma, muita memória e tempo de processamento.

Como o operador SWEEP pode ser utilizado em problemas multivariados, o que permite uma ampliação futura para a análise de Blocos Incompletos Multivariados, apresenta-se o algoritmo na sua forma mais geral, onde a abordagem univariada é o caso particular em que se conta somente con uma variável resposta.

Assim, trabalhou-se com o Modelo Linear Geral:

$$
Y=X B+E,
$$

onde $Y$ é uma matriz de dimensão $n \times p$, de observações individuais uni ou multidimensionais; $X$ é uma matriz $n \times q$, composta de zeros (0) e uns (1) (também -1's em caso de reparametrizações) e/ou variáveis contínuas; $B$ é uma matriz $q \times p$, de 
parâmetros; e $E$ é uma matriz $n \times p$, dos erros, onde

$$
\begin{gathered}
Y^{\prime}=\left[\begin{array}{llll}
\underline{Y}_{1} & \underline{Y}_{2} & \ldots & \underline{Y}_{n}
\end{array}\right], \quad E^{\prime}=\left[\begin{array}{llll}
\underline{\varepsilon}_{1} & \underline{\varepsilon}_{2} & \ldots & \underline{\varepsilon}_{n}
\end{array}\right], \\
\underline{\varepsilon}_{i}^{I I D} N_{p}(\phi, \mathcal{E}), \quad \underline{Y}_{i}^{I I D} N_{p}\left(\underline{\mu}_{i}, \mathcal{E}\right), \quad i=1,2, \ldots, n
\end{gathered}
$$

com $n=$ número de observações; $p=$ número de variáveis dependentes; e $q=$ número de colunas da matriz de coeficientes (ou matriz do delineamento).

Para dar uma idéia de como o algoritmo funciona, partir-se-á da matriz aumentada:

$$
\left(\begin{array}{cccc}
X^{\prime} X & X^{\prime} Y & \vdots & I \\
\cdots \cdots & \cdots \cdots & \vdots & \cdots \cdots \\
Y^{\prime} X & Y^{\prime} Y & \vdots & \phi
\end{array}\right)
$$

Primeiramente será considerada a matriz $X$ como sendo de "rank" coluna completo.

Aplicando-se somente dois tipos de operações, multiplica-se uma linha por uma constante e soma-se um múltiplo de uma linha à outra linha, sabendo-se que um dos mais importantes aspectos ao realizar operações sobre as linhas de uma matriz é a equivalência com a pré-multiplicação dessa matriz por outra.

Pré-multiplicando-se (1) por

$$
\left(\begin{array}{ccc}
\left(X^{\prime} X\right)^{-1} & \vdots & \phi \\
\cdots \cdots \cdots & \vdots & \cdots \\
-Y^{\prime} X\left(X^{\prime} X\right)^{-1} & \vdots & I
\end{array}\right)
$$

obtém-se

$$
\text { (2). }(1)=\left(\begin{array}{ccccc}
I & \vdots & \left(X^{\prime} X\right)^{-1} X^{\prime} Y & \vdots & \left(X^{\prime} X\right)^{-1} \\
\cdots & \vdots & \cdots \cdots \cdots \cdots \cdots \cdots & \vdots & \cdots \cdots \cdots \cdots \\
\underbrace{\phi}_{\mathbf{B}} & \vdots & \underbrace{Y^{\prime} Y-Y^{\prime} X\left(X^{\prime} X\right)^{-1} X^{\prime} Y}_{\mathrm{C}} & \vdots & \underbrace{-Y^{\prime} X\left(X^{\prime} X\right)^{-1}}_{\mathbf{D}}
\end{array}\right)
$$

Descartando-se a partição B e em seu lugar colocando-se a partição D, ter-se-á o resultado que o operador SWEEP fornecerá.

Desta forma, obtém-se uma matriz do tipo

$$
\left(\begin{array}{ccc}
\left(X^{\prime} X\right)^{-1} & \vdots & \left(X^{\prime} X\right)^{-1} X^{\prime} Y \\
\cdots \cdots \cdots \cdots \cdots \cdots \cdots \cdots & \vdots & \cdots \cdots \cdots \cdots \cdots \cdots \cdots \cdots \\
-Y^{\prime} X\left(X^{\prime} X\right)^{-1} & \vdots & Y^{\prime} Y-Y^{\prime} X\left(X^{\prime} X\right)^{-1} X^{\prime} Y
\end{array}\right)
$$


Já que (3) foi obtida pré-multiplicando-se (1) por (2) pode-se também obter (3) realizando-se operações sobre as linhas de (1). Visto que $X^{\prime} X$ neste caso é definida positiva, as operações em linha usadas para calcular (3) a partir de (1) necessitam ser somente uma sequência de pivôs sobre os elementos da diagonal de $X^{\prime} X$. Assim, restringindo-se as operações de linhas a pivôs sobre os elementos diagonais de $X^{\prime} X$, podem-se obter muitas informações estatísticas valiosas.

Com o intuito de economizar memória de computador, o operador SWEEP foi criado de tal forma a trabalhar somente sobre uma parte da matriz (1), a matriz "A":

$$
A=\left(\begin{array}{ccc}
X^{\prime} X & \vdots & X^{\prime} Y \\
\cdots \cdots & \vdots & \cdots \cdots \\
Y^{\prime} X & \vdots & Y^{\prime} Y
\end{array}\right)
$$

Definição: "OPERADOR SWEEP (K)"

Dada uma matriz "A", definida positiva, esta será modificada pelo $\operatorname{SWEEP}(K)$ da seguinte forma:

PASSO 1: Seja $D=a_{k k}$.

PASSO 2: Divide-se a linha $k$ por $D$.

PASSO 3: Para qualquer outra linha $i=k$, toma-se $B=a_{i k}$, subtraindo-se $B$ vezes a linha $k$ da linha $i$, e colocando-se este resultado na linha i. Em seguida, faz-se

$$
a_{i k}=-B / D
$$

PASSO 4: Toma-se $a_{k k}=1 / D$.

Para exemplificação, considera-se o seguinte conjunto de dados, que caracteriza um caso de regressão múltipla, com duas variáveis preditoras (GOODNIGHT, 1978):

\begin{tabular}{cccc}
\hline$X_{0}$ & $X_{1}$ & $X_{2}$ & $Y$ \\
\hline 1 & 1 & 1 & 1 \\
1 & 2 & 1 & 3 \\
1 & 3 & 1 & 3 \\
1 & 1 & -1 & 2 \\
1 & 2 & -1 & 2 \\
1 & 3 & -1 & 1 \\
\hline
\end{tabular}


Cada observação pode ser caracterizada por

$$
\begin{gathered}
Y_{i}=\beta_{0}+\beta_{1} X_{1 i}+\beta_{2} X_{2 i}+e_{i}, \\
e_{i}^{I \underline{I} D} N\left(O, \sigma^{2}\right), \quad i=1, \ldots, 6 .
\end{gathered}
$$

A matriz "A" será:

$$
\begin{gathered}
A=\left(\begin{array}{cccc}
N & \sum X_{1} & \sum X_{2} & \sum Y \\
& \sum X_{1}^{2} & \sum X_{1} X_{2} & \sum X_{1} Y \\
\ldots \ldots \ldots & \ldots \ldots & \sum \ldots \ldots & \ldots \ldots \ldots \\
\ldots X_{2}^{2} & \sum X_{2} Y \\
(\operatorname{Sim} .) & & & \sum Y^{2}
\end{array}\right) \\
A=\left(\begin{array}{cccc}
6 & 12 & 0 & 12 \\
12 & 28 & 0 & 25 \\
0 & 0 & 6 & 2 \\
\ldots \ldots & \ldots \ldots & \ldots \ldots & \ldots \ldots \\
12 & 25 & 2 & 28
\end{array}\right)
\end{gathered}
$$

Aplicando-se o SWEEP(K):

- Para $k=1$, ou seja, operando a coluna 1:

PASSO 1: $D=a_{11}=6$.

PASSO 2: Divide-se "linha 1" por 6. A linha 1 ficará:

$$
\left[\begin{array}{llll}
1 & 2 & 0 & 2
\end{array}\right]
$$

PASSO 3: $i=1,2,3,4$

$i=1$ : como $i=k=1$, toma-se o próximo $i$;

$i=2: B=a_{21}=12$. A "linha 2" ficará:

$\left[\begin{array}{llll}-2 & 4 & 0 & 1\end{array}\right]$

$i=3: B=a_{31}=0$. A "linha 3" ficará:

$\left[\begin{array}{llll}0 & 0 & 6 & 2\end{array}\right]$;

$i=4: B=a_{41}=12$. A "linha 4" ficará:

$\left[\begin{array}{llll}-2 & 1 & 2 & 4\end{array}\right]$.

PASSO 4: $a_{i i}=1 / 6$. A "linha 1" ficará:

$$
\left[\begin{array}{llll}
1 / 6 & 2 & 0 & 2
\end{array}\right] \text {. }
$$

A matriz $A$ operada na primeira coluna $A_{1}$, ficará:

$$
A_{1}=\left(\begin{array}{cccc}
1 / 6 & 2 & 0 & 2 \\
\ldots \ldots & \ldots \ldots & \ldots \ldots & \ldots \ldots \\
-2 & 4 & 0 & 1 \\
0 & 0 & 6 & 2 \\
-2 & 1 & 2 & 4
\end{array}\right)
$$


Pode-se ver que a primeira coluna é a resultante da aplicação das mesmas operações realizadas na coluna $j, j=k$, na primeira coluna de uma matriz identidade da mesma ordem que " $A$ ". A sub-matriz $3 \times 3$ inferior direita de " $A$ " é a matriz da soma de quadrados e de produtos cruzados do resíduo dos sub-modelos

$$
X_{1}=\beta^{\prime}+e^{\prime}, \quad X_{2}=\beta^{\prime \prime}+e^{\prime \prime}, \quad \text { e } Y=\beta^{\prime \prime \prime}+e^{\prime \prime \prime} .
$$

Por exemplo, na posição $a_{44}$ temos a soma de quadrados do resíduo para o modelo $Y=\beta^{\prime \prime \prime}+e^{\prime \prime \prime}$, que coincide com a soma de quadrados total corrigida do modelo inicial (5). Assim,

$$
a_{44}=\sum\left(Y_{i}-\bar{Y}\right)^{2}=Y^{\prime} Y-\left(\sum Y_{i}\right)^{2} / N=4 .
$$

$O$ vetor $1 \times 3$ superior direito contém os valores dos $\widehat{\beta}$ 's para esses sub-modelos.

- Para $k=2$, ou seja, operando a coluna 2 após ter operado a coluna 1, ter-se-á:

$$
A_{2}=\left(\begin{array}{cccc}
7 / 6 & -1 / 2 & 0 & 3 / 2 \\
-1 / 2 & 1 / 4 & 0 & 1 / 4 \\
\cdots \cdots & \cdots \cdots & \cdots \cdots & \cdots \cdots \\
0 & 0 & 6 & 2 \\
-3 / 2 & -1 / 4 & 2 & 15 / 4
\end{array}\right)
$$

A sub-matriz $2 \times 2$ superior direita contém os valores dos $\beta$ 's para os sub-modelos:

$$
X_{2}=\beta_{0}+\beta_{1}^{\prime} X_{1}+e^{\prime} \quad \text { e } \quad Y=\beta_{0}^{\prime \prime}+\beta_{1}^{\prime \prime} X_{1}+e^{\prime \prime}
$$

(exemplo $a_{13}=\widehat{\beta}_{0}^{\prime} ; a_{23}=\widehat{\beta}_{1}^{\prime}$ ).

A matriz $2 \times 2$ inferior direita é a matriz de soma de quadrados e de produtos cruzados dos resíduos desses dois sub-modelos.

- Para $k=3$, o que significa operar a coluna 3 após ter operado as colunas 1 e 2:

$$
A_{3}=\left(\begin{array}{cccc}
7 / 6 & -1 / 2 & 0 & 3 / 2 \\
-1 / 2 & 1 / 4 & 0 & 1 / 4 \\
0 & 0 & 1 / 6 & 1 / 3 \\
\cdots \ldots & \ldots \ldots & \cdots \ldots & \ldots \ldots \\
-3 / 2 & -1 / 4 & -1 / 3 & 37 / 12
\end{array}\right)
$$

Desta forma se completa a solução do sistema de equações normais do modelo (5), no vetor $3 \times 1$ superior direito e a soma de quadrados do resíduo do modelo completo na posição $a_{44}$.

Aplicando-se novamente o operador nas primeiras três colunas, verifica-se que se estará ante a matriz " $A$ " inicial, o que mostra a reversibilidade do 
mecanismo. Assim, além de a quantidade de memória e de tempo de computação usados neste processo ser menor que nos processos normais de obtenção dos valores dos $\widehat{\beta}$ 's, das somas de quadrados e de $\left(X^{\prime} X\right)^{-1}$, nenhuma informação original é perdida. Isto permite, por exemplo, calcular ainda o determinante de $X^{\prime} X$, a matriz de decomposição de Cholesky, a matriz de formas canônicas, etc., e todas as informações dos sub-modelos estarão disponíveis.

Como foi evidenciado no exemplo anterior, após cada uso do operador SWEEP $(\mathrm{K})$, os elementos da diagonal das colunas até então não operados representam as somas de quadrados dos erros dos sub-modelos entre variáveis independentes.

Suponha que sobre uma matriz $A$, como a utilizada no exemplo, se tenha aplicado o operador SWEEP(K) nas primeiras $k-1$ colunas. Então, o elemento $a_{k k}$ é a soma de quadrados de resíduo para o sub-modelo:

$$
X_{k}=\dot{\beta}_{0}+\beta_{1} X_{1}+\ldots+\beta_{k-1} X_{k-1}+e .
$$

O valor de $R^{2}$ para este sub-modelo é, então,

$$
R_{k}^{2}=\left(S Q T X_{k}-a_{k k}\right) / S Q T X_{k},
$$

onde $S Q T X_{k}=\sum X_{k}^{2}-\left(\sum X_{k}\right)^{2} / n_{k}$ é a soma de quadrados total corrigida para a média de $X_{k}$.

O valor de $R^{2}$ possibilita, segundo GOODNIGHT (1978), um valioso teste de colinearidade. Se $R^{2}$ é muito próximo de 1 , então $X_{k}$ é, ao menos estatisticamente, uma combinação linear dos $X$ 's precedentes. Os elementos da coluna $k$ associados com as variáveis previamente ajustadas mostram qual é essa combinação linear.

\section{Cálculo de Inversa Generalizada}

É comum existir dependência entre as colunas da matriz $X$ do delineamento. Para alguns modelos, a dependência é facilmente evidenciável, porém, para outros pode aparecer uma dependência inesperada. Então, pode-se detectar dependência entre as colunas da matriz $X$ usando-se o coeficiente de determinação $R^{2}$, ou a tolerância, $T$, onde $T_{k}=1-R_{k}^{2}$.

Valendo-se deste teste, encontra-se uma inversa para $X^{\prime} X$ e uma solução para o sistema de equações normais correspondente.

Este trabalho não se aprofundará na discussão do método de obtenção das diversas inversas generalizadas existentes. Será apresentado um procedimento para a obtenção da inversa generalizada "G2", que tem as seguintes propriedades: 

1) $A A^{g 2} A=A$
2) $A^{g 2} A A^{g 2}=A^{g 2}$
3) $A^{g 2}=\left(A^{g 2}\right)^{\prime}$

O tempo de operação do SWEEP pode ser reduzido aproximadamente pela metade, considerando-se as propriedades de simetria da matriz $A$. A quantidade de memória do computador também pode reduzir-se peìa metade, utilizando tais propriedades.

Assim, o algoritmo que se apresenta a seguir, trabalhará exclusivamente na parte triangular superior da matriz $A$, o que reduz o número de passos a serem realizados, porém não reduz a quantidade de memória a ser utilizada.

Para diminuir a quantidade de memória do computador, idealizouse um algoritmo que permite simular o trabalho numa matriz triangular superior, o que equivale, na realidade, simplesmente: a operações sobre um vetor.

Seja $a_{i} j$ um elemento da matriz $A$ que se encontra na i-ésima linha e j-ésima coluna. Os elementos $a_{i} j$ para $i>j$, abaixo da diagonal principal, podem ser construídos a partir dos elementos acima da diagonal principal da seguinte forma:

$$
a_{i j}= \begin{cases}a_{j i}, & \text { se } i \text { e } j \text { foram operados pelo SWEEP } \\ a_{j i}, & \text { se nem } i \text { nem } j \text { foram operados pelo SWEEP } \\ -a_{j i}, & \text { se } i \text { ou } j \text { (mas não ambos) foram operados pelo SWEEP. }\end{cases}
$$

A forma mais fácil de se saber quais colunas foram operadas ou não, é através de um vetor auxiliar, $V$. Os elementos do vetor $V$ são inicialmente um conjunto de uns, depois de se operar a coluna $k$ o elemento $V$ será mudado para $-V_{k}$. Se o vetor $V$ é aplicado, os elememtos abaixo da diagonal principal podem ser construídos a partir dos de cima, da seguinte forma:

$$
a_{i j}=a_{j i} \times V_{i} \times V_{j} \quad(\text { para } i>j)
$$

O operador, denominado por GOODNIGHT (1978) de UTG2 SWEEP (K), modificará a posição superior da matriz $A$ como segue:

PẠSSO 1: Seja $D=a_{k k}$

Se $V_{k}=1$ e $D \leq$ tolerância (T), então zere os elementos acima e à direita de $a_{k k}$, incluindo $a_{k k}$, então termine. Senão continue.

PASSO 2: Para cada valor de $i$, para $i=1,2, \ldots$ numero de linhas, exceto para $i=k$, realize o passo 3 . Depois vá para o passo 5 . 
PASSO 3: Se $i<k$, então seja $\beta=a_{i k} / D$, de outra forma, seja $\beta=V_{i} \times V_{k} \times a_{k i} / D$. Depois, para cada valor $j$, para $j=i, i+1, \ldots$ número de colunas, exceto para $j=k$, realize o passo 4 .

PASSO 4: Se $k<j$, então seja $C=a_{k j}$, senão, seja $C=V_{j} \times V_{k} * a_{J K}$. Seja $a_{i j}=a_{i j}-B \times C$.

PASSO 5: (Neste passo existe um erro de datilografia no trabalho original de GOODNIGTH).

Para cada valor de $i$, para $i=1, \ldots, k$ :

Seja $a_{k}=-a_{i k} / D$ (No trabalho original está $a_{i j}=-a_{i j} / D$ ).

Para cada valor de $j$, para $j=k, \ldots$ número de colunas, seja $a_{k j}=a_{j k} / D$.

Depois seja $a_{k k}=1 / D$ e $V_{k}=-V_{k}$.

$\mathrm{O}$ algoritmo, que simula o trabalho numa matriz triangular superior, sendo que, na realidade, se está operando simplesmente um vetor, é o seguinte. Seja $I$ índice de linha e $J$ índice de coluna: o elemento $(I, J)$ de uma matriz triangular superior será colocado num vetor na posição $K$, obtido mediante a fórmula

$$
K=J+(I-1)\left[-\frac{I}{2}+\text { número total de colunas }\right]
$$

Com o intuito de ilustrar o funcionamento do operador SWEEP num problema de blocos incompletos apresenta-se o seguinte exemplo, que se refere a um experimento delineado em Blocos Incompletos Desbalanceados, consistindo de 3 tratamentos e 2 blocos, conforme esquema abaixo:

\begin{tabular}{cl}
\hline Bloco I & Bloco II \\
\hline (1) 10 & (1) 6 \\
(2) 8 & (2) 6 \\
(3) 5 & \\
\hline
\end{tabular}

Cada observação pode ser caracterizada por :

$$
Y_{i j}=\mu+\beta_{j}+\tau_{i}+e_{i j}
$$

com $i=1,2,3$ e $j=1,2$. O modelo matemático, na forma matricial pode ser escrito da seguinte forma:

$$
\underline{Y}=X \underline{\beta}+\underline{e} .
$$


A matriz $\mathrm{X}$ acrescida de $\mathrm{Y}$, será:

$$
[X: Y]=\left(\begin{array}{rrrrrrrr}
1 & 1 & 0 & 1 & 0 & 0 & \vdots & 10 \\
1 & 1 & 0 & 0 & 1 & 0 & \vdots & 8 \\
1 & 1 & 0 & 0 & 0 & 1 & \vdots & 5 \\
1 & 0 & 1 & 1 & 0 & 0 & \vdots & 6 \\
1 & 0 & 1 & 0 & 1 & 0 & \vdots & 6
\end{array}\right)
$$

O programa calculará a matriz $A$ :

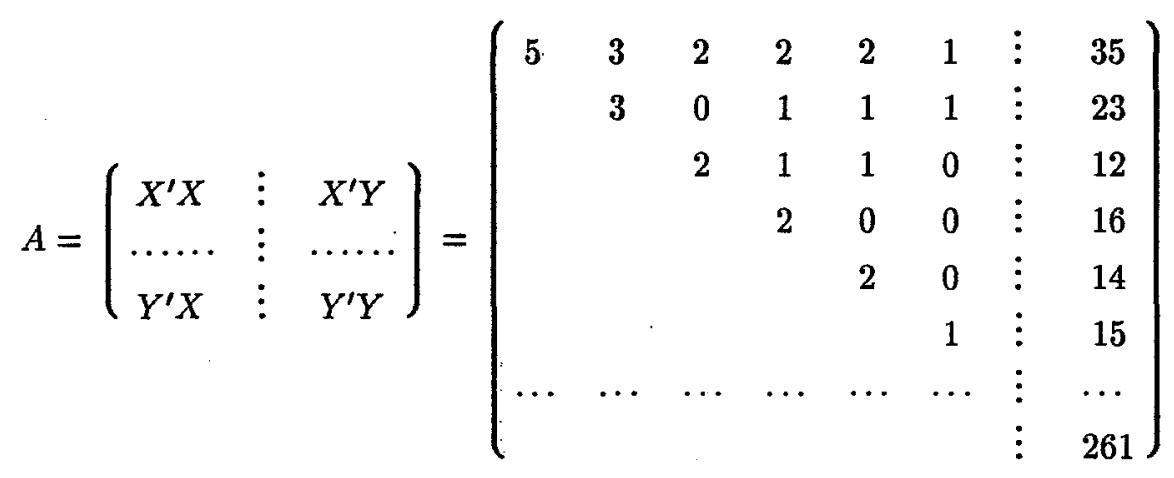

Para a construção do quadro de ANOVA ou MANOVA precisarse-á de uma sub-matriz inferior direita de dimensão $p \times p$ ( $p=$ número de variáveis dependentes), que mostrará sempre somas de quadrados ou soma de quadrados e de produtos de sub-modelos completos.

Neste exemplo $p=1$, por tratar-se de um caso univariado. Então, presta-se atenção ao elemento $a_{77}$.

Inicialmente $a_{77}^{[0]}$ é o elemento inferior direito da matriz " $A$ " antes de ser operado. Assim, $a_{77}^{[0]}=Y^{\prime} Y=261$.

Aplicando o operador SWEEP-G2(K) na coluna $1(k=1)$, tem-se:

$a_{77}^{[1]}=\mathrm{SQ}$ do resíduo do sub-modelo $\underline{Y}=\mu \underline{1}+\underline{\sigma} 1$, e também a $\mathrm{SQ}$ Total ajustada do modelo completo. Assim,

$$
\begin{gathered}
a_{77}^{[1]}=\left[Y^{\prime} Y-\left(\sum Y_{i}\right)^{2} / n\right]=Y^{\prime} Y-R(\mu)=a_{77}^{[0]}-R(\mu)=16 \\
\therefore R(\mu)=a_{77}^{[0]}-a_{77}^{[1]}=261-16=245 .
\end{gathered}
$$

onde $R(\mu)$ é a redução na soma de quadrados devida à média. coluna 1, obtém-se:

Operando da coluna 2 até a $3(k=2$ e $k=3)$ após ter operado a

$$
a_{77}^{[3]}=S Q \text { do residuo do modelo } Y=\mu \underline{1}+\underline{\beta}+\underline{\sigma}_{2}
$$


Assim,

$$
\begin{gathered}
a_{77}^{[3]}=Y^{\prime} Y-R(\mu)-R(\beta \mid \mu)=a_{77}-R(\beta \mid \mu)=12,6667 \\
\therefore R(\beta \mid \mu)=a_{77}^{[1]}-a_{77}^{[3]}=16-12,6667=3,3333,
\end{gathered}
$$

onde $R(\beta \mid \mu)$ é a redução devida a blocos, ajustada pela média.

Finalmente, operando da coluna 4 até a 6 (após 1, 2 e 3), obtém-se:

$a_{77}^{[6]}=\mathrm{SQ}$ do resíduo do modelo completo:

$$
\underline{Y}=\mu \underline{1}+\underline{\beta}+\underline{\tau}+\underline{\sigma}
$$

Assim,

$$
\begin{gathered}
a_{77}^{[6]}=Y^{\prime} Y-R(\mu)-R(\beta \mid \mu)-R(\tau \mid \mu, \beta)=a_{77}^{[3]}-R(\tau \mid \mu, \beta)=1 \\
\therefore R(\tau \mid \mu, \beta)=a_{77}^{[3]}-a_{77}^{[6]}=12,6667-1=11,6667,
\end{gathered}
$$

onde $R(\tau \mid \mu, \beta)$ é a redução devida a tratamentos, ajustada pela média e por blocos.

Ao se fazer as diferenças entre os $a_{77}$ 's, aplica-se o conceito de resíduo condicional. Após ter operado todas as colunas da matriz $\mathrm{X}^{\prime} \mathrm{X}$, tem-se, no lugar da matriz " $A$ ", os seguintes elementos:

$$
\begin{aligned}
& \left(\begin{array}{ccc}
\left(X^{\prime} X\right)^{g 2} & \vdots & \stackrel{\circ}{B} \\
\cdots \ldots & \vdots & \ldots \ldots \ldots \ldots \ldots \ldots \ldots \\
-\stackrel{\circ}{B} & \vdots & Y^{\prime} Y-Y^{\prime} X\left(X^{\prime} X\right)^{g 2} X^{\prime} X
\end{array}\right)= \\
& =\left(\begin{array}{rrrrrrrr}
2,00 & -1,00 & 0,00 & -1,50 & -1,50 & 0,00 & \vdots & 2,00 \\
-1,00 & 1,00 & 0,00 & 0,50 & 0,50 & 0,00 & \vdots & 3,00 \\
0,00 & 0,00 & 0,00 & 0,00 & 0,00 & 0,00 & \vdots & 0,00 \\
-1,50 & 0,50 & 0,00 & 1,75 & 1,25 & 0,00 & \vdots & 4,00 \\
-1,50 & 0,50 & 0,00 & 1,25 & 1,75 & 0,00 & \vdots & 3,00 \\
0,00 & 0,00 & 0,00 & 0,00 & 0,00 & 0,00 & \vdots & 0,00 \\
\ldots \ldots & \ldots \ldots & \ldots \ldots & \ldots \ldots & \ldots \ldots & \ldots \ldots & \vdots & \ldots \ldots \\
-2,00 & -3,00 & 0,00 & -4,50 & -3,50 & 0,00 & \vdots & 1,00
\end{array}\right)
\end{aligned}
$$

onde $\stackrel{B}{B}=\left(X^{\prime} X\right)^{g 2} X^{\prime} Y$ é a matriz de estimativas dos parâmetros (neste caso um vetor, porque o problema é univariado) do modelo, $\mathrm{e}\left(X^{\prime} X\right)^{g 2}$ a inversa generalizada de tipo 2 da matriz $X^{\prime} X$.

A sub-matriz inferior direita é a soma de quadrados dos erros do modelo completo. 
da variância.

Com os dados obtidos, construiu-se o seguinte quadro de análise

\begin{tabular}{lcr}
\hline Fontes de Variação & G.L. & \multicolumn{1}{c}{ S.Q. } \\
\hline$R(\mu)$ & 1 & 245,0000 \\
$R(\beta \mid \mu)$ & 1 & 3,3333 \\
$R(\tau \mid \mu, \beta)$ & 2 & 11,6667 \\
\hline$R(\tau, \beta, \mu)$ & 4 & 260,0000 \\
Residuo & 1 & 1,0000 \\
\hline TOTAL & 5 & 261,0000 \\
\hline
\end{tabular}

Pode-se utilizar $R(\tau \mid \mu, \beta)$ como a soma de quadrados do numerador,

para testar

$$
H_{0}: \tau_{1}=\tau_{2}=\tau_{3}
$$

Surge, porém, dificuldades nos casos não balanceados, se se deseja testar $H_{0}: \beta_{1}=\beta_{2}$, porque $R(\beta \mid \mu)$ aí não pode ser utilizada como soma de quadrados do numerador para testar esta hipótese. Assim, aparece a necessidade de calcular $R(\beta \mid \mu, \tau)$, o que não é difícil utilizando o programa proposto.

Simplesmente, após as operações realizadas, ter-se-ia que operar da coluna 1 até a 6 para chegar a uma matriz equivalente a " $A$ ", operar a coluna 1 para obter $R(\mu)$, em seguida de 4 a 6 para obter $R(\tau \mid \mu)$, e finalmente da 2 a 3 para obter $R(\beta \mid \mu, \tau)$. Obtém-se, então, o seguinte quadro de ANOVA:

\begin{tabular}{lcr}
\hline Fontes de Variação & G.L. & \multicolumn{1}{c}{ S.Q. } \\
\hline$R(\mu)$ & 1 & 245,0000 \\
$R(\tau \mid \mu)$ & 1 & 6,0000 \\
$R(\beta \mid \mu, \tau)$ & 2 & 9,0000 \\
\hline$R(\tau, \beta, \mu)$ & 4 & 260,0000 \\
(Residuo) & 1 & 1,0000 \\
\hline TOTAL & 5 & 261,0000 \\
\hline
\end{tabular}

\subsubsection{O Processo " $R$ "}

Num delineamento em blocos, completos ou incompletos, pode acontecer a perda de algumas observações, por não poderem ser coletadas, ou porque o experimentador não instalou o experimento como planejado. Esse tipo 
de problema acontece com frequência na pesquisa agropecuária.

Em tais situações o delineamento experimental perde o balanceamento e a simetria e, em alguns casos, quando se perde uma quantidade suficiente de parcelas, nem todas as funções paramétricas são estimáveis.

Isto pode levar ao cálculo dos graus de liberdade de uma forma incorreta para determinadas somas de quadrados e, o mais importante, pode fazer com que determinados contrastes entre níveis de tratamentos não sejam estimáveis.

Uma possível solução para o problema seria repetir o experimento em condições similares, e obter novos valores para as parcelas perdidas, o que em geral é inviável devido a questões econômicas e físicas.

A forma mais comum de contornar esse problema, quando o número de parcelas é pequeno, é a estimação de valores para as parcelas perdidas, através do método de mínimos quadrados. Tem-se aí, porém, o número de graus de liberdade do resíduo diminuído e a análise é apenas aproximada.

Uma outra alternativa é a utilização da teoria de Modelos Lineares, que permite a análise de dados balanceados ou não, utilizando operações matriciais. Essa teoria é aplicável para Modelos Lineares em geral, e, como caso particular, nos delineamentos em blocos.

Um método geral de testar estimabilidade de funções paramétricas em Modelos Lineares é dado por JOHN (1971) e por IEMMA (1987),$\lambda^{\prime} H=\lambda^{\prime}$, onde $\lambda^{\prime}$ é um vetor que expressa uma combinação linear dos parâmetros do modelo linear e $H=\left(X^{\prime} X\right)^{-} X^{\prime} X$, sendo $X$ a matriz do delineamento. Porém, na implementação desse teste num programa computacional, surgem limitações de memória e tempo de computador, implicando, em determinadas situações, na inviabilidade da aplicação do teste. O Processo " $R$ " dá uma solução a esse problema, de uma forma econômica e rápida, porém limitada apenas a modelos de dois fatores ou a delineamentos em blocos ao acaso (ou modelo de um fator com uma restrição na casualização).

O processo " $R$ " é um algoritmo que trabalha exclusivamente a partir da matriz de incidência $(N)$ do experimento, e foi criado para fornecer as parcelas cujas esperanças matemáticas sejam estimáveis, devido à possibilidade de que, para um valor de $n_{i j}$ igual a zero, a esperança matemática $\mu+\tau_{i}+\beta_{j}$ seja estimável. A partir dessa informação pode-se determinar uma base para as funções paramétricas estimáveis de tratamentos, assim como a dimensão do espaço vetorial gerado por essa base (informações necessárias para o cálculo dos graus de liberdade em delineamentos desbalanceados desconexos) e, por último, permite detectar os grupos de conexão do delineamento. 
Esse processo tem a vantagem de trabalhar exclusivamente com operações com números inteiros, precisando somente distinguir zeros e não zeros na matriz $N$ para fornecer todos os resultados. Assim, segundo DODGE (1985), o processo " $R$ " parece ser um algoritmo mais eficiente para determinar quais parcelas são estimáveis do que o processo de busca que se baseia na definição de conectividade de Bose.

O processo "R", baseado na matriz de incidência $N$ obtém a matriz $M$, chamada Matriz Final, a qual determina para quais parcelas é possível estimar a esperança matemática.

Os passos do processo " $R$ " são os seguintes:

1 - Seja $M$ uma matriz $a \times b$ de zeros, onde $a$ é o número de tratamentos e $b$ o número de blocos.

2 - Para cada $n_{i j}$, se $n_{i j} \neq 0$, seja $m_{i j}=1$.

3 - Para càda par $i, j$ se existem $k$ e $l$ tais que

$$
m_{i l}=m_{k l}=m_{k j}=1,
$$

então seja $m_{i j}=1$ (grafieamente deve-se agregar um quarto vértice a um quadrado quando os outros três vértices assumem valor um).

4 - Repita o passo 3 utilizando os $m_{i j}$ que não são zero como vértices de novos retângulos, até que não ocorra mais nenhuma substituição.

A seguir é apresentado um exemplo de utilização do processo " $R$ ".

Num experimento em blocos incompletos binario obteve-se a seguinte matriz de incidência ${ }^{3}$ :

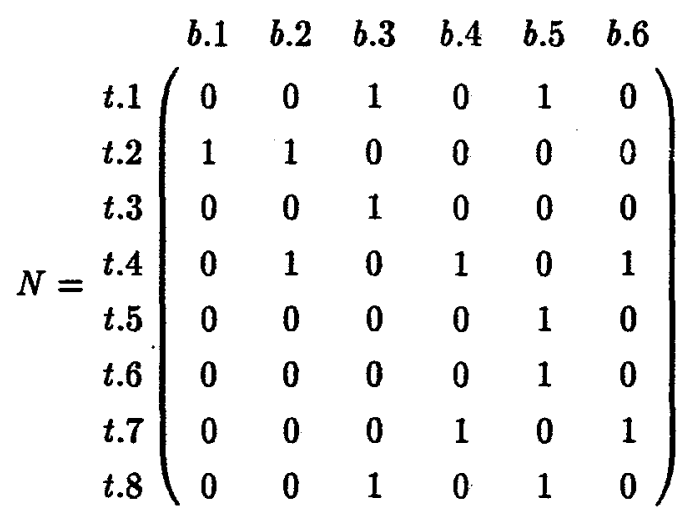

3 Existe no máximo uma observação para cada combinação de tratamento e bloco. Esse processo também pode ser aplicado em delineamentos não binários. 
O experimento consta de 8 tratamentos e 6 blocos.

Aplicando-se o processo " $\mathrm{R}$ " na matriz $N$ pode-se observar que:

- Os PASSOS 1 e 2 são triviais, sendo $a=8$ e $b=6$.

PASSO 3: $i$ e $k$ são índices do fator de tratamentos

$j$ e $l$ são índices do fator blocos

Se $m_{i j}=1$, mude de $j$ para $j+1$ (este teste não consta no algoritmo original, porém considerou-se conveniente sua inclusão para aumentar a velocidade do algoritmo).

Como $m_{i j}=0$, deve-se aplicar o teste enunciado no passo 3 do algoritmo original. Assim:

Se $i=1 ; j=1 ; k=1$ :

para $l=1$, a condição $m_{11}=m_{11}=m_{11}$, não se cumpre;

para $l=2, m_{12}=m_{12}=m_{11}=1$, também não se cumpre.

A condição não se cumprirá até que:

$$
i=2 ; j=6 ; k=4
$$

e

$$
l=2
$$

onde, $m_{22}=m_{42}=m_{46}=1$ se cumpre, então, $m_{26}=1$.

Pode se observar que $m_{26}$ é, na matriz $N$, vértice de um retângulo formado pelos componentes: $m_{22}, m_{42}$ e $m_{46}$, todos com valores diferentes de zero.

Deve-se continuar com este procedimento até chegar ao elemento $i=8, j=6, k=8$ e $l=6$.

PASSO 4: Houve alguma troca, pois observou-se que pelo menos o elemento $m_{26}$ mudou de $m_{26}=0$ para $m_{26}=1$, assim, deve-se aplicar novamente o passo 3 na matriz resultante anterior.

$O$ resultado é a seguinte Matriz Final:

$$
M=\left(\begin{array}{llllll}
0 & 0 & 1 & 0 & 1 & 0 \\
1 & 1 & 0 & 1 & 0 & 1 \\
0 & 0 & 1 & 0 & 1 & 0 \\
1 & 1 & 0 & 1 & 0 & 1 \\
0 & 0 & 1 & 0 & 1 & 0 \\
0 & 0 & 1 & 0 & 1 & 0 \\
1 & 1 & 0 & 1 & 0 & 1 \\
0 & 0 & 1 & 0 & 1 & 0
\end{array}\right)
$$


Considerou-se, neste ponto, necessário o enunciado de alguns teoremas, cujas demonstrações podem ser encontradas em DODGE (1985).

Teorema 1. A função paramétrica $\mu+\tau_{i}+\beta_{j}$ é estimável se e só se $m_{i j}=1$.

Do teorema 1 pode-se observar na matriz $M$ resultante que a combinação linear dos parâmetros $\mu+\tau_{7}+\beta_{2}$ é estimável, enquanto que $\mu+\tau_{7}+\beta_{3}$ não o é.

Se a matriz $M$ não tiver zeros, o delineamento é conexo e a Matriz $\mathrm{X}$ do delineamento é de posto máximo, $r(X)=a+b-1$, onde $r(X)$ é o posto ("rank") de $X$. No presente exemplo o delineamento é desconexo, e para saber o $r(X)$, os graus de liberdades das diferentes fontes de variação, e quais contrastes entre tratamentos são estimáveis, devem-se formar, a partir da Matriz $M$, os grupos conexos do experimento.

Assim, a formação dos grupos conexos a partir da matriz $M$, seguirá o seguinte princípio:

- Seja $J_{1}$ um vetor que contém os índices das colunas de $M$ que tem uns na primeira linha. No exemplo $J_{1}=\{3,5\}$ (existem outras linhas que têm valores um precisamente nessas colunas, as demais linhas não têm nenhum valor um nas colunas indicadas por $J_{1}$ ).

- Seja $j \in J_{1}$ e $I_{1}$ um vetor que denota os índices das linhas de $M$ para as quais há um um na coluna $j$. Note-se que $1 \in I_{1}$ e que qualquer $j$ gerará o mesmo conjunto de índices para o conjunto $I_{1}$.

- Escolhe-se, se possível, um $i^{\prime} \notin I_{1}$ e seja $J_{2}$ um vetor de índices que indica as colunas para as quais existe um um na linha $i^{\prime}$.

- Seja $I_{2}$ um vetor cujos elementos são as linhas de $M$, para o qual existe um um na coluna $j^{\prime}$, onde $j^{\prime}$ pode ser selecionado arbitrariamente de $J_{2}$.

- Continua-se com esse procedimento até que os índices das linhas de $M$ se esgotem. Isto resultará em uniões disjuntas do tipo:

$$
1, \ldots, a=\bigcup_{k=1}^{s} I_{k} \text { e } 1, \ldots, b=\bigcup_{k=1}^{s} J_{k}
$$

tal que $m_{i j}=1$, se e somente se existir algum $k(1 \leq k \leq s)$, tal que $i \in I_{k} \mathrm{e}$ $j \in J_{k}$.

mento.

- Os pares $\left(I_{1}, J_{1}\right), \ldots,\left(I_{s}, J_{s}\right)$ descrevem as porções conexas do delinea- 
No exemplo considerado, pode-se observar que o número de grupos conexos é 2 , ou seja, $s=2$, onde:

$$
\begin{aligned}
& J_{1}=\{3,5\}, I_{1}=\{1,3,5,6,8\} \\
& J_{2}=\{1,2,4,6\}, I_{2}=\{2,4,7\}
\end{aligned}
$$

Teorema 2. Uma função paramétrica da forma $\sum_{i=1}^{a} \underline{\lambda}_{i} \tau_{i}$ é estimável se e só se $\sum_{i \in I_{k}} \underline{\lambda}_{i}=0$, para $k=1,2, \ldots, s$.

Do Teorema 2, infere-se que somente serão estimáveis as comparações entre tratamentos que estiverem num determinado grupo $I_{k}$. Por exemplo, os contrastes $\tau_{1}-\tau_{3}$ e $2 \tau_{1}-\tau_{3}-\tau_{5}$ são estimáveis, porém, $\tau_{1}-\tau_{2}$ não o é.

Os graus de liberdade de tratamentos ajustados para blocos são calculados a partir da dimensão do espaço vetorial das funções lineares paramétricas estimáveis que envolvem unicamente parâmetros do fator tratamento. Com esta finalidade são enunciados os seguintes teoremas:

Teorema 3. O conjunto de funções paramétricas estimáveis envolvendo unicamente parâmetros do fator tratamentos é um espaço vetorial, e é o mesmo espaço vetorial dos contrastes estimáveis entre tratamentos.

Teorema 4. A dimensão do espaço vetorial dos contrastes estimáveis entre tratamentos é

$$
f_{\tau}=a-s=r(X)-b .
$$

O número de graus de liberdade de tratamentos ajustados para blocos é $f_{\tau}=a-s$ (número de tratamentos menos número de grupos conexos no experimento). A partir do Teorema 4 pode-se também obter o posto da Matriz $X$, $r(X)=f_{\tau}+b$.

No exemplo considerado, lembrando que $a=8, b=6$ e $s=2, f_{\tau}=$ $=8-2=6$. Assim o número de graus de liberdade de tratamentos ajustados para blocos será 6 , não $7,(a-1)$, como em primeira instância poder-se-ia pensar em atribuir, erro bastante frequente quando se trabalha com delineamentos desconexos. O posto da matriz do delineamento é $r(X)=6+6=12$.

Considerando o fator bloco como o fator $\beta$ num modelo de dois fatores, poder-se-iam fazer as mesmas considerações que para o fator tratamento $(\tau)$. Assim, o número de graus de liberdade do fator $\beta$ ajustado para o fator $\tau$ será $\int_{\beta}=b-s=r(X)-a=6-2=4$.

Os graus de liberdade, para o exemplo considerado, podem ser resumidos no seguinte quadro: 


\begin{tabular}{lcc}
\hline FONTE DE VARIAÇÃO & G.L. & \\
\hline Modelo Completo & 12 & \\
$R(\mu)$ & & 1 \\
$R(\beta \mid \mu)$ & 5 \\
$R(\tau \mid \mu, \beta)$ & 6 \\
Ou, no modelo de dois fistorer: & \\
$R(\mu)$ & \\
$R(\tau \mid \mu)$ & 1 \\
$R(\beta \mid \mu, \tau)$ & 7 \\
Residuo & 4 \\
\hline TOTAL & 2 & \\
\hline
\end{tabular}

\subsubsection{Metodologia de cálculos utilizada no SABI}

Para delineamentos balanceados a metodologia foi obtida de JOHN (1971), GOMES (1986), CHEW (1977) e RIBOLDI (1988).

A propriedade que caracteriza os Delineamentos em Blocos Incompletos Equilibrados, é que cada tratamento aparece com cada um dos outros tratamentos sempre um número determinado de vezes num mesmo bloco.

Optou-se por definir:

$$
\begin{aligned}
v & =\text { número total de tratamentos; } \\
b & =\text { número total de blocos; } \\
k & =\text { número de parcelas por bloco; } \\
r & =\text { número de repetições de cada tratamento; } \\
g & =\text { número total de grupo de repetições. }
\end{aligned}
$$

Para os Blocos Incompletos Balanceados são válidas as seguintes relações:

$b . k=v . r$, representando o número total de parcelas e $\lambda(v-1)=r(k-$ 1) que é a condição de balanceamento. As duas relações são utilizadas no programa para detectar erros no arquivo de dados.

Os Blocos Incompletos Balanceados podem ser classificados em 5 tipos, segundo COCHRAN e COX (1976), que podem ser enquadrados em somente três, descritos a seguir e implementados no sub-programa "Blocos Incompletos Balanceados" do sistema SABI. 
Tipo I: Experimentos em que os blocos podem ser agrupados em repetições. Para esse tipo de quadro de ANOVA será:

\begin{tabular}{lc} 
CAUSAS DE VARIAÇ̃̃ & GL \\
\hline Repetições & $r-1$ \\
Blocos D. Repetições & $b-r$ \\
Tratamentos $\left(A_{j}\right)$ & $v-1$ \\
Resíduo & $b(k-1)-(v-1)$ \\
\hline Total & $b k-1$
\end{tabular}

Adotando a notação:

$S Q:$ Soma de quadrados

$Q M$ : Quadrado Médio

$T_{i}:$ Total de tratamento $i, i=1, \ldots, k$

$R_{s}$ : Total da repetição $s, s=1, \ldots, r$

$B_{j}$ : Total do bloco $j, j=1, \ldots, b$

$G R_{l}:$ Total do grupo $l, l=1, \ldots, g$

$G$ : Total geral

$A_{i}$ : Total dos blocos onde aparece o tratamento.

$\mathrm{O}$ cálculo das somas de quadrados é dado por:

SQ Total $=\sum y^{2}-C$ onde $C=\frac{G^{2}}{r}$

$\mathrm{SQ}$ Repetições $=\frac{1}{V} \sum_{s=1}^{r} R_{s}^{2}-C$

$\mathrm{SQ}$ Blocos $=\frac{1}{k} \sum_{j=1}^{b} B_{j}^{2}-C$

SQ Blocos D. Repetições = SQ Blocos

- SQ Repetições

SQ Tratamentos (Ajustada) $=\frac{1}{\lambda k v} \sum_{i=1}^{r} Q_{i}^{2}$ onde

$$
Q_{i}=k T_{i}-A_{i}
$$

SQ Resíduo $=$ SQ Total - (SQ Repetições

+ SQ Blocos dentro de Repetições

- SQ Tratamentos (Ajustados))

A obtenção dos Quadrados Médios é realizada da maneira usual, dividindo-se as Somas de Quadrados pelos correspondentes graus de liberdade. O 
Teste F para tratamentos ajustados é obtido dividindo-se o QM de Tratamentos ajustado pelo QM de Resíduo. Essa estatística tem distribuição F de Snedecor com o número de graus de liberdade de tratamento no numerador e do resíduo, no denominador.

TIPO II: Experimentos em que os Blocos podem ser dispostos em grupos de repetições. $\mathrm{O}$ quadro de análise de variância será:

CAUSAS DE VARIÂNCIA G.L.

\begin{tabular}{lc}
\hline Grupos & $q-1$ \\
Blocos D. Grupos & $b-q$ \\
Tratamentos (ajustados) & $v-1$ \\
Resíduo & $b(k-1)-(v-1)$ \\
\hline Totai & $b k-1$
\end{tabular}

Cuịgs somas de quadrados são obtidas por:

$$
\text { S.Q.Grupos }=\frac{q}{r v} \sum_{i=1}^{g} G R_{i}-C
$$

S.Q.Blocos dentro de Grupos = S.Q.Blocos - S.Q.Grupos

S.Q.Resíduo = S.Q.Total - (S.Q.Grupos

+ S.Q.Blocos dentro de Grupos

+ S.Q.Tratamentos $\left.\left(A_{j}\right)\right)$

E a S.Q.Tratamentos $\left(A_{j}\right)$ é calculada de maneira análoga à anterior.

TIPO III : Experimentos cujos Blocos não podem ser agrupados em repetições ou grupo de repetições. O quadro de análise de variância será:

Fontes de variação GL

\begin{tabular}{lc}
\hline Blocos & $b-1$ \\
Tratamentos $\left(A_{j}\right)$ & $v-1$ \\
Resíduo & $b(k-1)-(v-1)$ \\
\hline Total & $b k-1$
\end{tabular}

Sendo as somas de quadrados obtidas por:

SQResíduo $=$ SQTotal $-\left(\mathrm{SQBlocos}+\mathrm{SQ}\right.$ Tratamentos $\left.\left(A_{j}\right)\right)$

As médias de tratamentos ajustadas para qualquer dos três tipos de Blocos Incompletos Balanceados é dada por:

$$
\hat{m}_{i}=\text { média ajustada do tratamento } i
$$




$$
\hat{m}_{i}=\hat{m}+\hat{t}_{i}
$$

A eficiência dos Blocos Incompletos Balanceados em relação aos Blocos Completos é obtida por:

$$
E=\frac{\lambda v}{k r} \quad \text { onde } \quad 0<E<1
$$

O teste de comparações múltiplas de Tukey (HSD, "honesty significant difference") requer igual número de repetições por tratamento, utilizando um valor constante para todos os contrastes entre duas médias de tratamentos. Assim, dois tratamentos são considerados diferentes (em seus efeitos sobre a variável considerada) se a magnitude do valor absoluto da diferença entre as médias dos tratamentos considerados excede este valor.

$$
H S D=q(\alpha, v, G L R e s i d u o) \sqrt{\frac{Q M R e s i d u o}{r}}
$$

onde $H S D$ é o valor utilizado na comparação das duas médias de tratamentos consideradas;

$q(\alpha, v$, GL Resíduo) é o valor da amplitude total estudentizada para uma confiança $1-\alpha, v$ tratamentos e GL Resíduo graus de liberdade do resíduo;

$r$ é o número de repetições dos tratamentos.

Para cálculo da decomposição da soma de quadrados de tratamentos em contrastes, seja:

$$
\begin{aligned}
& A=\text { um conjunto de médias de tratamentos ajustadas; } \\
& n_{a}=\text { número de médias do conjunto } A ; \\
& B=\text { um outro conjunto de médias de tratamentos ajustadas; } \\
& n_{b}=\text { número de médias do conjunto } B ; \\
& \text { então, } \\
& S Q(A \text { Vs. B })=\frac{(\text { Soma das médias do Grupo } A)^{2}}{n_{a}}+ \\
& +\frac{(\text { Soma das médias do Grupo } B)^{2}}{n_{b}}-\frac{(\text { Soma de Todas as Médias })^{2}}{n_{a}+n_{b}}
\end{aligned}
$$


A soma de quadrados desse contraste ajustada para blocos é:

$$
S Q(A \quad V s . \quad B)_{a j u s t a d a}=\frac{\lambda v}{k} S Q\left(\begin{array}{lll}
A & V s . & B
\end{array}\right)
$$

Para a obtenção de intervalos de confiança (IC), a variância de um contraste entre médias de tratamentos é dada por:

$$
\hat{V}(\hat{Y})=\frac{k}{\lambda v}\left[\sum_{i=1}^{v} C_{i}^{2}\right] Q M R e s i d u o
$$

onde $\hat{Y}$ é a estimativa de um contraste entre médias de tratamentos e $C_{i}$ é o coeficiente da média do tratamento $i$. A expressão para obtenção de IC pelo teste "t" de Student utilizada é:

$$
I C[Y]: \hat{Y} \pm t_{\left[\frac{\alpha}{2}, G . L . R e s i d u o\right]} \sqrt{\hat{V}(\hat{Y})}
$$

onde

$\alpha$ : nível de significância individual

G.L. Resíduo: graus de liberdade do Resíduo

Esses "IC" trabalham com um controle individual da confiança, assim, quando se está interessado em várias estimativas é desejável a obtenção de IC com uma determinada confiança conjunta de que todos sejam verdadeiros. Com essa finalidade são introduzidos no presente trabalho os procedimentos de Bonferroni e Scheffé.

O método de Scheffé permite construir IC para um número infinito de contrastes com uma confiança $1-\alpha$ de que todos sejam simultaneamente verdadeiros. Frequentemente o experimentador está interessado somente num subconjunto pequeno de $m$ contrastes. Caso os contrastes sejam pré-selecionados e não sugeridos pelos dados, DUNN (1961), citado por CHEW (1977), recomenda o método usual baseado na distribuição " $\mathrm{t}$ " de Student para construir um IC, utilizando coeficiente de confiança $1-(\alpha / m)$, baseando-se na desigualdade de Bonferroni. Dessa forma, o nível conjunto de confiança para os $m$ contrastes conjuntamente é, ao menos, $1-\alpha$. Aplicando-se esse critério, a formação de um IC é representada pela fórmula,

$$
I C[Y]: \hat{Y} \pm t_{\left[\frac{\alpha}{2 m}, G . L . R e s i d u o\right]} \sqrt{\hat{V}(\hat{Y})}
$$

onde $t_{\left[\frac{\alpha}{2 m} G . L . R e s i d u o\right]}$ indica o valor de uma variável aleatória com distribuição " $\mathrm{t}$ " de Student com graus de liberdade igual ao número de GL do Resíduo, tal que delimita-se uma região de confiança de 1- $\alpha$. Esses IC, frequentemente, são menores que os obtidos pelo Método de Scheffé. 
SCHEFFÉ (1959), citado por CHEW (1977), sugere utilizar uma confiança conjunta de $10 \%$ na aplicação do seu método como apto para a obtenção de infinitos contrastes. A expressão do IC para cada um desses contrastes é a seguinte:

$$
I C[Y]: \hat{Y} \pm \sqrt{(v-1) F_{[\alpha ;(v-1), G . L . R e s i d u o]} \hat{V}(\hat{Y})}
$$

onde $(v-1)$ é o número de graus de liberdade da fonte de variação considerada. Esse número poderá ser menor em se tratando de contrastes sobre um sub-grupo de tratamentos.

Foram testadas algumas rotinas estatísticas em Turbo Pascal apresentadas pelo Grupo PC SOFTWARE INTEREST GROUP (1985), com o.intuito de facilitar o cálculo dos IC. Encontraram-se deficiências nas rotinas de cálculo dos valores de $\mathrm{F}$ de Snedecor e $t$ de Student dada uma determinada probabilidade e os graus de liberdade correspondentes.

Para delineamentos desbalanceados a obtenção das somas de quadrados para as diferentes fontes de variação, assim como da estrutura de conexão, são as abordadas nos itens 3.2.1 e 3.2.2.

Para realização de Testes de Hipóteses, o valor de F de Snedecor para testes de hipóteses do tipo

$$
\begin{aligned}
& H_{0}: H=0 \\
& H_{1}: H \neq 0
\end{aligned}
$$

(onde H é a matriz da hipótese e $\Theta$ é o vetor de parâmetros), foi calculado usando-se a seguinte expressão:

$$
F_{[N L I, G . L . R e s i d u o]}=\frac{(H \hat{\Theta})^{\prime}\left[H\left(X^{\prime} X\right)^{-} H^{\prime}\right]^{-} H \hat{\Theta} / N L I}{Q M R e s i d u o}
$$

onde $N L I$ é o número de linhas independentes da matriz $H$, GLResíduo é o número de graus de liberdade do resíduo, $X$ é a matriz de coeficientes do delineamento e QM Resíduo é o quadrado médio do resíduo.

O cálculo de $N L I$ e de $\left[H\left(X^{\prime} X\right)^{-} H^{\prime}\right]^{-}$foi realizado utilizando-se o Algoritmo SWEEP (ítem 3.2.1).

A informação sobre estimabilidade da hipótese baseou-se na estrutura de conexão do delineamento obtida mediante o Processo " $R$ ".

O processo de obtenção dos Intervalos de Confiança (IC) foi similar ao utilizado nos Blocos Incompletos Balanceados, com exceção da expressão da 
estimativa da variância da estimativa dos contrastes entre efeitos de tratamentos. A estimativa dessa variância foi obtida mediante a expressão:

$$
\hat{V}(\hat{Y})=\hat{V}\left(C^{\prime} \hat{\Theta}\right)=C^{\prime}\left(X^{\prime} X\right)^{-} C
$$

onde $\hat{V}(\hat{Y})=\left(C^{\prime} \hat{\Theta}\right)$ é a estimativa da variância da estimativa de um contraste, C é um vetor que expressa o contraste desejado e $X$ é a matriz de coeficientes do delineamento.

De acordo com o processo de absorção das equações, descrito por SEARLE (1971), o sistema de equações normais é resolvido invertendo-se uma matriz cuja dimensão é igual ao número de tratamentos ou de blocos menos um. Supondo-se que o número de blocos seja menor que o de tratamentos, opta-se por inverter uma matriz que permite obter-se as estimativas de parâmetros para o fator blocos e a partir dessas estimativas obtêm-se as estimativas para tratamentos. $\mathrm{O}$ procedimento é descrito a seguir:

Utiliza-se o modelo matemático

$$
Y_{i j}=\mu+\alpha_{i}+\beta_{j}+e_{i j}
$$

onde

$$
\begin{aligned}
Y_{i j}= & \text { é a observação correspondente ao i-ésimo tratamento no j-ésimo } \\
& \text { bloco; } \\
\mu= & \text { é uma média; } \\
\alpha_{i}= & \text { é o efeito do i-ésimo tratamento }(i=1, \ldots, a) ; \\
\beta_{j}= & \text { é o efeito do j-ésimo bloco }(j=1, \ldots, b) ; \\
e_{i j}= & \text { é o erro correspondente a observação } Y_{i j} .
\end{aligned}
$$

Fazendo-se $\mu^{0}=0$ (estimativa de $\mu$ ) e $\beta_{b}^{0}=0$ (estimativa de $\beta_{b}$ ), pode-se obter um vetor da estimativa de parâmetros para blocos como segue:

$$
\underline{\beta}^{0}=C^{-1} \underline{n}
$$

onde

$$
\begin{gathered}
C=C_{k k^{\prime}} \text { e } r=r_{k} \text { para } k=1, \ldots, b-1 \\
C_{k k}=n_{. k}-\sum_{i=1}^{a} \frac{n_{i k}^{2}}{n_{i .} .}, \quad C_{k k^{\prime}}=-\sum_{i=1}^{a} \frac{n_{i k} n_{i k^{\prime}}}{n_{i} .} \text { para } k \neq k^{\prime} \\
r_{k}=Y_{. k}-\sum_{i=1}^{a} n_{i k} \bar{y}_{i .} .
\end{gathered}
$$

onde 
$n_{i k}=$ é o número de observações do tratamento $i$ no bloco $k$;

$n . k=$ é o número de observações no bloco $k$;

$n_{i}=$ é o número de observações para o tratamento $i$;

$Y . k=$ somatória de resultados das parcelas do bloco $k$.

Para obter-se um vetor de estimativa de parâmetros define-se:

$$
\begin{gathered}
D_{a}=D\left\{n_{\dot{i} .}\right\} \\
N_{a \times(b-1)}=\left(\begin{array}{ccc}
n_{1,1} & \cdots & n_{1, b-1} \\
\vdots & & \\
n_{a, 1} & \cdots & n_{a, b-1}
\end{array}\right) \\
M_{a \times(b-1)}=D_{a}^{-1} N=\left\{\frac{n_{i k}}{n_{i .}}\right\} \\
\bar{Y}_{a}=D_{a}^{-1} \underline{Y}_{a}=\left\{\bar{Y}_{i .}\right\}
\end{gathered}
$$

onde $\underline{Y}_{a}$ é o vetor de totais de tratamentos.

Assim

$$
\underline{\boldsymbol{\alpha}}^{0}=\overline{\underline{Y}}_{a}-M \underline{\underline{\beta}}_{b-1}^{0}
$$

As reduções para as diversas fontes de variação são obtidas da seguinte forma.

Define-se: ${\underline{\underline{Y}_{b}}}_{b}=\left[y_{1} \ldots y_{b-1}\right]$

$$
R(\mu)=n . . \bar{y}_{. .}^{2}
$$

$\bar{y}_{. .}^{2}=$ média geral de ensaio; $n . .=$ número de observações total;

$$
\begin{gathered}
R\left(\alpha / \mu=\sum_{i} n_{i .} \bar{y}_{i .}^{2}-n . \bar{y}_{. .}^{2}\right. \\
R(\beta / \mu, \alpha)=\underline{r}^{\prime} 1 c^{-1} \underline{r} \\
R(\beta / \mu)=\sum_{j} n_{. j} \bar{y}_{. j}^{2}-n . . \bar{y}_{. .}^{2} \\
R(\alpha / \mu, \beta)=\sum_{i} n_{i} \bar{y}_{i .}^{2}+\underline{r}^{\prime} c^{-1} \underline{r}-\sum_{j} n_{. j} \bar{y}_{. j}^{2}
\end{gathered}
$$

O resultado dessas reduções é exatamente o mesmo obtido utilizando-se o operador SWEEP, como no item 2.1.1.

Apesar desse processo ser vantajoso, pois demanda a inversão de matrizes de dimensão bem mais reduzida que utilizando-se o modelo completo, 
optou-se pela segunda alternativa porque permite, com pequenas modificações, abordar os blocos incompletos no ponto de vista multivariado, incluindo-se covariáveis no modelo.

\subsection{Procedimentos na Área de Informática}

\subsubsection{Documentação do Sistema}

Para representação da estrutura lógica do sistema, utilizaram-se os Diagramas Hierárquicos de Blocos ("Structure Chart") e os Diagramas de Nassi-Scheiderman ("Structures Flowchart" ou Diagrama de Chapin), descritos por YOURDON (1979), GANE \& SARSON (1983) e GUIMARÃES \& LAGES (1985), dentre outros.

\subsubsection{Diagramas Hierárquicos de Blocos}

YOURDON (1979) afirma que:

"A organização de um sistema computacional mediante uma estrutura hierárquica facilita sua implementação e manutenção. Em geral, todos os tipos de sistemas podem ser organizados hierarquicamente."

Os Diagramas Hierárquicos de Blocos contribuem para evidenciar a hierarquia dos sistemas, de uma forma simples, simbólica, e muito eficiente na descrição da estrutura lógica.

Como exemplo desta técnica de documentação de sistemas apresenta-se, na Figura 4, o Diagrama Hierárquico de Blocos, que mostra a estrutura lógica do procedimento "Faça Testes de Hipóteses", que integra o módulo "Análise de Blocos Incompletos Desbalanceados" do SABI.

Os retângulos que aparecem na Figura 4 denominam-se módulos, implicando cada um numa atividade ou conjunto de atividades. As descrições das atividades realizadas pelos módulos encontram-se nas legendas que aparecem dentro dos retângulos, o símbolo " $\mathrm{D}$ " no módulo "Entre ccm a Hipótese a ser testada" indica que esse módulo é desdobrado em sub-módulos que podem ser encontrados em outro Diagrama Hierárquico de Blocos. Cada instrução em linguagem Pascal integrante do sistema pertence exclusivamente a um módulo.

Os módulos são conectados por segmentos de retas denominados conexões, que mostram a relação entre eles.

A flecha curva representa uma repetição ("loop"). No exemplo a flecha envolve todas as conexões, assim, a sequência de execução de todos os 


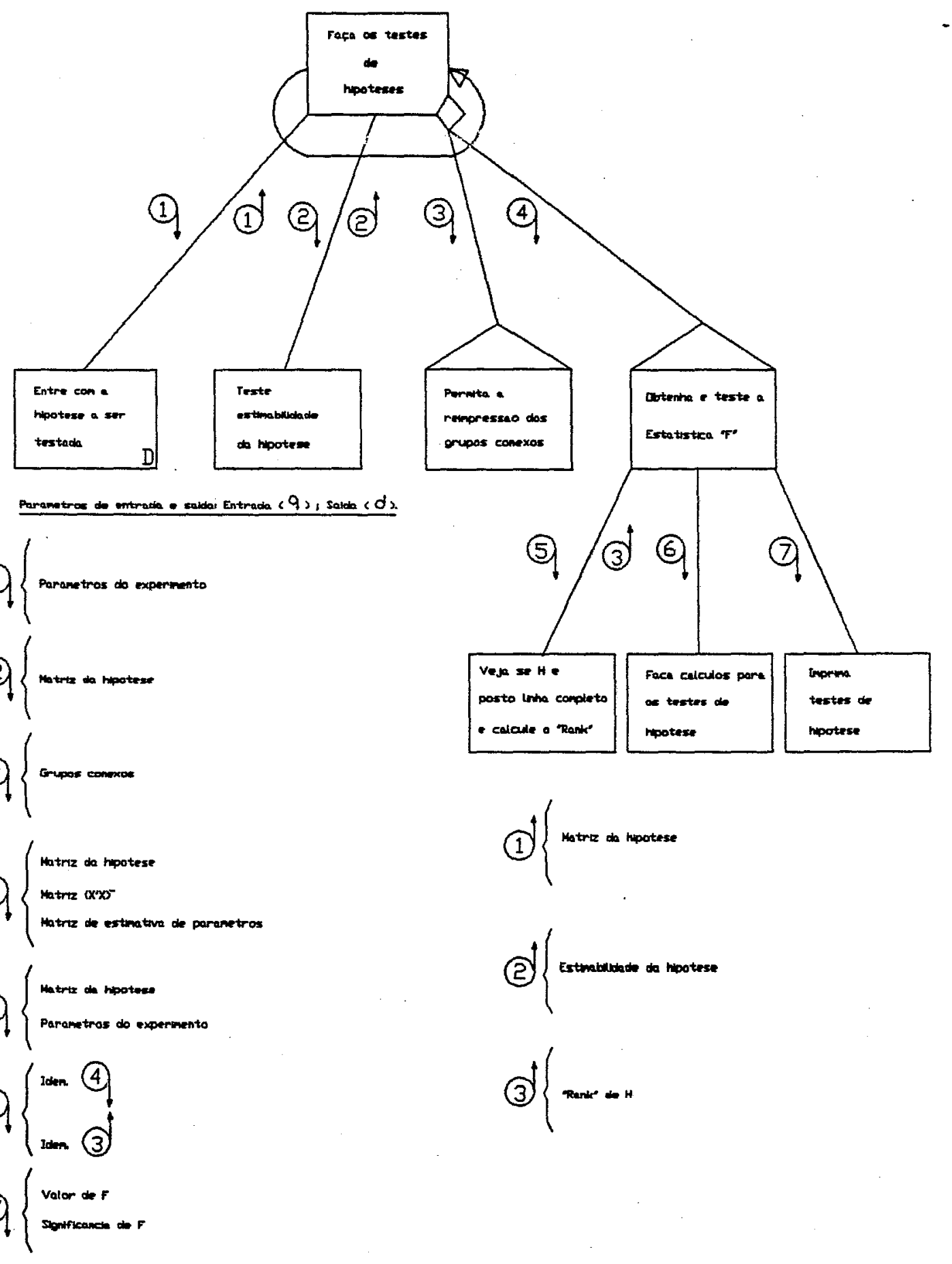

Figura 4 - Diagrama Hierárquico de Blocos do Módulo "Faça Testes de Hipóteses". 
módulos do sistema poderá ser repetida. Observe-se que esse tipo de diagrama não indica quando a repetição vai terminar. Poder-se-ia colocar um comentário fornecendo essa informação, porém, o mais usual é colocar essa informação num Diagrama de Nassi-Schneiderman, correspondente ao Diagrama Hierárquico de Blocos.

Os losangos são símbolos de decisão. Assim, em função de uma determinada informação, será executado o módulo "Possibilite a Reirripressão dos Grupos Conexos", ou o módulo "Obtenha e Teste a Estatística F". O diagrama não mostra qual é essa informação, que constaria, sim, num Diagrama de NassiSchneiderman.

Os Diagramas Hierárquicos de Blocos devem ser lidos de cima para baixo. $\mathrm{O}$ módulo superior controla os módulos do segundo nível, estes os de terceiro nível, e assim sucessivamente. A sequência de execução será de cima para baixo e da esquerda para a direita. No exemplo, a sequência de execução será a seguinte:

- "Entre com a Hipótese a ser Testada";

- "Teste a Estimabilidade da Hipótese";

- "Possibilidade e Reimpressão dos Grupos Conexos", ou "Obtenha e Teste a Estatística F".

Se o fluxo for para o módulo "Obtenha e Teste a Estatística F", a sequência será:

- "Veja se H tem Posto Linha Completo e Calcule o Rank";

- "Faça Testes de Hipóteses";

- "Imprima Testes de Hipóteses".

Em seguida o controle volta para "Faça Testes de Hipóteses", que determinará se deverá existir repetição de todas as atividades, ou se o controle deverá ser cedido a um módulo de hierarquio. superior.

A presença do triângulo, acima do retângulo na representação de um módulo, está relacionada com a implementação física desse módulo, indicando que ele está incluído no módulo de hierarquia imediatamente superior, em forma de linhas de programação. A não existência do triângulo indica que o módulo está incluído como um procedimento, do qual constará somente o nome, mas cujas linhas de programação correspondentes serão encontradas em outro lugar.

Nos Diagramas Hierárquicos de Blocos tradicionais, os parâmetros 
de entrada e saída dos módulos são representados por flechas indicativas de entrada ou saída, e pelo nome do parâmetro. Neste trabalho optou-se pela representação mediante um círculo, uma flecha e um numero, para permitir uma melhor visualização da estrutura dos módulos, devido a, muitas vezes, existirem vários parâmetros de entrada e saída dos módulos. Por exemplo, indica que trata-se de um parâmetro ou conjunto de parâmetros de saída, cuja descrição encontra-se na parte de baixo da figura: neste caso trata-se do parâmetro de saída numero 2 que fornece informação sobre a estimabilidade da hipótese proposta.

YOURDON et alii (1979) recomenda que esses diagramas devem incluir todos os módulos e conexões, mas comenta que não é necessário mostrar todas as repetições e decisões, mostrando simplesmente as estruturas deste tipo que sejam importantes para se entender o módulo principal em linhas gerais.

\subsubsection{Diagramas de Nassi-Schneiderman}

Esses diagramas pertencem à categoria dos fluxogramas, ferramentas importantes para a documentação de sistemas, por mostrarem todas as ações e conexões na ordem de tempo em que ocorreram no sistema.

Segundo GANE \& SARSON (1983), os fluxogramas tradicionais não permitem que sejam adotadas naturalmente as técnicas de programação estruturada, assim como apresentam uma séria dificuldade na manutenção dos sistemas, sendo mais recomendáveis, então, os Diagramas de Nassi-Schneiderman ou o Pseudocódigo.

No presente trabalho considerou-se necessária a incorporação de fluxogramas, para complementação em determinadas circunstâncias dos Diagramas Hierárquicos de Blocos, que são menos informativos quanto à estrutura de repetição e decisão. Considerou-se necessária a presença de Diagramas de NassiScheneiderman, quando existiam, nos Diagramas Hierárquicos de Blocos, estruturas de repetição e decisão de relevância. Em outros casos dispensou-se o uso desses diagramas.

Come exemplo dessa técrica de documentação de sistemas, apresenta-se na Figura 5 o diagrama de Nassi-Schneiderman, correspondente ao diagrama da Figura 4. Pode-se observar que nesse diagrama as estruturas de repetição e decisão aparecem mais detalhadas.

\subsubsection{Recursos Computacionais Utilizados na Docu- mentação Gráfica}

A documentação gráfica foi elaborada no Sistema AUTOCad (Au- 
todesk Inc.,1987), uma ferramenta para desenho técnico em computador (CAD). Pelo fato do sistema não ser específico para elaboração de documentação, a construção dos Diagramas Hierárquicos de Blocos e os de Nassi-Schneiderman não é trivial, incluindo-SE, por isso, um capítulo específico para elaboração desses diagramas utilizando-se os sistemas AUTOCad no Manual de Referência do Sistema SABI (SARRIEŚ, 1988b).

O tempo de processamento para a realização dos diagramas ś grande quando se utilizam microcomputadores da linha IBM PC/XT compativeis, porém essa dificuldade pode ser sanada trabalhando-se com equipamentos mais rápidos, como o IBM $\mathrm{PC} / \mathrm{AT}$ compativeis ou com equipamentos $\mathrm{PS} / 2$.

A estrutura de repetição é simbolizada por um sub-retângulo dentro de um retângulo maior. Na Figura 5 , a sequência de ações que aparecem dentro do sub-retângulo, é repetida enquanto se desejar fazer testes de hipóteses.

Em caso de decisões dicotômicas (como na Figura 5) a estrutura de decisão é representada por 3 triângulos, e por vários quando existem múltiplas possibilidades. No exemplo a decisão vai ser tomada em função da hipótese ser estimável ou não: se for estimável, será obtida e testada a estatística "F", caso contrário, obter-se-á a reimpressão dos grupos conexos do experimento.

\subsubsection{Implementação do: Sistema}

$\mathrm{Na}$ implementação (geração de código fonte do sistema) foram utilizados os gráficos de estrutura para os diversos sub sistemas. A técnica utilizada foi a "top-down", ou seja, criou-se um "esqueleto do Sistema" e foi-se adicionando procedimentos realizando-se refinamentos sucessivos cada vez que um novo procedimento fosse adicionado. Houve exceção apenas para o Sistema de Blocos Incompletos Desbalanceados, implementado diante da técnica de "bottom-up", que consiste na divisão de um programa em sub-programas, cada um escrito e testado separadamente, e no fim agrupados num programa que os controla.

Utilizou-se a técnica "bottom-up" por serem os procedimentos relativamente complexos e pela necessidade da realização de testes individuais exaustivos para cada um deles. Contrastando com a opnião encontrada na literatura consultada (GANE \& SARSON, 1983), não foi sentida muita dificuldade para a remoção dos erros de "interface", devido provavelmente ao fato dos sub-programas terem sido desenvolvidos sempre somente pelo autor deste trabalho.

Para os testes de procedimentos envolvendo Algebra Matricial, utilizou-se o módulo ALGEMA (DIAS, 1987), componente do Sistema MOLIMU (GODOI, 1987). Esse módulo permite testar procedimentos matriciais, apresen- 


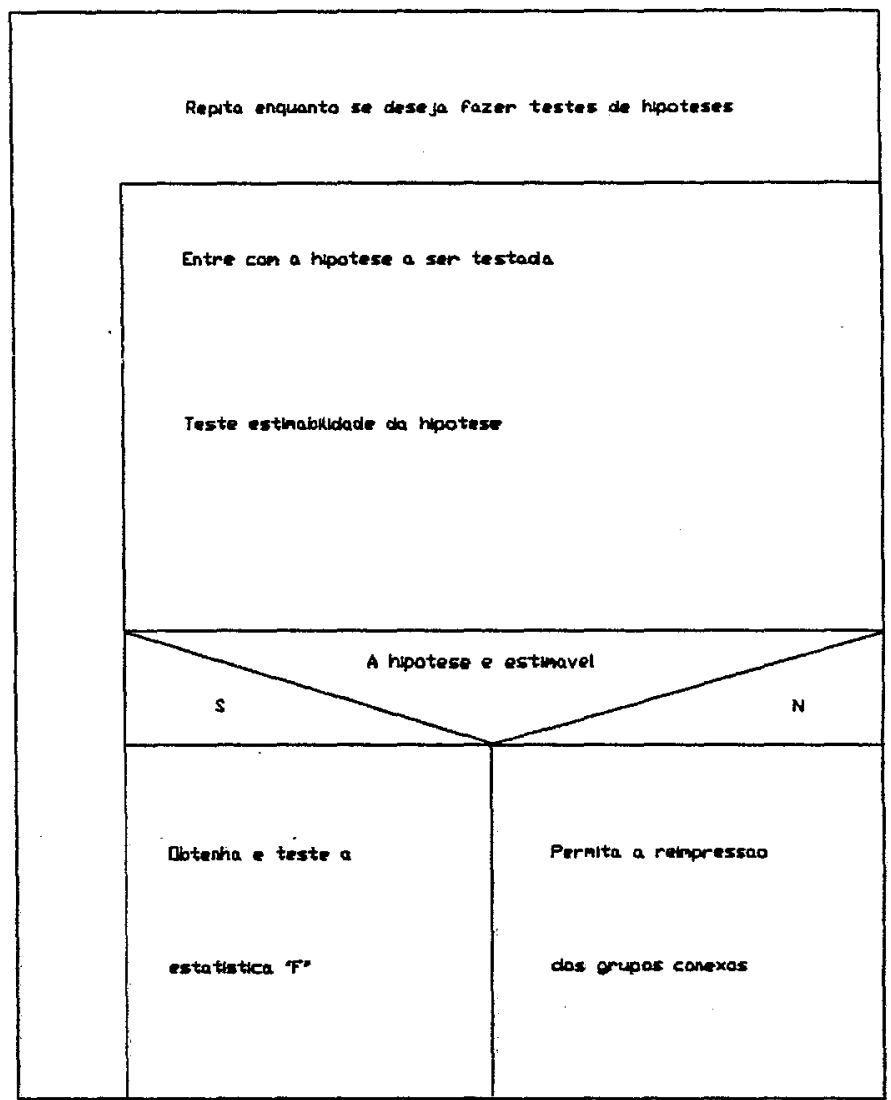

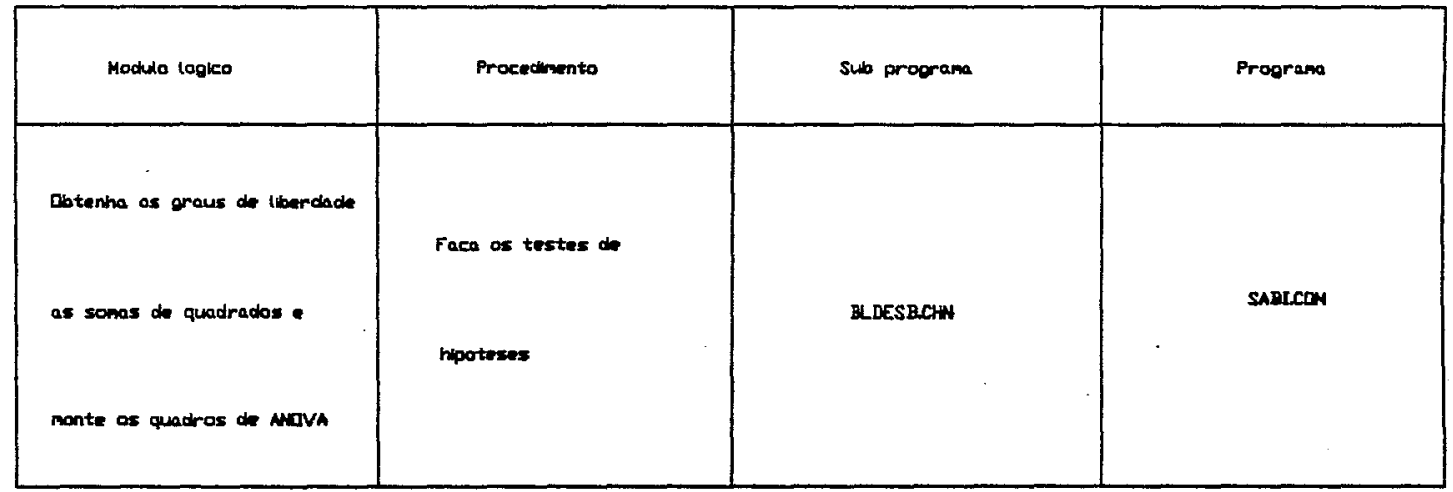

Figura 5 - Diagrama de Nassi-Schneiderman correspondente ao diagrama da Figura 4. 
tando vários sub-módulos de operação matriciais, como os de inversão, soma e multiplicação de matrizes, cálculo de autovalores e autovetores, determinantes, etc. O Sistema MOLIMU também foi útil na etapa de testes do Sistema já implementado, utilizando-se o módulo de Modelos Lineares Multivariados.

$\mathrm{Na}$ implementação do Sistema foi usado o conjunto de procedimentos :

- TURBO PASCAL (BORLAND INC., 1985), para uso como ambiente de desenvovimento;

- TURBO TOOLBOX (BORLAND INC.,1986), consistindo em rotinas para uso geral, utilizando o princípio das "rotinas de caixa preta" bem documentadas e facilmente implementáveis.

A utilização desse último recurso poupa tempo do analista e do programador na elaboração de rotinas inespecíficas, que podem ser usadas em diversos sistemas como, por exemplo, rotinas para a edição de dados, funções matemáticas e classificação e recuperação de informações. Utilizaram-se principalmente as rotinas para edição de dados.

Foram testadas algumas rotinas estatísticas em PASCAL, apresentadas pelo grupo PC SOFTWARE INTEREST GROUP (1985), nas quais foram encontradas deficiências nas rotinas para cálculo de valores de $F$ de Snedecor e $\mathrm{T}$ de Student dada uma determinada probabilidade e os graus de liberdade.

\subsection{Descrição do SABI - Sistema para Análise de Blocos Incomple- tos}

\subsubsection{Introdução}

O SABI é um sistema para microcomputadores compatíveis com IBM-PC, desenvolvido utilizando-se técnicas de documentação e implementação de sistemas estruturados, na linguagem Pascal. $O$ sistema possibilita a análise de experimentos no delineamento em Blocos Incompletos, balanceados ou não. Trabalha em forma interativa e poderia ser classificado como um sistema "amigo do usuário", dispensando conhecimentos especializados de computação para seu uso e oferecendo recursos desejáveis em "software" para microcomputadores como telas de ajuda, recursos de operação com arquivos, edição de dados e a possibilidade de mudança de fluxo de execução em qualquer etapa da análise.

A apresentação do SABI ao usuário inclui um disquete de 5 1/4" contendo os programas, exemplos de utilização, e a documentação correspondente, composta por: 
- "Manual do Usuário do SABI" (SARRIÉS, 1988a), que introduz o usuário na utilização do sistema através da análise de casos particulares que representam situações típicas. Nesse manual, as informações são apresentadas na ordem lógica da instalação e utilização do "software".

- "Manual de Referência SABI" (SARRIÉS, 1988b), onde cada tópico do sistema é apresentado de forma sistemática, com ênfase no detalhamento analítico dos comandos, arquivos e resultados apresentados pelo sistema, permitindo ao usuário manusear situações diferentes daquelas apresentadas nos exemplos do "Manual do Usuário".

- "Projeto do SABI" (SARRIÉS, 1988c), destinado à apresentação de detalhes técnicos computacionais do sistema para usuários avançados ou especialistas em desenvolvimento de "software". Esse documento inclui: especificações, representação gráfica do sistema mediante Diagramas Hierárquicos de Blocos e Diagramas de Nassi-Schneiderman, e a listagem completa do código fonte em Pascal.

O disquete e a documentação acessória são apresentados em pasta plástica apropriada para proteção e armazenagem desse material, segundo padrão utilizado pelo CIAGRI - Centro de Informática na Agricultura - do "Campus" de Piracicaba da Universidade de São Paulo.

\subsubsection{Recursos Oferecidos pelo Sistema}

O sistema SABI possibilita a análise de experimentos em delineamentos em Blocos Incompletos Binários, balanceados ou não, fornecendo informações tais como: Quadro de Análise da Variância completo, Testes de Hipóteses, Intervalos de Confiança, Teste de Comparações Múltiplas de Tukey, e a estrutura de conexão do experimento. As análises podem ser realizadas a partir de dados originais ou mediante à utilização do procedimento Transformação de Dados, a partir de dados transformados segundo as transformações mais frequentemente utilizadas na Estatística Experimental.

As informações disponíveis nos Quadros de Análise da Variância foram adaptadas às necessidades de cada tipo de análise. Nos casos balanceados, os Blocos Incompletos Balanceados de Tipo I, II e III são tratados de forma diferente e as informações resultantes dessas análises gerarão Quadros de Análise da Variância específicos. Nos casos desbalanceados poderá ser obtido um Quadro de Análise da Variância complementar para blocos ajustados pela média e por tratamentos.

Para os experimentos desbalanceados é aplicado o Processo " $R$ ", permitindo a obtenção da estrutura de conexão e os graus de liberdade das diversas 
fontes de variação, quando os experimentos são desconexos. A informação sobre a estrutura de conexão será utilizada para detectar estimabilidade de contrastes nos intervalos de confiança, e estimabilidade de hipóteses quando forem realizados testes de hipóteses.

Nos testes de hipóteses, além de ser analisada a estimabilidade, é calculado o posto da matriz da hipótese para o cálculo de graus de liberdade do numerador da estatística $F$ de Snedecor, utỉlizada para a obtenção da significância dessa hipótese. Para os experimentos balanceados existe uma opção especial para o desdobramento da Soma de Quadrados de Tratamentos em contrastes ortogonais.

O procedimento "Intervalos de Confiança" permite a obtenção de intervalos de confiança utilizando o Teste " $t$ " de Student, que trabalha com confiança individual para cada intervalo, e mediante os procedimentos de Bonferroni e Scheffé, que o fazem com confiança conjunta.

A criação dos arquivos de dados, necessária para a execução das análises, pode ser feita através do próprio sistema, que dispõe de recursos para a realização de operações com arquivos e manuseio de dados, permitindo a criação, eliminação, modificação, impressão e documentação de arquivos. Para serem analisados pelo sistema, os arquivos de dados devem responder a um padrão de documentacão. $\mathrm{O}$ sistema permite a criação de arquivos documentados, não documentados, assim como transforma arquivos não documentados, criados em qualquer processador de texto (como WordStar, Word, Redator, etc.), em arquivos documentados. A documentacão consiste na identificação dos arquivos, do tipo de bloco incompleto, assim como dos tratamentos e das variáveis de resposta.

A criação e modificacão de arquivos de dados é realizada num editor de dados próprio do sistema, que dispõe de recursos e comandos semelhantes aos dos processadores de textos mais conhecidos.

\subsubsection{Estrutura do Sistema}

A estrutura do sistema será apresentado mediante algumas telas utilizadas nos meinus de opcões do SABI e Diagramas Hierárquicos de Blocos, que constam no projeto do sistema.

Na Figura 6 apresenta-se o menu principal do sistema, onde aparecem as principais funções disponíveis: Operações com Arquivos, Manuseio de Dados, Análise de Blocos Incompletos Balanceados e Análise de Blocos Incompletos Desbalanceados.

A estrutura lógica dos módulos para análise de blocos incompletos 


\section{SABI - MENU PRINCIPAL}

A. OPERACOES COM ARQUIVOS
A. Apagar arquivos
B. Editar arquivos
C. Ver conteudo de arquivos
D. Voltar

B. MANUSEIO DE DADOS

A. Criacao de arquivo nao documentado no Editor

B. Criacao de arquivo documentado no Editor

C. Documentacao de arquivo nao documentado

D. Impressao de arquivos

E. Voltar

C. ANALISE DE BLOCOS INCOMPLETOS BALANCEADOS

D. ANALISE DE BLOCOS INCOMPLETOS DESBALANCEADOS

E. ENCERRA

Ctrl-H p. Ajuda / ESC Encerra

Figura 6 - Menu principal do SABI.

balanceados e desbalanceados aparecem nas Figuras 7 e 8, respectivamente. Esses diagramas constam no projeto do sistema desdobrados em procedimentos menores. 


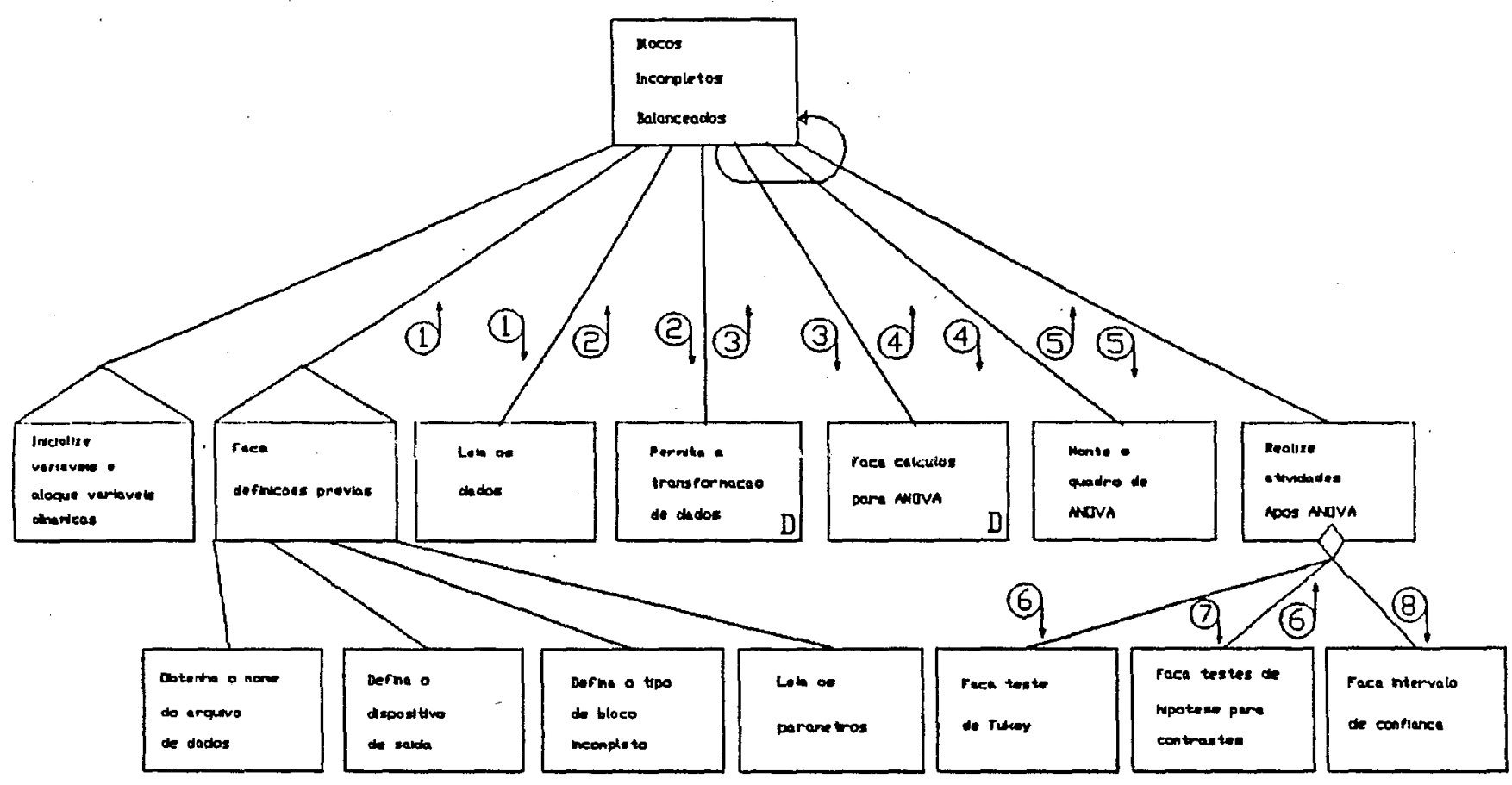

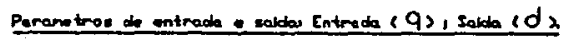

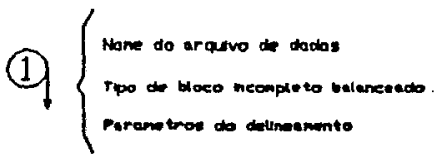

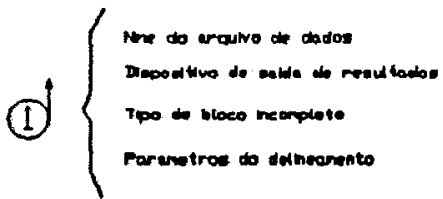

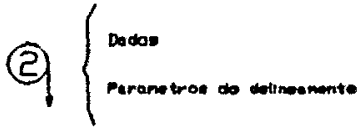

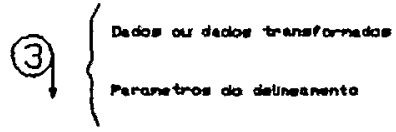

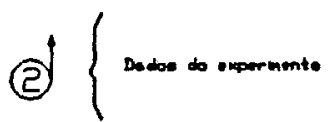

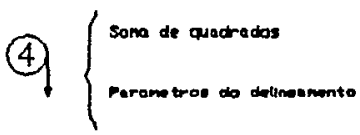

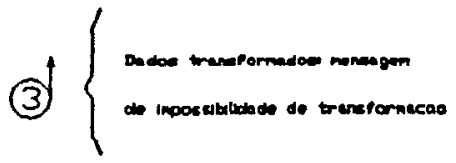
(5) $\left\{\begin{array}{l}\text { Iolen (4) } \\ \text { valores do } \\ \text { Parane tros do detineanento }\end{array}\right.$

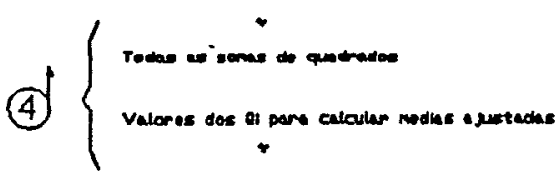
6) $\left\{\begin{array}{l}\text { Parenetros do expermento } \\ \text { Medas ajustades } \\ \text { anadrado modio do rescluso }\end{array}\right.$
(7) $\{\lim 6\}$

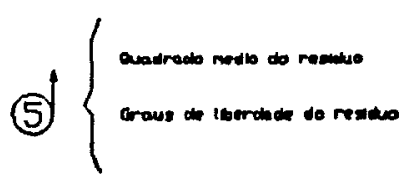
(8) $\left\{\begin{array}{l}\operatorname{lom} 6 \\ \lim 6\end{array}\right.$

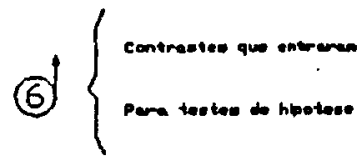

Figura 7 - Diagrama hierárquico de blocos, representando a estrutura do módulo para análise de Blocos Incompletos Balanceados. 


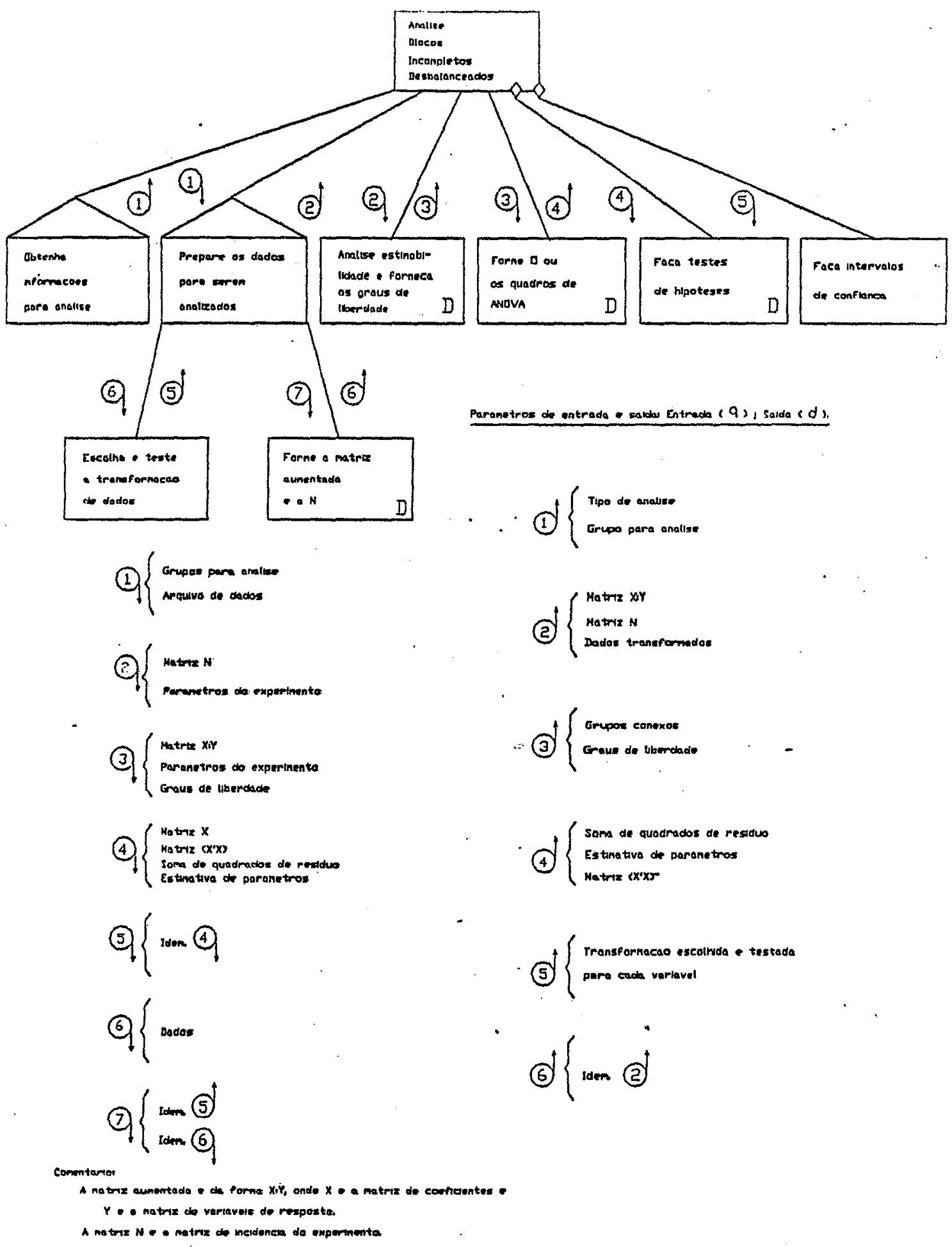

Figura 8 - Diagrama hierárquico de blocos, representando a estrutura do módulo para análise de Blocos Incompletos Desbalanceados. 


\section{RESULTADOS E DISCUSSÃo}

\subsection{Análise de Experimentos no Sistema SABI}

A fim de apresentar o funcionamento e as informações fornecidas pelo SABI, escolheram-se para realização da análise estatística, dois experimentos padrões.

Para analisar dados no SABI - Sistema para Análise de Blocos Incompletos, o usuário deverá em primeira instância criar um arquivo de dados seguindo uma sequência pré-estabelecida. A opção "Criação de Arquivo Documentado" incluida no menu principal do SABI, Figura 6 [item 3.4.3], é a alternativa mais adequada para a criação do arquivo de dados, especialmente para as pessoas não familiarizadas com o sistema, dado que essa opção mostra a estrutura que o arquivo deverá ter, indicando em cada tipo de bloco incompleto quais informações são necessárias e a ordem em que deverão ser introduzidas.

A criação de arquivos segue o mesmo padrão para os diferentes tipos de blocos incompletos, porém a análise de dados apresenta várias características diferentes em se tratando de uma análise balanceada ou desbalanceada. Essas diferenças aparecem na introdução de parâmetros para a análise e nos relatórios de saída de resultados. Assim, considerou-se necessária a apresentação de dois exemplos de utilização do sistema: um para blocos incompletos balanceados e outro para desbalanceados.

Explicações detalhadas sobre a operação do sistema podem ser encontradas no "Manual do Usuário do SABI" (SARRIÉS, 1988a). Informações com maior fundamentação e generalidade poderão ser encontradas no "Manual de Referência do SABI" (SARRIÉS, 1988b), onde instruções e resultados são explicados sistematicamente.

Para utilização do sistema, o usuário deve ter ao seu dispor a pasta plástica que abriga o material que compõe o Sistema SABI, incluindo o disquete com o sistema e a documentação acessória.

Seguindo os procedimentos descritos nessa documentação o 
usuário deverá carregar o sistema na memória do computador, dessa forma aparecendo na tela o Menu Principal do SABI, já apresentado na Figura 6.

Para operar o sistema basta que o usuário selecione a opção desejada, deslocando o cursor por intermédio das setas que se encontram no teclado numérico ou digitando a letra correspondente à opção. Nesse momento o usuário poderá solicitar informações sobre as opções do sistema, consultando um texto de ajuda com explicações sucintas dos recursos disponíveis e técnica de operação.

\subsubsection{Criąão de aruivo e análise de um experimento som delinamento em Blosos Ineompletos Balan- seados}

Será analisado um experimento do Tipo I, na classificação apresentada em COCHRAN \& COX (1957), tratando-se do caso em que existe controle local por repetições dos tratamentos, além dos blocos incompletos dentro dessas repetições.

Os dados do exemplo considerado aparecem na Tabela 1, onde pode-se observar que existem 5 repetições, 6 tratamentos (representados pelos números entre parênteses) e 15 blocos incompletos, cada um deles de tamanho 2 . Deve-se também observar o número de vezes em que dois tratamentos aparecem juntos no mesmo bloco, pois nos delineamentos balanceados esse número será igual para todos os pares de tratamentos. Por exemplo, os tratamentos 1 e 2 aparecem juntos exclusivamente no bloco número 1 , o que implica em $\lambda=1$.

Na Figura 9 aparece a primeira tela do procedimento que permite a criação de um arquivo documentado do SABI. Pode-se observar que o sistema possibilita a introdução de diversas informações úteis para a identificação dos dados a serem introduzidos, por isso denominado "Arquivo Documentado".

Posteriormente, deverão ser introduzidas informações sobre tratamentos, variáveis de resposta e índices de repetições ou grupo de repetições (se existirem), blocos incompletos e tratamentos.

A listagem do arquivo criado consta no Apêndice 1.

O editor de dados, utilizado nos módulos de criação de arquivos do SABI, dispõe de múltiplos recursos acionados através de diversos comandos. Esses comandos são similares aos dos processadores de texto de uso popular em microinformática, como o WordStar, SideKick ou o editor do Turbo Pascal. Durante o processo de criação dos arquivos poderá ser solicitado um texto de ajuda, contendo referências sobre os comandos do editor. 
Tabela 1 - Dados de um experimento em Blocos Incompletos Balanceados do Tipo I, extraídos de COCHRAN \& COX (1957).

Rep.I Rep.II ${ }_{B}$ Rep.III

B
(1) 7 (2) 1724
(1) 17 (3) 2744
(1) 10 (4) 2535
(3) 26 (4) 2551
(2) 23 (5) 2750
(2) 26 (6) 3763
(5) 33 (6) 2962
(4) 29 (6) 3059
(3) 24 (5) 2650

Rep.IV

B

(1) 25 (5) 4065

(2) 25 (4) 3459

(3) 34 (6) 3266
Rep.V

B

(4) 26 (5) 3258

\section{B}


Indique a transformacao para a variavel 1 :

Endurecimento

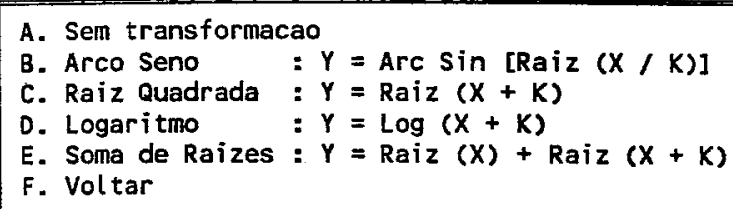

A. Sen transformacao

B. Arco Seno $: Y=\operatorname{Arcsin}[R a i z(X / K)]$

C. Raiz Quadrada : $Y=\operatorname{Raiz}(X+K)$

D. Logaritmo : $Y=\log (X+K)$

E. Soma de Raizes : $Y=\operatorname{Raiz}(X)+\operatorname{Raiz}(X+X)$

F. Voltar

Figura 12 - Menu de escolha da transformação e dados.

do menu principal do sistema (Figura 6).

A primeira informação solicitada pelo sistema é o nome do arquivo de dados documentado. Em seguida, o usuário poderá ver esse arquivo novamente no vídeo,ou processá-lo diretamente, e, posteriormente, escolher o dispositivo de saída de resultados segundo as opções apresentadas na Figura 10. Note-se que existe uma opção para voltar ao menu anterior, a opção "D.".

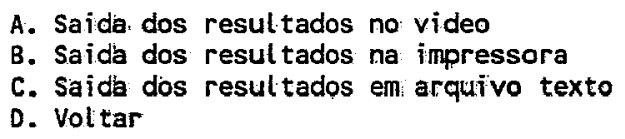

Figura 10 - Menu com os dispositivos de saída de resultados.

O sistema foi programado para analisar experimentos delineados em Blocos Incompletos Balanceados dos tipos I, II e III. Assim, deve-se escolher o tipo de análise a ser realizada a partir do menu transcrito na Figura 11. O exemplo adotado é do tipo I.

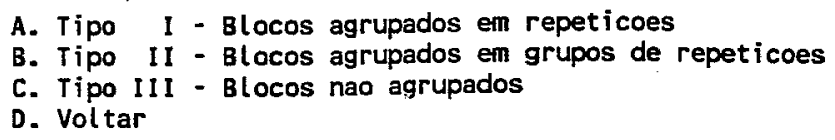

Figura 11 - Menu para selecionar o tipo de análise em Blocos Incompletos Balanceados.

Antes da saída do relatório de resultados da análise solicitada, pode-se optar por alguma das transformações de dados que o SABI oferece, cujo menu de opções aparece na Figura 12. 
Quando a transformação escolhida for possível, ou caso não se deseje transformar os dados, aparecerá na tela o Quadro de Análise de Variância (Quadro de ANOVA), apresentado na Figura 13.

Deve-se salientar que a Soma de Quadrados de Tratamentos já estará ajustada para blocos, o que permite a realização do teste de $\mathrm{F}$ a partir dessa informação. Deve ser salientado também que, como não se obteve recuperação da informação interblocos, a análise foi realizada exclusivamente com informação intrablocos. A informação "Prob. > F" é o "Nível Mínimo de Significância", ou a probabilidade de ter acontecido esse resultado por acaso se a Hipótese de Nulidade, "todos os tratamentos não diferem", for verdadeira. Como o valor obtido foi menor que 0.01 rejeita-se a Hipótese de Nulidade com mais de 0.99 ou $99 \%$ de confiança.

A Soma de Quadrados de Blocos dentro de Repetições não está ajustada para Tratamentos, como a apresentada em COCHRAN \& COX (1957).

A informação "Eficiência" representa a medida da eficiência desse delineamento em blocos incompletos em relação a um delineamento com o mesmo número de repetições, delineado em blocos completos.

Detalhes sobre as informações contidas no Quadro de ANOVA, cálculos, referências bibliográficas e interpretações, podem ser encontrados no "Manual de Referência" do SABI (SARRIÉS, 1988b).

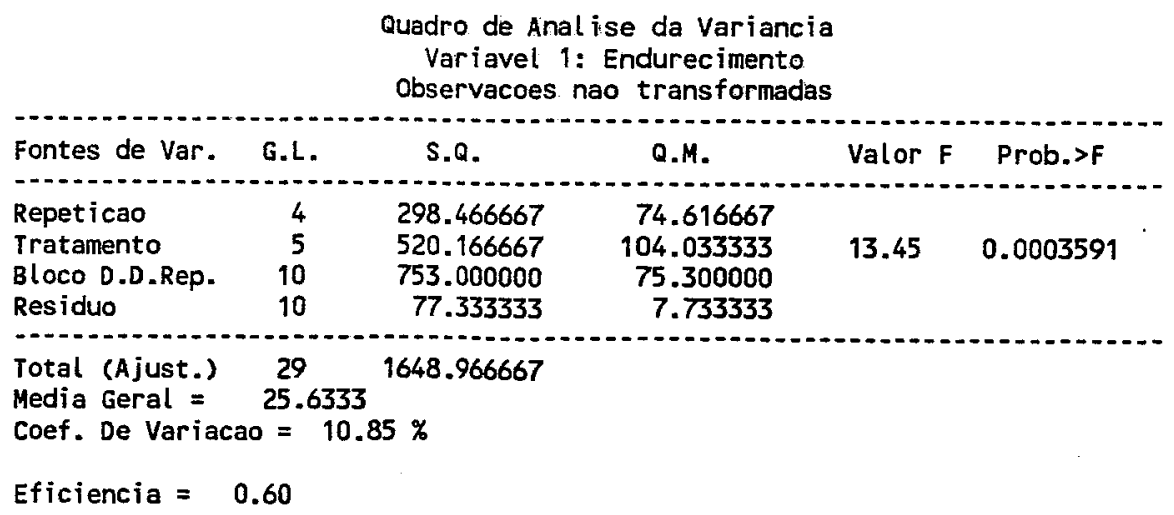

Figura 13 - Quadro de ANOVA para a variável Endurecimento, apresentada pelo SABI.

Depois da obtenção do Quadro de ANOVA, podem ser realizadas diversas operações enumeradas na Figura 14, a qual reproduz parcialmente a tela oferecida depois do mencionado quadro. 


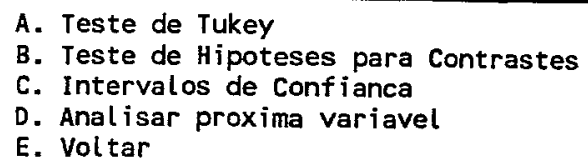

Figura 14 - Opções após a obtenção do Quadro de ANOVA.

Entrando-se na opção

\section{"A. Teste de Tukey"}

obtêm-se a seguinte mostrada na Figura 15.

TESTE DE TUKEY PARA MEDIAS DE TRATAMENTOS

Variavel 1: Endurecimento

Observacoes nao transformadas

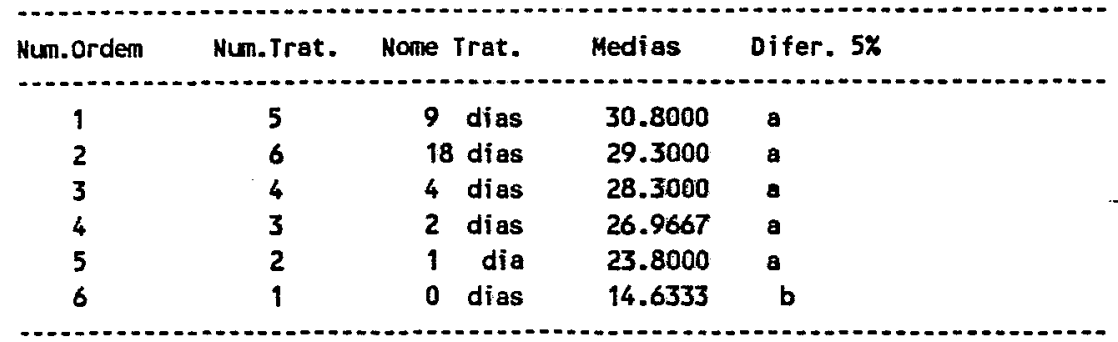

Medias seguidas por alguma letra igual nao diferem $805 \%$ de significancia

Figura 15 - Resultado da aplicação do Teste de Tukey.

O sistema voltará ao menu de opções após a obtenção do Quadro de ANOVA (Tabela 2), entrando-se na opção:

\section{"B. Testes de Hipóteses para Contrastes"}

podendo aí ser desdobrada a Soma de Quadrados de Tratamentos Ajustada em contrastes de interesse do usuário.

Na Figura 16 pode-se observar o relatório de saída de resultados para o solicitado na realização dos testes das hipóteses: "O tratamento 1 não difere do 6" e "O tratamento 2 nao difere do 3 ". O contraste 1 , referente à primeira da hipótese formulada, sendo altamente significativo (Prob. $>F$ foi menor que 0.01 ) faz com que essa hipótese seja rejeitada, isto é, o tratamento 1 difere do tratamento 6 . O contraste 2 não foi significativo, o tratamento 2 não difere do 3 , o que concorda com Tuckey. 


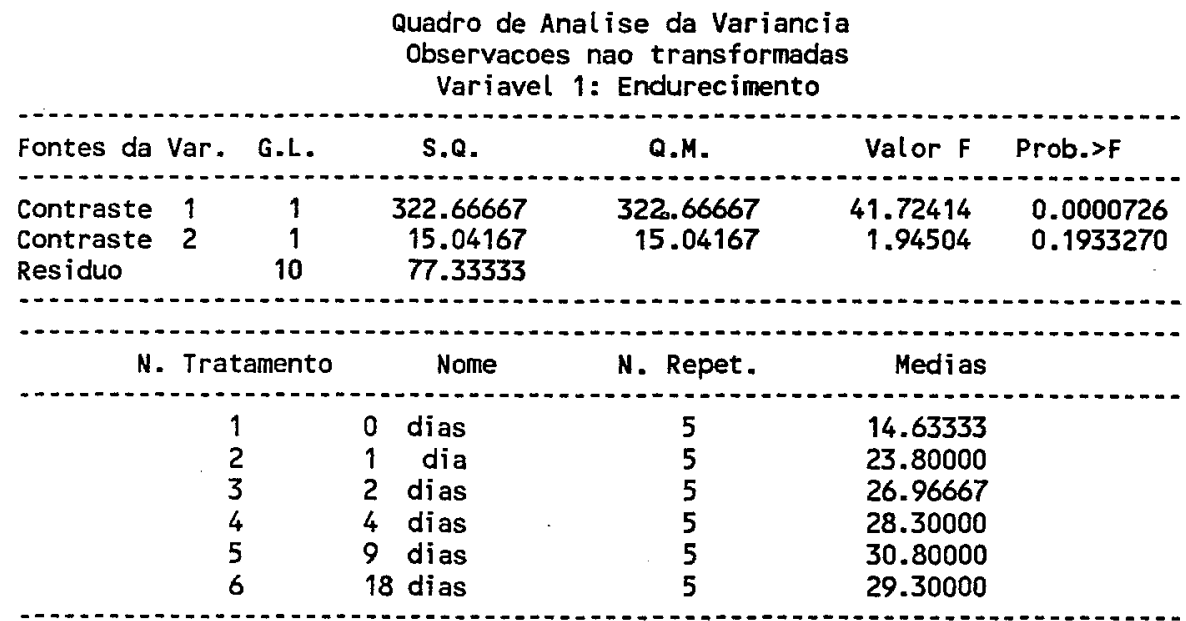

Valores dos Coeficientes dos Contrastes

\begin{tabular}{cc}
\hline Contraste & 1 Contraste 2 \\
1 & 0 \\
0 & 1 \\
0 & -1 \\
0 & 0 \\
0 & 0 \\
-1 & 0 \\
\hline
\end{tabular}

Contraste 1 - Tratamento 1 Vs. Tratamento 6

Contraste 2 - Tratamento 2 vs. Tratamento 3

Figura 16 - Relatório de saída de resultados dos testes de hipótese para os contrastes solicitados.

Após a obtenção do Quadro de ANOVA o Sistema voltará ao menu de opções (Figura 14), escolhendo-se:

\section{"C. Intervalos de Confianz̧a"}

onde aparece o menu de opções para a realização de intervalos de confiança (IC), transcrito na Figura 17, podendo-se optar pela realização de um ou mais tipos de IC.

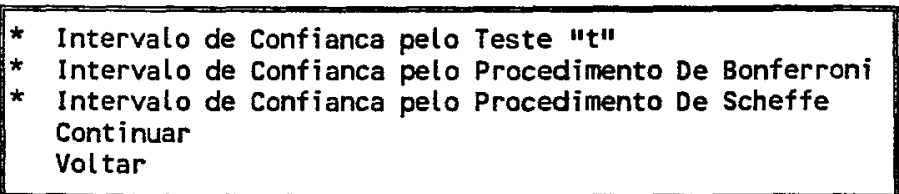

Figura 17 - Menu de opções para a realização de intervalos de confiança. 
Nas figuras 18, 19 e 20, aparecem os resultados da obtenção dos IC para os mesmos contrastes solicitados no módulo de "Testes de Hipóteses", tendo-se solicitado para o exemplo o Teste " $t$ " de Student, o Procedimento de Bonferroni, e o Procedimento de Scheffe, respectivamente.

Para os três tipos de IC trabalhou-se com um nível de confiança de $95 \%$, individual para o primeiro tipo, e com o mesmo nível de confiança conjunta para os dois seguintes.

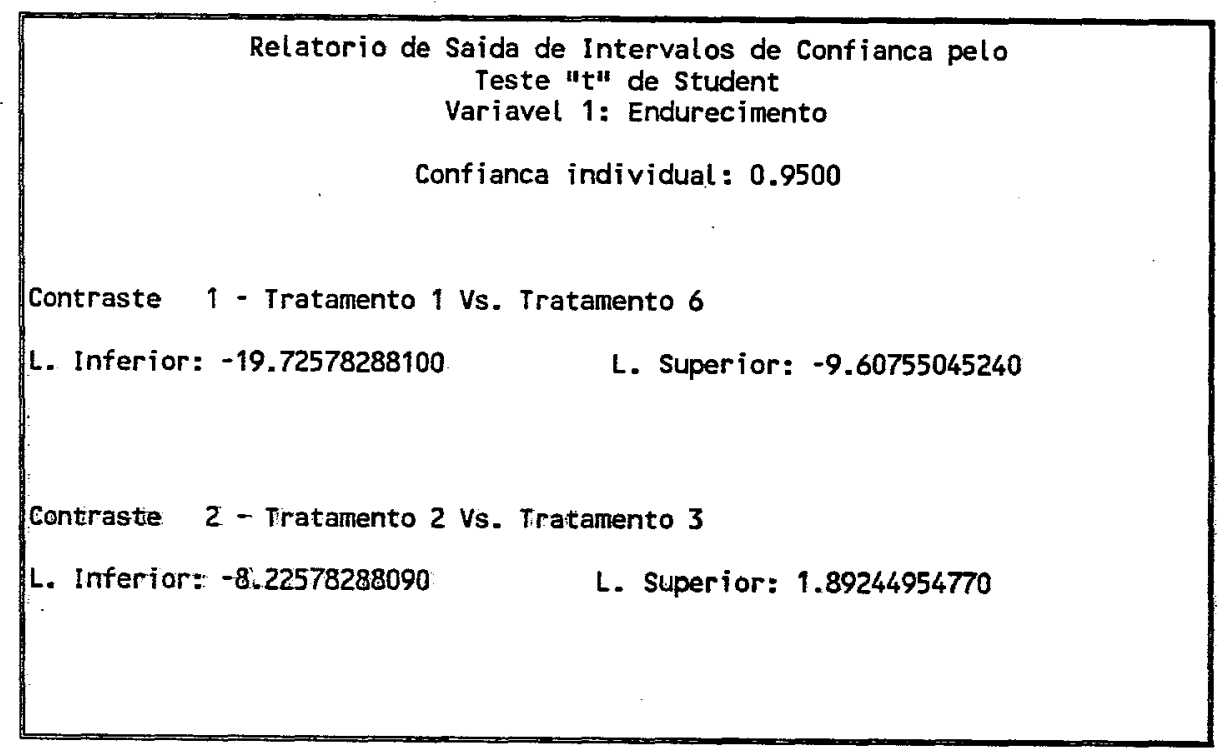

Figura 18 - Relatório de saída de intervalos de confiança pelo Teste " $t$ " de Student.

As conclusões dos resultados dos três tipos de IC são concordantes com as dos testes de hipóteses. Vê-se que para o primeiro contraste não houve mudança de sinal, sendo negativos os limites do intervalo, o que evidencia que a média do tratamento 6 é significativamente superior a do 1. Para o segundo contraste houve mudança de sinal, ou seja, não houve diferença significativa entre os tratamentos 2 e 3 , já que o IC cobre o zero.

Os IC calculados usando-se uma confiança individual pelo Teste " $t$ " de Student são menores, em amplitude, que os calculados usando-se confiança conjunta. Esse resultado é devido a que, na realidade a confiança conjunta no Teste " $t$ " não é controlada e é menor que $95 \%$.

Como foram englobados somente dois IC, os resultados obtidos pelo Procedimento de Bonferroni foram menores que os obtidos pelo Procedimento de Scheffé, porém, essa relação pode inverter-se quando o número de IC for maior, 


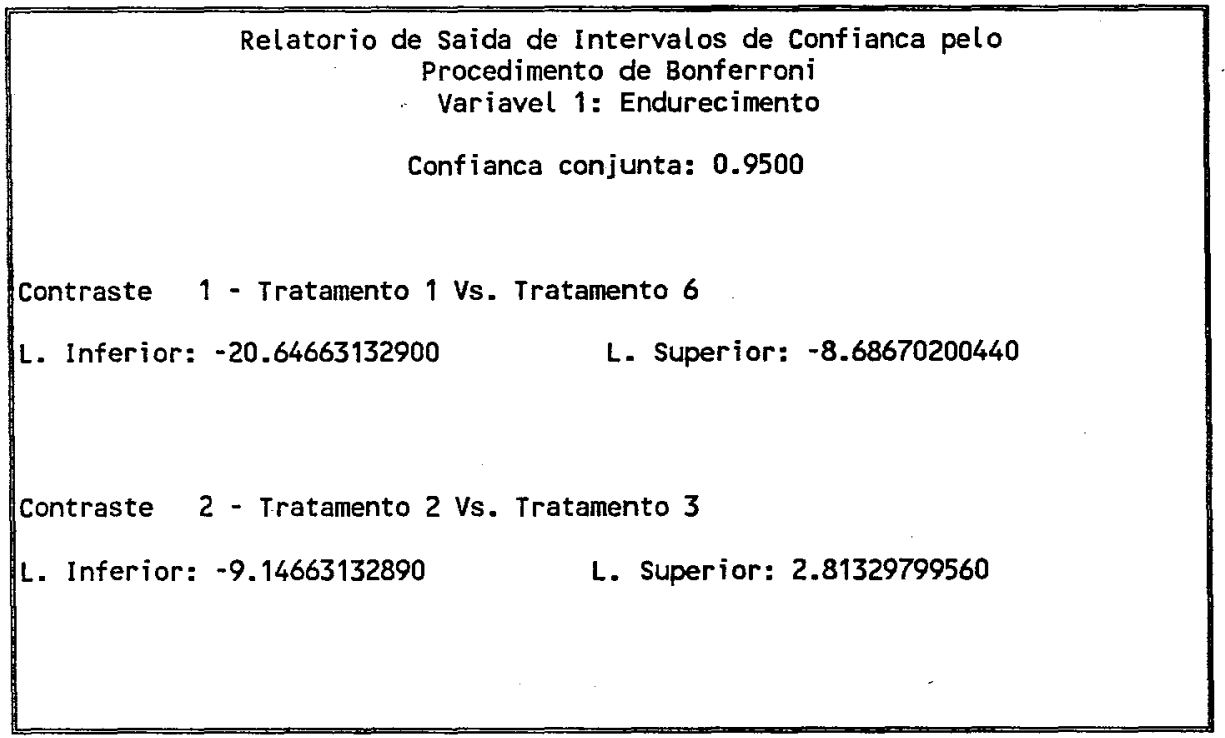

Figura 19 - Relatório de saída de intervalos de confiança pelo Procedimento de Bonferroni.

\begin{tabular}{|c|}
\hline $\begin{array}{r}\text { Relatorio de Saida de Intervalos de Confianca pelo } \\
\text { Procedimento de Scheffe } \\
\text { Variavel } 1: \text { Endurecimento }\end{array}$ \\
Confianca conjunta: 0.9500
\end{tabular}

Figura 20 - Relatório de saída de intervalos de confiança pelo Procedimento de Scheffé.

como é mencionado em HERRERA (1986).

4.1.2. Crią̧ão de aruivo e análise de um experimento som delineamento em Blosos Insompletos Desbalanseados Dessonexos 
O exemplo adotado é uma modificação do apresentado anteriormente no item 4.1.1, quando os blocos eram balanceados. Foram eliminadas 5 observações levando a um desbalanceamento e à perda de conexão do delineamento. As observações eliminadas foram as seguintes:

$\begin{array}{cccc} & \text { repetições } & \text { blocos } & \text { tratamentos } \\ 1) & 1 & 2 & 4 \\ 2) & 2 & 4 & 1 \\ 3) & 3 & 9 & 5 \\ 4) & 4 & 12 & 6 \\ 5) & 5 & 14 & 2\end{array}$

A criação do arquivo de dados poderá ser realizada a partir do arquivo criado para o exemplo anterior, já que arquivos respondem ao padrão ASCII (arquivos tipo texto). A modificação,isto é, eliminação de 5 observações, poderá ser realizada em qualquer processador de texto ou no próprio editor do SABI.

Devido ao delineamento ser desbalanceado, o usuário deverá entrar no procedimento

\section{"D. ANALISE DE BLOCOS INCOMPLETOS DESBALANCEADOS" do "Menu Principal do SABI" (Figura 6).}

A entrada das informações para a análise é similar a do módulo utilizado anteriormente quando se analisou um delineamento balanceado (item 4.1.1). Porém a saída dos resultados é adaptada à análise de dados desbalanceados, assim será fornecido, primeiramente, um relatório informando sobre a estrutura de conexão do delineamento.

$O$ resultado desse estudo encontra-se na Figura 21 onde pode-se observar que os tratamentos $1,2,4,5$ e 6 pertencem a um mesmo grupo conexo; assim é possível estimar contrastes entre estes tratamentos; porém o tratamento 3 pertence a outro grupo conexo o que faz com que qualquer comparação com os outros tratamentos não seja estimável.

Logo após emitir o resultado da análise de conexão o sistema fornecerá o Quadro de ANOVA, reproduzido na Figura 22. Pode-se observar que o número de graus de liberdade para tratamentos ajustados não é 5 (número de tratamentos menos um), como poder-se-ia supor "a priori" se não se conhecesse a estrutura de conexão, mas sim 4 (número de tratamentos menos número de grupos conexos).

Também observa-se que houve um efeito altamente significativo 


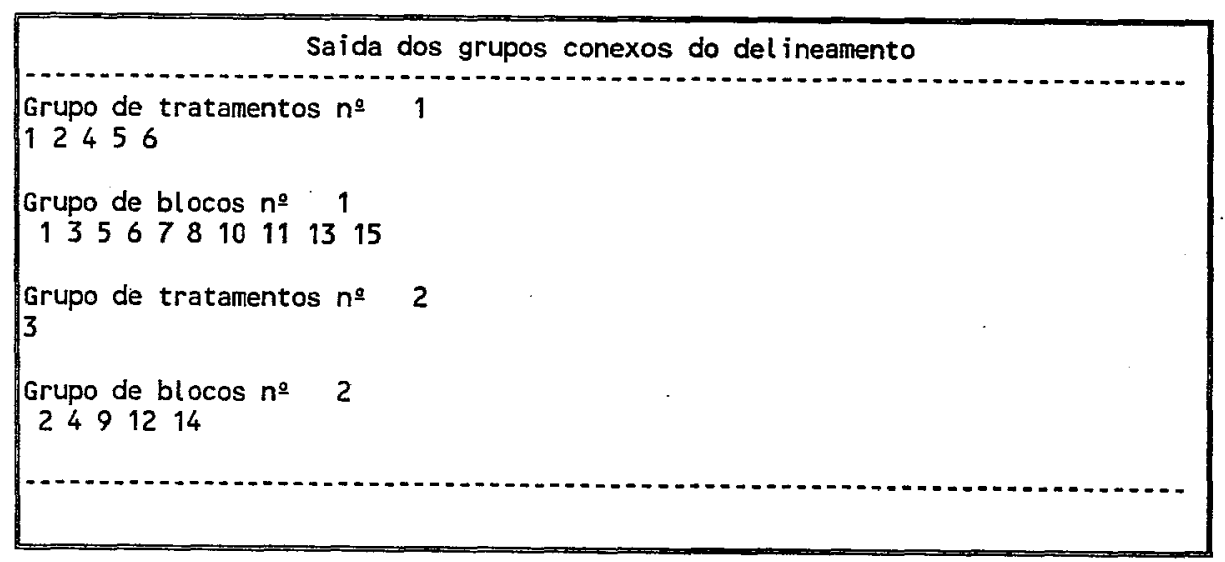

Figura 21 - Estutura de conexão do delineamento adotado.

de tratamentos, evidenciado pelo valor da probabilidade de se achar um valor maior que o valor de "F" resultante da análise realizada, aparecendo no Quadro de ANOVA com a notação "Prob. > F". Essa informação é o Nível Mínimo de Significância ou a probabilidade de ter ocorrido esse resultado por acaso, se a hipótese de nulidade (não há diferença entre os tratamentos) fosse verdadeira. Como o valor obtido foi menor que 0,01 , rejeita-se a hipótese de nulidade com mais de 0,99 ou $99 \%$ de confiança.

O Quadro de ANOVA encontra-se agora aumentado de algumas linhas para a apresentação de blocos ajustados para tratamentos e média. No cabeçalho aparece a variável que está sendo analisada e a transformação realizada.

Após a saída do quadro de ANOVA o usuário poderá optar pela realização de testes de hipóteses. O sistema oferece uma série de alternativas para a introdução da hipótese desejada, apresentadas na Figura 23.

Selecione a entrada da hipotese desejada:

A. Do tratamento I ao tratamento $\mathrm{d}$ iguais

B. Entrar com os tratamentos iguais pelo teclado

C. Definir a hipotese por medio da matriz de hipotese

Figura 23 - Alternativas para introdução da hipótese desejada.

Com o intuito de ilustrar o funcionamento do procedimento "Testes de Hipóteses" realizaram-se dois testes: o primeiro deles permite testar a hipótese "Os Tratamentos 4, 5 e 6 são iguais ", e como os índices desses 


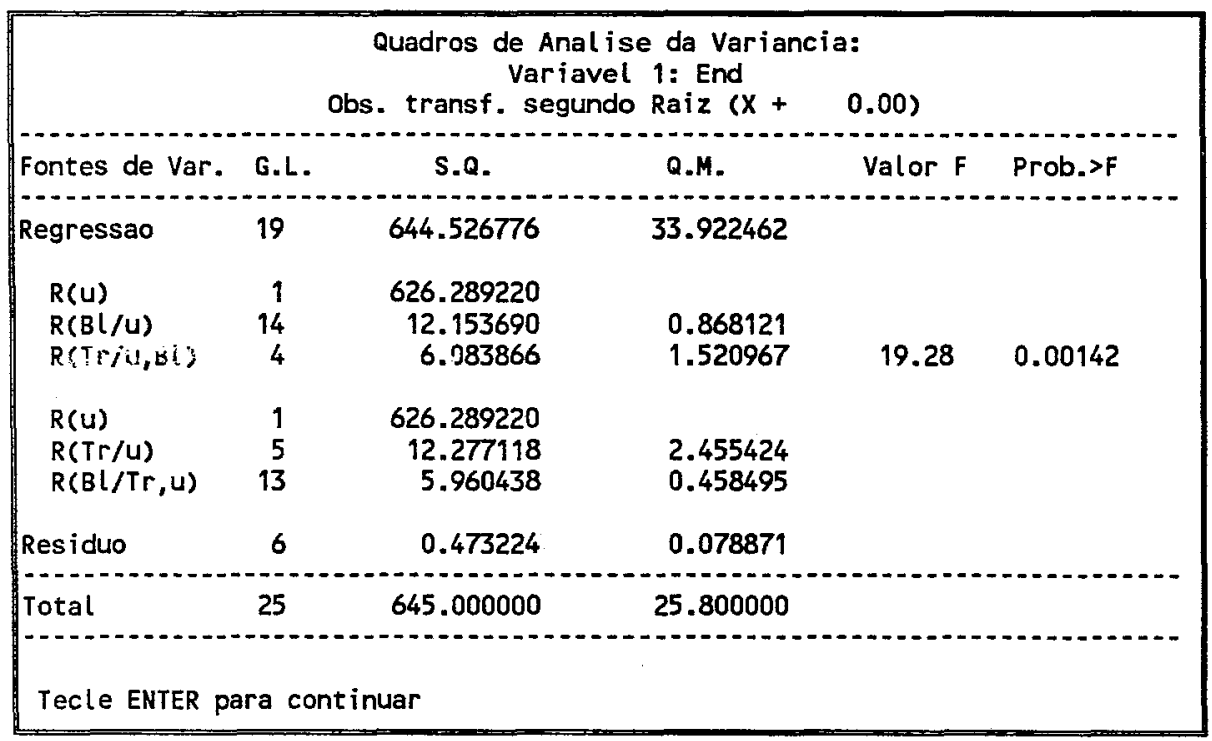

Figura 22 - Quadro de ANOVA para o exemplo de blocos incompletos desbalanceados desconexos.

tratamentos seguem uma sequência continuua é recomendável entrar na opção

\section{"A. Do tratamento I ao tratamento I iguais"}

assumindo I o valor $4 \mathrm{e} \mathrm{J}$ o valor 6 . O relatírio de saída desse teste de hipótese aparece na Figura 24. Como o valor de "Prob. > F" é maior que 0.05 aceitou-se a hipótese formulada.

\begin{tabular}{lll}
$\begin{array}{l}\text { Numero de linhas independentes }= \\
\text { Variavel }\end{array}$ & Valor de $F$ & Prob.> F \\
\hdashline 1: End & 0.152947 & 0.861418
\end{tabular}

Figura 24 - Resultado do teste da hipótese "Os tratamentos 4, 5 e 6 não diferem".

A segunda hipótese testada é "Os tratamentos 1 e 6 não diferem", para a qual é conveniente entrar pela opção:

\section{"B. Entrar aom os tratamentos iguais pelo teslado"}

Nessa alternativa deve ser informado o número de tratamentos envolvidos na hipótese (no exemplo, 2 tratamentos), e os índices desses tratamentos (1 e 6). O relatório de saída de resultados aparece na Figura 25. Pode-se observar que a hipótese foi rejeitada. Essa mesma hipótese foi testada para o experimento completo, sem retirar as 5 observações, (quando se abordou a análise de dados 
balanceados no item 4.1.1) tendo sido também rejeitada, o que leva a concluir que a eliminação das observações não modificou as conclusões.

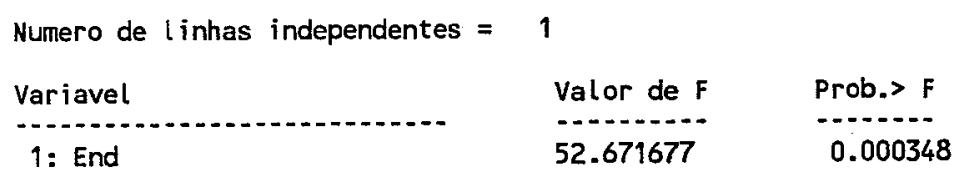

Figura 25 - Resultado do teste da hipótese "os tratamentos 1 e 6 não diferem."

Quando a hipótese formulada não é estimável, o sistema indica essa inestimabilidade e pergunta se o usuário deseja expor, novamente, na tela, os grupos conexos do delineamento, para saber quais hipóteses são estimáveis. Por exemplo, não é estimável a hipótese "Os Tratamentos 1 e 3 não Diferem", devido a esses tratamentos não pertencerem ao mesmo grupo conexo de tratamentos.

A terceira alternativa para entrada da hipótese é através da matriz da hipótese, que poderá ser introduzida pelo teclado ou lida de um arquivo tipo texto. Por exemplo, a hipótese "Os tratamentos 4, 5 e 6 são iguais" poderá ser testada com uma matriz de 2 linhas e 22 colunas, com todos os componentes assumindo valor 0 exceto os 4 componentes relacionados abaixo:

$\begin{array}{ccc}\text { Linha } & \text { Coluna } & \text { Valor } \\ 1 & 20 & 1 \\ 1 & 21 & -1 \\ 2 & 21 & 1 \\ 2 & 22 & -1\end{array}$

As 22 colunas dessa matriz são compostas por: uma para a média, 15 para blocos e 6 para tratamentos, correspondendo os tratamentos sempre às últimas.

Não apresentou-se aqui um exemplo de apliçção do Sistema para Blocos Incompletos Desbalanceados Conexos, por ser um caso particular desse último discutido, que pode ser resolvido sem maiores detalhes.

O SABI permite resolver problemas até agora somente resolvidos por sistemas relativamente caros (como o SAS, 1989), ou relativamente complexos para um usuário não especializado (como o MOLIMU GODOI 1987). Além disso, devido à incorporação do Processo "R", o SABI é mais rápido que os demais sistemas estatísticos avaliados, (discutidos no item 2.2.3, Revisão da Literatura) 
para detectar estimabilidade de funções paramétricas em modelos de 2 fatores.

\subsection{Consideraşões sobre a doะumentaß̧ão do SABI}

A documentação do sistema foi um dos aspectos inovadores do trabalho desenvolvido, aspecto não atendido o suficiente em outros sistemas produzidos no país, que contribuiu em muito para a melhorar comunicação entre cs integrantes da equipe, tornando-se talvez numa ferramenta indispensável em projetos de maior envergadura. Uma outra contribuição, sentida nas etapas de implementação e de testes, foi que os erros foram detectados sem dificuldade o que leva a pensar que a manuntenção também será facilitada.

Os Diagramas Hierárquicos de Blocos funcionaram bem na comunicação estatístico-analista e analista-programador. Sua simplicidade permite que, praticamente sem treinamento prévio, os integrantes da equipe compreendam a estrutura lógica dos módulos do sistema.

Já para os diagramas de Nassi-Schneiderman sentiu-se alguma dificuldade de entendimento dos mesmos por parte dos integrantes não treinados, mas, ainda com essa restrição; seu uso é recomendável para complementar os Diagramas Hierárquicos: de Blocos, fornecendo maior informação sobre as estruturas de decisão e repetição; permitindo obter-se uma visualização estruturada dos módulos. Assim, para determinados módulos, principalmente os mais complexos, considerou-se indispensável a elaboração dos diagramas de Nassi-Schneiderman.

Esses diagramas poderiam ser substituídos por representações em pseudocódigo, especialmente para auxiliar na comunicação analista-programador, devido a que, o treinamento em programação estruturada desses dois tipos de profisionais, permite a visualização imediata das estruturas em pseudocódigo, dispensando a utilização de gráficos, que demandam um tempo maior de elaboração. Adotando esse critério, o uso dos diagramas de Nassi-Shneiderman ficaria circunscrito à representação de estruturas com menor nível de especificação, destinadas à comunicação estatístico-analista.

\subsection{Contribuiş̃ões do trabalho}

1 - Fornece uma ferramenta especializada para analisar experimentos delineados em Blocos Incompletos, relativamente rápida, versátil, e com uma estrutura que permite aperfeiçoamentos futuros, pelo fato do sistema estar documentado e ser implementado utilizando-se técnicas de programação estruturada. 
2 - A experiência acumulada ao longo do trabalho, utilizando-se técnicas modernas de documentação de sistemas, e trabalhando-se com uma equipe interdisciplinar, poderá contribuir como referência para empreendimentos maiores, com equipes de trabalho mais numerosas e até heterogêneas.

3 - Encontrou-se um modo prático e econômico de viabilizar a incorporação, num projeto de desenvolvimento, dos Diagramas Hierárquicos e os de Nassi-Schneiderman, mediante o uso do sistema AUTOCad (1985). No "Manual Referência do SABI" (SARRIES, 1988), existe um capítulo específico com indicações sobre o uso do AUTOCad em documentação gráfica de sistemas.

4 - Podem ser aproveitados em outros sistemas diversos procedimentos do SABI, como o SWEEP ou o editor de dados.

5 - No decorrer do trabalho detectaram-se inconvenientes e necessidades que são apresentadas como sugestỗes no item 4.4. Essa experiência poderá servir para aperfeiçoamentos do SABI, assim como para desenvolvimento de novos sistemas.

\subsection{Sugestões para aperféigoamento do trabalho e para o desen- volvimento de sistemas similares}

No sistema SABI poder-se-iam incluir a análise de blocos incompletos do ponto de vista multivariado. No item 3.3.1. (operador SWEEP) foram feitos alguns comentários a respeito, pois o operador SWEEP calcula as somas de produtos necessárias para obtenção do quadro de MANOVA (Análise da Variância Multivariada) e das correlações residuais. Bastaria incluir um procedimento para cálculo de autovalores e autovetores, assim como procedimentos para os cálculos dos testes de hipóteses multivariadas (Testes de Roy, Hotelling Laurey e Pillai). Procedimentos para a realização dessas inclusões encontram-se disponíveis na biblioteca de procedimentos do sistema MOLIMU (GODOI 1987). Também seria de interesse a inclusão da análise de covariância e da técnica de regressão polinomial.

Nem todos os procedimentos desenvolvidos correspondem ao conceito de "caixa preta", ou seja, procedimentos desenvolvidos de tal forma que o usuário não precise conhecer a estrutura interna para utilizá-los, bastando conhecer a função que desempenha, os parâmetros de entrada e saída e as suas limitações. Seria ideal que todos os procedimentos respondessem a esse príncipio, o que não foi possível neste trabalho.

Com respeito à técnica de documentação utilizada seria re- 
comendável:

- A incorporação de um texto de prenchimento diário, onde se colocariam as decisões tomadas e sua fundamentação, e talvez discriminando as decisões dos analistas e decisões dos programadores.

- A incorporação de dicionários de variáveis, constantes, e tipos utilizados. $\mathrm{O}$ de variáveis deveria informar o significado de cada váriavel, em que procedimentu é definida, modificada e utilizada, bem como seu tipo (real, inteiro, cadeia de caracteres ou outros).

- A incorporação de um manual de procedimentos informando:

- função do procedimento;

- parâmetros que recebe;

- os parâmetros que retorna;

- arquivo em que foi implementado;

- limitações, equipamento necessário;

- exemplos de utilização (opcional);

- última atualizaçãoj:

- comentários (opcional).

- Adotar uma documentação para a comunicação Estatístico-Analista, talvez pelos Diagramas Hierárquicos de Blocos e os de NassiSchneiderman, e outra mais detalhada para a comunicação AnalistaProgamador, através dos mesmos diagramas, ou substituindo os de NassiSchneiderman por Pseudocódigo, como foi discutido no item 4.2 (Consideraçõoes sobre a documentação do SABI). Seria interessante experimentar a utilidade dos Diagramas de Fluxo de Dados na comunicação Estatistico-Analista.

Com respeito à organização da equipe de trabalho, considera-se necessário um nivelamento dos integrantes com relação à documentação do sistema. Além disso, os programadores deverão receber instruções e, se necessário, treinamento na técnica de programação a ser adotada. Dentre as instruções mencionadas dever-se-ia enfatizar as técnicas estruturadas para mudanças condicionais de fluxo, padronização de nomes de variáveis e procedimentos, uso de bibliotecas de procedimentos já desenvolvidas, etc. 


\section{CONCLUSÕES}

Considerando-se os objetivos deste trabalho e com base nos resultados obtidos, pode-se concluir:

- O sistema SABI - Sistema para Análise em Blocos Incompletos, atingiu as características desejadas quanto à velocidade de processamento, funcionabilidade e facilidade de uso.

- O operador SWEEP mostrou-se altamente eficiente na obtenção de somas de quadrados ajustadas, estimativas de parâmetros e detecção de colinearidade, operações realizadas com boa velocidade e economia de memória.

- Confirmaram-se as recomendações da literatura quanto às qualidades do processo " $R$ " para obtenção da estrutura de conexão de um delineamento e das funções lineares estimáveis no modelo referente. Sua incorporação ao SABI contribuiu altamente para melhorar a eficiência do sistema.

- A estrutura do sistema permite, com poucas modificações, adaptações futuras para obtenção de análises de covariância, regressão polinomial e correlações residuais. Outra adaptação relativamente simples é a generalização da técnica de Blocos Incompletos Univariados para Multivariados, requerendo apenas que fossem acrescidos aos procedimentos já existentes, outros processos para obtenção de auto-valores e autovetores. O processo "Q-R" (FLANDERS, 1984) poderia ser utilizado com sucesso para tal fim.

- Ficou comprovada a necessidade de documentação de sistemas, aspecto que não tem recebido muita atenção em "softwares" brasileiros. Outros sistemas de documentação, como dicionário de dados, texto de preenchimento diário com as decisões tomadas, poderiam ser recursos de documentação complementares. Essas ferramentas contribuem efetivamente no desenvolvimento, manutenção e testes de sistemas estatísticos, bem 
como facilitam a comunicação entre os profissionais das várias áreas que integram uma equipe para trabalhos deste tipo.

- Os Diagramas Hierárquicos de Blocos e de Nassi-Schneiderman foram adequados para a etapa de elaboração do projeto do sistema, porém na etapa de análise do sistema seria recomendável a utilização de outro tipo de diagramas, talvez os Diagramas de Fluxo de Dados.

- Sentiu-se, porém, durante o desenvolvimento do SABI, falta de recursos computacionais para elaboração da documentação do sistema quanto à parte gráfica, onde foi usado o sistema AUTOCad que se mostrou deficiente em velocidade de processamento nos equipamentos disponíveis, que foram IBM/PC/XT compatíveis, concluindo-se que microcomputadores com processador 286 ou 386 (IBM/XT compatíveis ou PS/2) dariam uma maior eficiência e rapidez para desenvolvimento do sistema. Os monitores de vídeo dos equipamentos utilizados não apresentaram resolução satisfatória. Esse problema poderia ser solucionado mediante a utilização de placas e monitores tipo "EGA" ou Hercules. O mais adequado, possivelmente, seria a utilização de ferramentas tipo CASE ("software" para auxílio na engenharia de sistemas) em equipamentos mais avançados que os utilizados neste trabalho. Esta solução, porém, demandaria em maiores investimentos em "software" e "hardware".

- A linguagem Pascal, no ambiente de desenvolvimento Turbo Pascal, é especialmente adequada para o desenvolvimento de sistemas aplicando conceitos de programação estruturada. Devem ser mencionadas, porém, as limitações quanto à precisão de cálculos quando se utiliza a versão 3.0 do Turbo Pascal, que deixa a desejar quanto ao numero de dígitos significativos. Outra limitação é a dificuldade de portabilidade dos sistemas desenvolvidos de um equipamento para outro de mesmo porte, ou de microcomputadores para computadores de grande porte. Para suprir essa deficiência, deveriam ser utilizados compiladores de linguagem Pascal que permitam a geração de um código fonte mais versátil, ou outras linguagens de programação, como, por exemplo, a linguagem C. 


\section{BIBLIOGRAFIA CONSULTADA}

ABREU, C. \& SARRIÉS, G. A. Sistema de correção por Stand. 1.ed. Piracicaba, USP/PCP/CIAGRI, 1986. 35p.

ANDERSON, V. L. \& McLEAN, A. Another Dimension in Teaching Experimental Statistics. The American Statistician, Vol. 28 № 4, 1974. 8p.

AUTODESK Inc. Autocad User Reference, version 2.1. San Jose, C.A., AUTODESK Inc., 1985. 434p.

AZEVEDO FILHO, A. J. B. V. ALEAXPRJ - Sistema para Simulação e Análise Econômica em Condições de Risco: Leitura Obrigatória. Piracicaba, USP/PCP/CIAGRI - Centro de Informática na Agricultura, 1988a. 2p.

AZEVEDO FILHO, A. J. B. V. ALEAXPRJ - Sistema para Simulação e Análise Econômica em Condições de Risco: Manual do Usuário. Piracicaba, USP/PCP/CIAGRI - Centro de Informática na Agricultura, 1988b. 43p.

AZEVEDO FILHO, A. J. B. V. ALEAXPRJ - Sistema para Simulação e Análise Econômica em Condições de Risco: Manual de Referência. Piracicaba, USP/PCP/CIAGRI - Centro de Informática na Agricultura, 1988c. 29p.

CHEW, V. Comparisons among treatment means in an analysis of variance. Washington D. C., Agricultural Research Service, 1977. 64p.

COChRAN, W. G. \& COX, G. M. Experimentals Designs. John Wiley and Sons, Inc., 1957. 611p.

COMPUCENTER. CASE, a nova era do desenvolvimento. Ábacus 55, julho 1987. 1p.

DIAS, C. T. ALGEMA: Sistema Computacional para Álgebra de Matrizes. Piracicaba, 1988. 236p. (Mestrado- ESALQ/USP) 
DODGE, Y. Analysis of Experiments with Missings Data. John Wiley and Sons, Inc., 1985. $499 \mathrm{p}$.

EMBRAPA/NTIA. "Software” SOC. Campinas, EMBRAPA/NTIA, 1988.

FLANDERS, H. Scientific Pascal. Virginia, Reston Publishing Company Inc. Reston, 1984. 563p.

GANE, C. \& SANSON, T. Análise Estruturada de Sistemas. Livros Técnicos e Científicos, 1983. 257p.

GODOI, C. R. Análise Estatística Multidimensional. $1^{\circ}$ Simpósio de Estatística Aplicada à Experimentação Agronômica. Piracicaba, 30a. Reunião Anual da Região Brasileira da Sociedade Internacional de Biometria, 1985 . 187p.

GODOI, C. R.; DIAS, C. T. \& MATTIOLLI, C.H. MOLIMU - Sistema de Análise de Modelos Lineares Multidimensionais e Álgebra de Matrizes. Londrina, 2o Simpósio de Estatística Aplicada à Experimentação Agronômica, 32a. Reunião Anual da Região Brasileira da Sociedade Internacional de Biometria, 1987. 72p p.

GOMES, F. P. Curso de Estatística Experimental. 11.ed. Piracicaba, Ed. Nobel, 1985. $466 \mathrm{p}$.

GOODNIGHT, J. H. The SWEEP Operator: Its Importance in Statistical Computing. SAS Institute Inc., 1978. 41p.

GUIMARÃES, A. \& LAGES, N. Algoritmos e estruturas de dados. 1.ed. Rio de Janeiro, Livros Técnicos e Científicos Editora S/A, 1988. 216p.

HERRERA, L. Desigualdade de Bonfferroni. Piracicaba ESALQ/USP, Departamento de Matemática e Estatística, 1986. 26p. (Seminário do curso de Doutoramento em Agronomia).

HERRERA, L. Dados Categorizados em Tabelas de Contingências Tridimensionais. Piracicaba ESALQ/USP, 1987 94p.

IEMMA, A. F. Modelos Lineares uma Introdução para Profissionais de Pesquisa Agropecuária. Londrina, 2o Simpósio de Estatística Aplicada à Experimentação Agronômica, 32a. Reunião Anual da Região Brasileira da Sociedade Internacional de Biometria, 1987. 263p. 
JOHN, J. W. M. Statistical Design and Analysis of Experiments. New York, The Macmillan Company, 1971. 356p.

MACHADO, A.A. Análise de variância e de covariância linear de dados de uma classificação dupla não balanceada. Piracicaba, 1982. 97p. (Mestrado - ESALQ/USP)

MATTIOLLI, C. H. et alii. Sïsterna LATICE: Manual de Referência. 1.ed. Piracicaba, USP/PCP/CIAGRI, 1987a. 30p.

MATTIOLLI, C. H. et alii. Sistema LATICE: Manual do Usuário. 1.ed. Piracicaba, USP/PCP/CIAGRI, 1987b. 16p.

RIBOLDI, J. Decomposição da Soma de Quadrados de Tratamentos nos Delineamentos em Blocos Incompletos Parcialmente Balanceados. Piracicaba, 1988. 165p. (Doutorado - ESALQ/USP)

SARRIÉS, G. A. RESICOND: Manual do Sistema. 1.ed. Piracicaba, USP/PCP/CIAGRI, 1987a. 34p.

SARRIÉS, G. A. O Operador "SWEEP": Algumas Aplicações na Estatística. Piracicaba, ESALQ/USP Departamento de Matemática e Estatística, 1985. $13 p$.

SARRIÉS, G. A. Sistema SABI: Manual do Usúário. Piracicaba, USP/PCP/CIAGRI, 1988a.

SARRIÉS, G. A. Sistema SABI: Manual de Referência. Piracicaba, USP/PCP/CIAGRI, $1988 \mathrm{~b}$.

SARRIÉS, G. A. Sistema SABI: Projeto do Sistema. Piracicaba, USP/PCP/CIAGRI, $1988 \mathrm{c}$.

SARRIÉS, G. A. Sistema para Análise de Dados Categorizados em Tabelas de Contingência Tridimensionais. Piracicaba, USP/PCP/CIAGRI, 1987 a.

SARRIÉS, G. A. RESICOND, Sistema para Aplicação de Residuo Condicional em Modelos Lineares. Piracicaba, USP/PCP/CIAGRI, 1987b.

SAS Institute Inc. , SAS, System for a Linear Models. 1986 Edition. CARY, N.C., SAS Institute Inc., 1986. 210p. 
SEARLE, S. R. Linear Models. John Wiley and Sons, Inc., 1971. 531p.

UNITED COMMUNICATIONS GROUP. Improving large application development. I/S Analyzer, 1988. Vol. 26, 14p.

YOURDON, E.; GANE, C.; SARSON, T.; LISTER, T. R. Learning to Program in Structured COBOL. 3.ed. New York, Yourdon Inc. 1979. 478p.

ZACHMAN, J. A. A framework for information system architecture. IBM System Journal, 1987. Vol. 26, no 3, 16p.

ZONTA, P.E.; MACHADO, A.A.; SILVEIRA Jr., P. "Software" SANEST. S.E.D. 1988. 
Apêndice 1 - Listagem do arquivo de dados documentado para o exemplo da Seção 4.1.1. 
TITULO: Exemplo de Blocos Incompletos de Tipo I

CODIGO DO PROJETO: Primeiro exempo do Manual do Usuario do SABI-Sistema para Blocos Incompletos

EXPERIMENTO: Pagina 443 do Livro Cochram \& Cox

DATA DE MEDICAO:

DATA DE ELABORACAO DO ARQUIVO: 24/9/88

RESPONSAVEL PELA ANALISE: Gabriel Adrian Sarries

NOME DO ARQUIVO DE DADOS:

DISCO QUE CONTEM O ARQUIVO DE DADOS:

NUMERO DE OBSERVACOES: 30

DELINEAMENTO: Bal anceado

TIPO DE BLOCO INCOMPLETO: 1

COLUNA $1 \rightarrow$ Indice de Repeticao

COLUNA $2 \rightarrow$ Indice de Bloco

COLUNA $3 \rightarrow$ Indice de Tratamento

NUMERO DE TRATAMENTOS: 6

TRATAMENTO 1 : 0 dias

TRATAMENTO $2: 1$ dia

TRATAMENTO $3: 2$ dias

TRATAMENTO $4: 4$ dias

TRATAMENTO $5: 9$ dias

TRATAMENTO $6: 18$ dias

$\$ \$ \$$

NUMERO DE VARIAVEIS: 1

COLUNA $4 \rightarrow$ VARIAVEL 1 : Endurecimento

***

101107

$\begin{array}{llll}1 & 01217\end{array}$

$\begin{array}{lll}1 & 02326\end{array}$

102425

103533

103629

204117

$\begin{array}{llll}2 & 04327\end{array}$

205223

$\begin{array}{llll}2 & 05 & 5 & 27\end{array}$

206429

206630

307110

307425

308226

$\begin{array}{llll}3 & 08 & 6 & 37\end{array}$

$\begin{array}{llll}3 & 09 & 324\end{array}$

309526

410125

410540

411225

4. 11434

412334

412632

$\begin{array}{llll}5 & 13 & 1 & 11\end{array}$

$\begin{array}{llll}5 & 13 & 6 & 27\end{array}$

$\begin{array}{llll}5 & 14 & 2 & 24\end{array}$

$\begin{array}{llll}5 & 14321\end{array}$

$\begin{array}{llll}5 & 15 & 4 & 26\end{array}$

515532 